\title{
SILVIA MINHYE KIM
}

\section{Avaliação hemodinâmica durante a revascularização do miocárdio sem utilização de circulação extracorpórea}

Tese apresentada à Faculdade de Medicina da Universidade de São Paulo para obtenção do título de Doutor em Ciências

Área de Concentração: Anestesiologia

Orientadora: Profa. Dra. Maria José Carvalho Carmona

São Paulo

2008 


\section{DEDICATÓRIA}

A minha filha Nara Yoo:

o que aprendi aqui foi para melhor lhe ensinar. 


\section{AGRADECIMENTOS}

Ao meu marido Yong Soo Yoo, pelo amor e paciência.

À Prof. Dra. Maria José Carvalho Carmona, pela orientação, motivação e persistência.

Ao Prof. Dr. José Otávio Costa Auler Junior, por abrir portas para concretizar o sonho do doutorado.

Ao Dr. Luiz Marcelo Sá Malbouisson, pelo apoio e presença.

Aos Drs. Kátia Beck LeBihan, Raquel Pei Chen Chan, Marilde de Albuquerque Piccioni, por me deixarem tumultuar suas anestesias.

À minha amiga Silvia Daniela Scarpel de Azevedo, pelo trabalho de conclusão da residência que seria o piloto para essa tese.

A José da Silva Amorim Filho, por me atender sempre, disponibilizando os monitores necessários para este estudo.

Às amigas Solange Rullo Barbosa e Claudia Alexandria Pereira, pelo apoio constante, também durante a Pós-Graduação.

À Fundação de Amparo à Pesquisa do Estado de São Paulo (FAPESP), pelo Auxílio a Pesquisa de processo número 03/07092-6. 


\section{SUMÁRIO}

Lista de abreviaturas

Lista de figuras.

Lista de tabelas.

Resumo.

Summary

1. INTRODUÇÃO

2. OBJETIVOS. 16

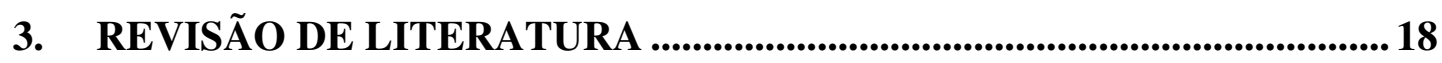

A monitorização hemodinâmica durante a RM sem CEC ...................................227

4. CASUÍSTICA E MÉTODOS ......................................................................... 33

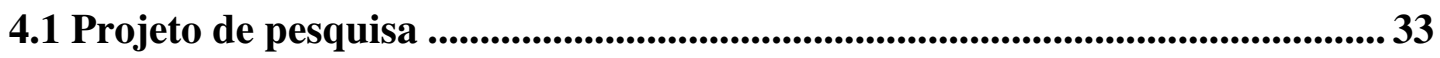

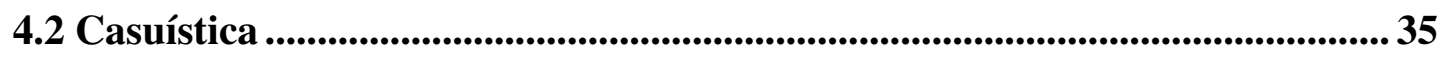

4.3 Métodos ....................................................................................................................................... 36

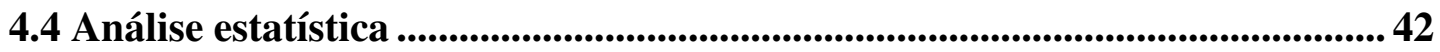

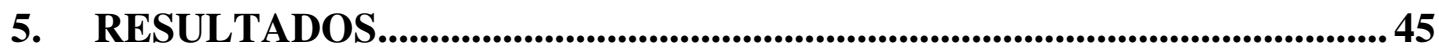

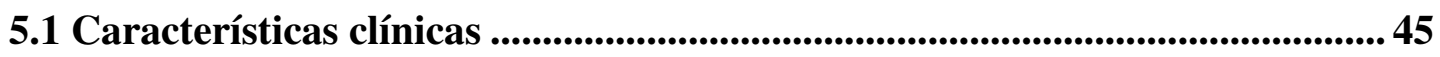

5.2 Ajuste de volemia e uso de fármacos vasoativos............................................ 48

5.3 Freqüência cardíaca....................................................................................................... 49

5.4 Pressão arterial média

5.5 Pressão média de artéria pulmonar....................................................................51

5.6 Pressão de oclusão de artéria pulmonar ........................................................52

5.7 Pressão venosa central ..................................................................................................5 54

5.8 Saturação venosa mista de oxigênio .............................................................................5 56

5.9 Débito cardíaco intermitente.......................................................................57

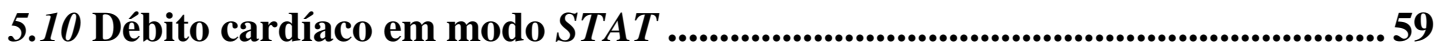

5.11 Débito cardíaco medido por ecodoppler transesofágico .............................. 60 
5.12 Volume diastólico final de ventrículo direito.......................................................62 62

5.13 Fluxo sangüíneo aórtico.....................................................................63

5.14 Tempo de ejeção de ventrículo esquerdo corrigido........................................... 65

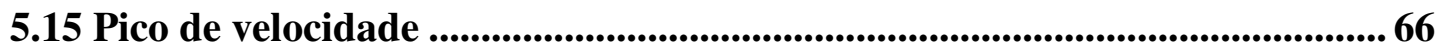

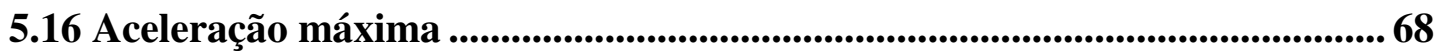

5.17 Comparação das medidas de débito cardíaco ................................................69

5.18 Comparação das medidas de débito cardíaco na parede anterior................. 73

6. DISCUSSÃO

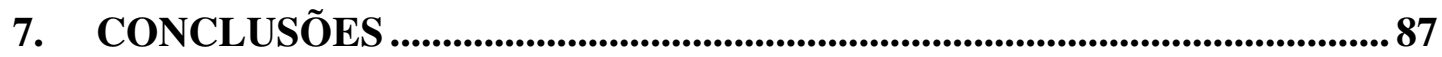

8. REFERÊNCIAS BIBLIOGRÁFICAS .............................................................. 89

9. APÊNDICES $\ldots \ldots \ldots \ldots$

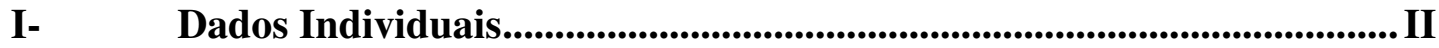

II- Termo de Consentimento............................................................................VIII 


\section{Lista de abreviaturas}

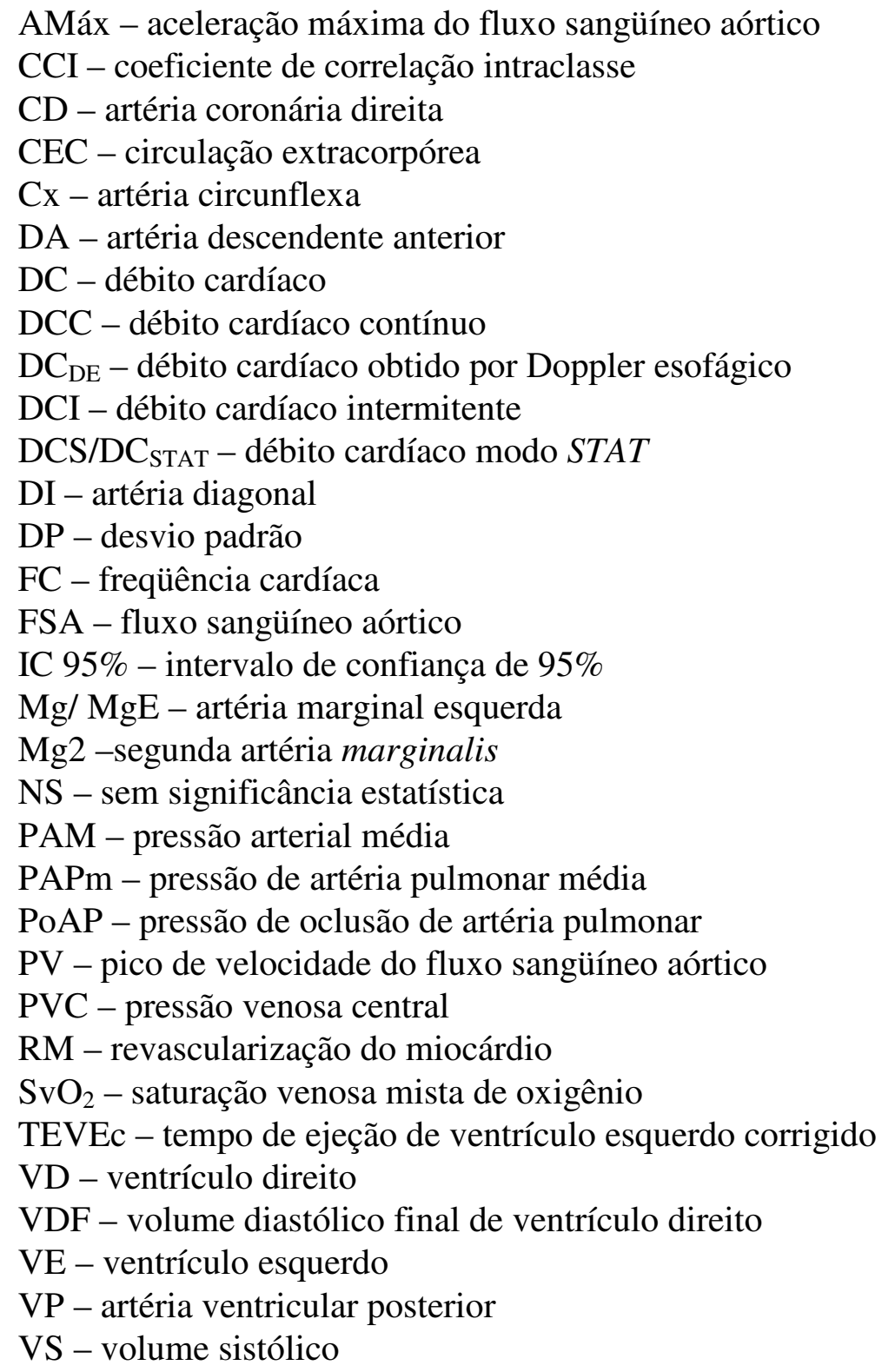




\section{Lista de figuras}

Figura 1. Tela de monitorização do Hemosonic 100 .................................................................39

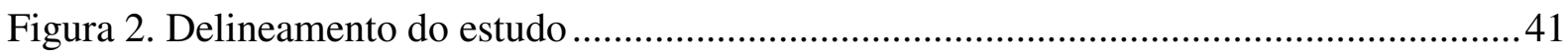

Figura 3. Valores médios e erros-padrões de PoAP por grupo de estudo ................................53

Figura 4. Valores médios e erros-padrões de PVC por grupo de estudo ..................................55

Figura 5. Valores médios e erros-padrões de DCI por grupo de estudo .................................58

Figura 6. Valores médios e erros-padrões de $\mathrm{DC}_{\mathrm{DE}}$ por grupo de estudo...............................61

Figura 7. Valores médios e erros-padrões de FSA por grupo de estudo.................................64

Figura 8. Valores médios e erros-padrões de PV por grupo de estudo..................................67

Figura 9. Gráfico das diferenças entre os débitos cardíacos medidos em modo STAT e por termodiluição intermitente $\left(\mathrm{DC}_{\mathrm{STAT}} \mathrm{e} \mathrm{DCI}\right)$ em relação às medidas médias, nos momentos BASAL, INÍCIO e FINAL DA ANASTOMOSE.

Figura 10. Gráfico das diferenças entre os débitos cardíacos medidos com ecodoppler transesofágico e por termodiluição intermitente $\left(\mathrm{DC}_{\mathrm{DE}}\right.$ e $\left.\mathrm{DCI}\right)$ em relação às medidas médias, nos momentos BASAL, INÍCIO e FINAL DA ANASTOMOSE ...........................................72

Figura 11. Gráfico das diferenças entre os débitos cardíacos medidos em modo STAT e por termodiluição intermitente (DC STAT $\left._{\text {e }} \mathrm{DCI}\right)$ na parede anterior em relação às medidas médias, nos momentos BASAL, INÍCIO e FINAL DA ANASTOMOSE ........................................ 75

Figura 12. Gráfico das diferenças entre os débitos cardíacos medidos com ecodoppler transesofágico e por termodiluição intermitente $\left(\mathrm{DC}_{\mathrm{DE}} \mathrm{e} \mathrm{DCI}\right)$ na parede anterior em relação às medidas médias, nos momentos BASAL, INÍCIO e FINAL DA ANASTOMOSE .............76 


\section{Lista de tabelas}

Tabela 1. Dados antropométricos, risco cirúrgico e anastomoses coronarianas realizadas ...47

Tabela 2. Análise descritiva da variável FC

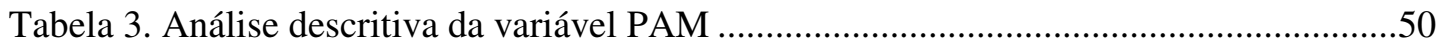

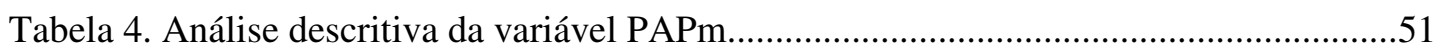

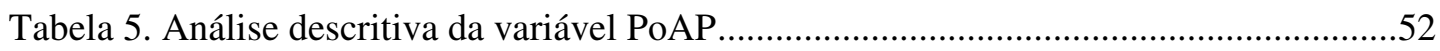

Tabela 6. Resultados do pós-teste de Newman-Keuls (variável PoAP) ...................................53

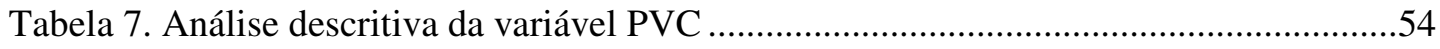

Tabela 8. Resultados do pós-teste de Newman-Keuls (variável PVC)....................................55

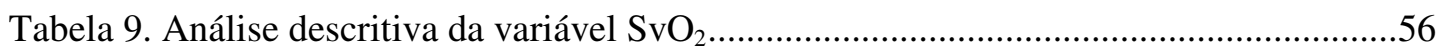

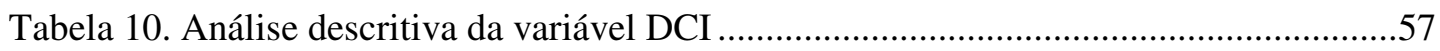

Tabela 11. Resultados do pós-teste de Newman-Keuls (variável DCI)...................................58

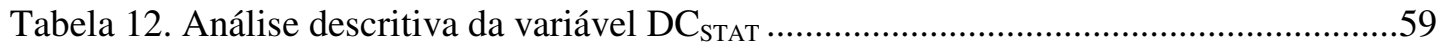

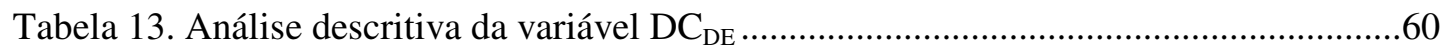

Tabela 14. Resultados do pós-teste de Newman-Keuls (variável $\mathrm{DC}_{\mathrm{DE}}$ ) ...............................61

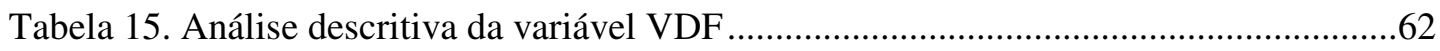

Tabela 16. Análise descritiva da variável FSA......................................................................63

Tabela 17. Resultados do pós-teste de Newman-Keuls (variável FSA) ..................................64

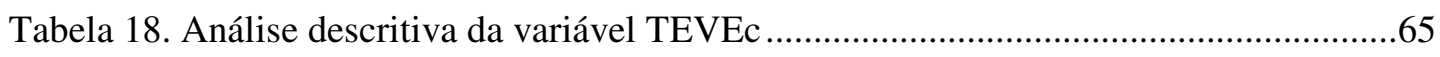

Tabela 17. Análise descritiva da variável PV ......................................................................66

Tabela 20. Resultados do pós-teste de Newman-Keuls (variável PV) ...................................67

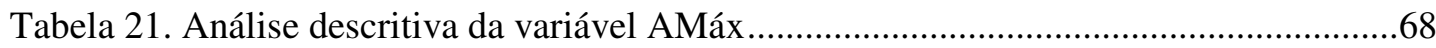

Tabela 22. Resultados da análise de concordância dos métodos de medida de débito cardíaco em modo STAT $\left(\mathrm{DC}_{\mathrm{STAT}}\right)$ ou por ecodoppler transesofágico $\left(\mathrm{DC}_{\mathrm{DE}}\right)$ com o método intermitente (DCI).

Tabela 23. Resultados da análise de concordância dos métodos de medida de débito cardíaco em modo STAT $\left(\mathrm{DC}_{\mathrm{STAT}}\right)$ ou por ecodoppler transesofágico $\left(\mathrm{DC}_{\mathrm{DE}}\right)$ com o método intermitente (DCI). 


\title{
Resumo
}

\author{
Kim SM. Avaliação hemodinâmica durante a revascularização do miocárdio \\ sem utilização de circulação extracorpórea. 2008. 104 p. Tese (doutorado) - \\ Faculdade de Medicina, Universidade de São Paulo; São Paulo.
}

INTRODUÇÃO: A cirurgia de revascularização miocárdica sem utilização de circulação extracorpórea (CEC) tem sido cada vez mais utilizada, especialmente após a introdução de dispositivos estabilizadores da parede cardíaca. Entretanto, a técnica pode causar alterações hemodinâmicas durante a realização das anastomoses coronárias. OBJETIVOS: Analisar as alterações hemodinâmicas decorrentes das mudanças de posição do coração para abordar as artérias coronárias sem CEC e comparar os monitores de débito cardíaco semi-contínuo e de ecodoppler transesofágico quanto à precisão das medidas hemodinâmicas. MATERIAL E MÉTODOS: Foram selecionados aleatoriamente 20 pacientes adultos com idade inferior a 80 anos, candidatos a cirurgia eletiva de revascularização miocárdica sem utilização de circulação extracorpórea. A avaliação hemodinâmica incluiu a utilização de ecodopppler com transdutor esofágico e de cateter de artéria pulmonar com filamento térmico. A coleta de dados foi realizada: 1 - após a indução da anestesia, antes do início da revascularização propriamente dita, 2 - durante a realização das anastomoses distais, logo após o posicionamento e estabilização do coração e 3 - após cinco minutos do início da anastomose. Os dados hemodinâmicos foram analisados por análise de variância de duplo fator com repetição, complementada por teste de Newman-Keuls. O nível de significância considerado foi de 5\%. Os valores de débito cardíaco foram comparados segundo método proposto por Bland e Altman, analisando a correlação intraclasses, diferenças médias e intervalos de confiança de $95 \%$. RESULTADOS: Alterações hemodinâmicas significativas foram detectadas para o aumento de pressão de oclusão de artéria pulmonar (de 17,7 $\pm 6,1$ para 19,2 $\pm 6,5 \mathrm{mmHg}-\mathrm{p}<0,001$ e para 19,4 \pm $5,8 \mathrm{mmHg}-\mathrm{p}<0,001$ ) e pressão venosa central (de 13,9 $\pm 5,4$ para 14,9 \pm 5,9 mmHg $-\mathrm{p}=0,007 \mathrm{e}$ para $15,1 \pm 6,0 \mathrm{mmHg}-\mathrm{p}=0,006)$, além de diminuição do débito cardíaco obtido por termodiluição intermitente (de 4,70 $\pm 1,43$ para 4,23 $\pm 1,22 \mathrm{~L} / \mathrm{min}-\mathrm{p}<0,001$ e para 4,26 $\pm 1,27 \mathrm{~L} / \mathrm{min}-\mathrm{p}<0,001$ ). Houve interação grupo-tempo estatisticamente significativa no débito cardíaco por Doppler esofágico, que apresentou redução no grupo lateral de 4,08 $\pm 1,99$ para 2,84 $\pm 1,81 \mathrm{~L} / \mathrm{min}(\mathrm{p}=0,02)$ e para $2,86 \pm$ $1,73 \mathrm{~L} / \mathrm{min}(\mathrm{p}=0,02)$, e no fluxo sanguíneo aórtico, que diminuiu de $2,85 \pm 1,39$ para $1,99 \pm 1,26$ $\mathrm{L} / \mathrm{min}(\mathrm{p}=0,02)$ e para $2,00 \pm 1,21 \mathrm{~L} / \mathrm{min}(\mathrm{p}=0,02)$. As medidas de débito cardíaco intermitente, semicontínuo e por Doppler esofágico apresentaram diferenças médias e intervalos de confiança de $95 \%$ acima de limites aceitáveis clinicamente. CONCLUSÕES: Houve deterioração hemodinâmica significativa durante a revascularização miocárdica sem CEC. Pelo Doppler esofágico, o débito cardíaco apresentou redução detectada apenas na parede lateral. As diferenças nos valores de débito cardíaco foram muito amplas para considerar os métodos concordantes, em quaisquer das condições hemodinâmicas estudadas.

Descritores: 1.Cirurgia cardíaca 2.Revascularização miocárdica 3.Ponte de artéria coronária sem circulação extracorpórea 4.Débito cardíaco 5.Monitorização intraoperatória 


\title{
Summary
}

\author{
Kim SM. Hemodynamic evaluation during off-pump coronary artery bypass \\ surgery. 2008. 104 p. Thesis (Doctoral) - Faculdade de Medicina, Universidade de \\ São Paulo; São Paulo.
}

INTRODUCTION: Coronary artery bypass graft (CABG) surgeries have been performed increasingly without cardiopulmonary bypass (off-pump CABG), specially with introduction of cardiac wall stabilizing devices. However, hemodynamic changes can occur during coronary anastomosis. OBJECTIVES: To study hemodynamic alterations caused when cardiac position is changed to operate coronary arteries and to compare continuous cardiac output and esophageal Doppler monitor regardig accuracy of hemodynamic measurements. MATERIALS AND METHODS: Twenty adult patients under age of 80 undergoing elective off-pump CABG were enrolled. Hemodynamic evaluation was performed with esophageal echodoppler and continuous thermodilution pulmonary artery catheter. Data were collected 1 - after induction of anesthesia, before revascularization, 2 - during distal anastomosis, right after heart positioning and stabilization, and 3 -five minutes following the beginning of anastomosis. Repeated measures two-way ANOVA with post hoc Newman-Keuls tests were used to analyse hemodynamic data and level of significance was set at 0.05. Cardiac output values were compared using the method proposed by Bland and Altman, and included analysis of correlation, mean differences and 95\% confidence intervals. RESULTS: Significant hemodynamic alterations were detected during revascularization of coronary arteries as elevation of pulmonary artery occlusion pressure (from $17.7 \pm 6.1$ to $19.2 \pm 6.5 \mathrm{mmHg}-P<0.001$, and to $19.4 \pm 5.8 \mathrm{mmHg}-P$ $<0.001$ ) and of central venous pressures (from $13.9 \pm 5.4$ to $14.9 \pm 5.9 \mathrm{mmHg}-P=0.007$, and to 15.1 $\pm 6.0 \mathrm{mmHg}-P=0.006$ ), and as reduction of intermittent cardiac output (from $4.70 \pm 1.43$ to $4.23 \pm$ $1.22 \mathrm{l} / \mathrm{min}-P<0.001$, and to $4.26 \pm 1.27 \mathrm{1} / \mathrm{min}-P<0.001)$. Statistically significant group-time interaction was observed in esophageal Doppler cardiac output, that decreased in the lateral wall from $4.08 \pm 1.99$ to $2.84 \pm 1.81 \mathrm{l} / \mathrm{min}(P=0.02)$ and to $2.86 \pm 1.73 \mathrm{l} / \mathrm{min}(P=0.02)$, and in aortic blood flow, that decreased from $2.85 \pm 1.39$ to $1.99 \pm 1.26 \mathrm{l} / \mathrm{min}(P=0,02)$ and to $2.00 \pm 1.21 \mathrm{l} / \mathrm{min}(P$ $=0.02$ ). Intermittent, STAT -mode or esophageal Doppler cardiac output mean differences and $95 \%$ confidence intervals were beyond clinically acceptable limits. CONCLUSIONS: There was significant hemodynamic deterioration during off-pump CABG. On the esophageal Doppler monitor, cardiac output decrease was detected only in the lateral wall. Differences in cardiac output measurements were too wide to say methods agreed, in all hemodynamic conditions studied.

Descriptors: 1.Thoracic surgery 2.Myocardial revascularization 3.Coronary artery bypass, off-pump 4.Cardiac output 5.Monitoring, intraoperative 


\section{INTRODUÇÃO}

Alterações hemodinâmicas importantes podem ocorrer durante a revascularização do miocárdio realizada sem o uso da circulação extracorpórea (CEC), período em que o coração deve manter sua função de bomba enquanto está sendo operado e manipulado. Prevendo-se as alterações que podem ocorrer e dispondo-se de monitorização contínua e de resposta rápida é possível o pronto reconhecimento da instabilidade hemodinâmica, possibilitando a otimização da função cardíaca para reduzir o sofrimento e sobrecarga do coração frente à manipulação externa.

Os mecanismos responsáveis pelas alterações hemodinâmicas foram avaliados e adequações foram propostas à técnica cirúrgica e anestésica (1-4). Diversos estudos foram realizados para observar essas alterações, empregando cateteres de artéria pulmonar e ecocardiografia (5-23). Foi observado, por exemplo, que a deterioração hemodinâmica ocorria principalmente na realização da anastomose distal dos ramos posteriores das artérias coronárias, devido à necessidade de um deslocamento anterior do ápice cardíaco. Ocorre nesse momento queda da pressão arterial média, do débito cardíaco e do volume sistólico (11). À ecocardiografia observa-se obstrução da saída do fluxo pelo ventrículo direito e diminuição do tamanho desta câmara $(11,16,17)$.

Com o reconhecimento das alterações que ocorrem durante a manipulação do coração para expor as artérias coronárias a serem abordadas, foi 
possível estudar a melhor estratégia para diminuir esses eventos. A manobra de Trendelenburg foi capaz de minimizar as alterações da pressão arterial média e do volume sistólico (11), por promover redistribuição volêmica e melhora do retorno venoso. Essa manobra tem grande importância também porque a dimensão do ventrículo direito é a mais afetada durante a anteriorização do coração, devido a sua maior vulnerabilidade à compressão mecânica sobre o coração (16).

Por outro lado, monitores hemodinâmicos têm sido desenvolvidos para proporcionar informações sobre a função cardíaca. Cateteres de artéria pulmonar com filamento térmico são capazes de mensurar a fração de ejeção do ventrículo direito e, a partir daí, o volume diastólico final. A ecocardiografia transesofágica intraoperatória permite visualizar diretamente as câmaras cardíacas para obter os volumes e pressões durante o ciclo cardíaco. O Doppler transesofágico de aorta pode informar, a partir da análise do fluxo sangüíneo aórtico, o débito cardíaco e o tempo de ejeção do ventrículo esquerdo, um parâmetro que se correlaciona com as alterações de pré-carga (24). Nas situações de mudança das condições hemodinâmicas, a saturação venosa mista de oxigênio $\left(\mathrm{SvO}_{2}\right)$ pode se alterar rapidamente (25) pelo aumento da extração periférica de oxigênio. Analisando a $\mathrm{SvO}_{2}$ em conjunto com o fluxo sangüíneo aórtico pode-se obter informações adicionais relacionadas à função cardíaca e à oferta periférica de oxigênio durante a agressão ao coração.

Além da coronariopatia que justificou a necessidade de intervenção cirúrgica e da função cardíaca prévia, a manipulação cirúrgica contribui para a instabilidade hemodinâmica durante a revascularização do miocárdio realizada sem 
CEC. A monitorização do paciente durante a cirurgia deve fornecer informações que permitam decisões rápidas para o ajuste hemodinâmico sem causar aumento da morbidade cirúrgica ao trazer riscos adicionais. Informações sobre fluxo e volemia podem trazer substratos para a melhor abordagem dessas cirurgias. 


\section{OBJETIVOS}

Este estudo teve como objetivos avaliar as alterações hemodinâmicas que ocorrem durante a realização de anastomoses coronarianas distais na cirurgia de revascularização do miocárdio sem utilização de circulação extracorpórea:

considerando a parede cardíaca contendo a artéria coronariana abordada em cada procedimento e

comparando os valores de débito cardíaco (DC) obtidos por termodiluição intermitente ou semi-contínua (em modo STAT) e por ecodoppler transesofágico. 
REVISÃO DA LITERATURA

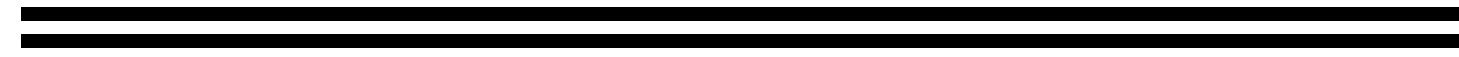




\section{REVISÃO DE LITERATURA}

A revascularização miocárdica $(\mathrm{RM})$ é tradicionalmente realizada com o uso de circulação extracorpórea (CEC) e soluções cardioplégicas, de modo que haja imobilização da parede miocárdica, o que facilita o posicionamento das artérias coronárias e a realização de suas anastomoses. Entretanto, o emprego da CEC pode causar diversas alterações como a síndrome da resposta inflamatória sistêmica, alterações da coagulação, hemodiluição e risco de embolia aérea, além de alterações da função pulmonar e cerebral no período pós-operatório, dentre outras complicações (26).

Kolessov, em 1967 (27), já descrevia a realização de revascularização miocárdica sem o uso de CEC na tentativa de minimizar as reações adversas a ela relacionadas. Atualmente, com o desenvolvimento de dispositivos estabilizadores da parede miocárdica, a realização de cirurgias para revascularização miocárdica sem CEC passou a ser uma opção menos invasiva e com menor morbidade (28).

Pacientes submetidos à RM sem CEC apresentam diminuição no tempo de internação no período pós-operatório, na necessidade de transfusões sanguíneas e na incidência de fibrilação atrial paroxística (29). Em uma revisão sistemática da literatura comparando a RM com e sem CEC, Bainbridge et al. (2005) (30) buscaram informações relacionadas à mortalidade, incidência de acidentes vasculares cerebrais, infarto miocárdico, fibrilação atrial e insuficiência renal, patência dos enxertos e recorrência de angina após essas cirurgias. A meta-análise desses fatores não 
demonstrou diferença estatística na redução de mortalidade em 30 dias ou na ocorrência de acidentes vasculares cerebrais, infartos miocárdicos ou insuficiência renal. Nos pacientes submetidos à RM sem CEC, houve redução significativa na incidência de fibrilação atrial, nas transfusões sangüíneas e na duração da internação hospitalar e em terapia intensiva, além do tempo de ventilação mecânica.

No entanto, os pacientes avaliados na maioria dos estudos eram relativamente jovens e mais saudáveis e os procedimentos realizados por um número limitado de cirurgiões experientes, em centros de referência. Poucos estudos avaliaram adequadamente o resultado em pacientes de alto risco e ainda permanece controversa a realização da cirurgia sem CEC em pacientes com baixa fração de ejeção do ventrículo esquerdo, uma vez que a alteração do eixo cardíaco, necessária para realização de algumas anastomoses coronarianas, pode promover importantes alterações hemodinâmicas.

A revascularização do miocárdio sem utilização de CEC é realizada desde o início da década de 60, junto com o desenvolvimento das cirurgias coronarianas $(5,27,31)$. No entanto, com a introdução e o desenvolvimento das técnicas de circulação extracorpórea nesse mesmo período, a cirurgia com o coração em atividade foi praticamente abandonada. A cardioplegia eletromecânica também passou a ser mais utilizada e trazia as vantagens de prover um campo cirúrgico estático e sem sangue.

Várias técnicas e conceitos se desenvolveram durante os anos 80 e, com isso, foi possível a implantação da cirurgia coronariana minimamente invasiva no início da década de 90. Essa técnica pioneira permitia que a revascularização 
miocárdica se realizasse em situações selecionadas, usando uma incisão bastante reduzida, sem o emprego da circulação extracorpórea (32). Em 1996, Calafiore et al. (33) publicaram um estudo em que 155 pacientes foram submetidos a uma pequena toracotomia esquerda pelo quarto espaço intercostal para realizar a anastomose da artéria torácica interna esquerda à artéria descendente anterior, sem o uso da circulação extracorpórea. Esta técnica era adequada para o tratamento de coronariopatia uniarterial, mas havia grande dificuldade imposta pela movimentação excessiva do campo operatório. Em 1997, Boonstra et al. (34) desenvolveram um dispositivo estabilizador que poderia ser introduzido pela mini-toracotomia. $\mathrm{Na}$ mesma época, Borst et al. (35) apresentaram um estabilizador do tipo sucção que também permitia realizar anastomoses em um campo imóvel. Com o advento das novas técnicas para exposição das coronárias e estabilização miocárdica, a revascularização completa sem circulação extracorpórea tornou-se possível e passou a apresentar seus primeiros resultados positivos (36).

Devido à dificuldade de exposição de ramos de coronárias mais laterais e posteriores, o acesso por esternotomia mediana, combinado a métodos apropriados de posicionamento do coração e estabilização mecânica, tornou-se a abordagem mais empregada nessas cirurgias. Com a esternotomia mediana convencional, as artérias descendente anterior, diagonal e ramos da coronária direita são visualizados com mais facilidade e as anastomoses distais podem ser realizadas sem CEC, com alterações hemodinâmicas menos significativas. O desafio encontrava-se em abordar os ramos circunflexos sem causar instabilidade hemodinâmica. Lima, em 1999 (37), propôs em tese de doutorado uma manobra envolvendo quatro suturas pericárdicas e 
demonstrou que este território poderia ser abordado com mínima instabilidade. Mais tarde, a partir da avaliação desta técnica, D’Ancona et al.(2000) (7) propuseram o uso de uma sutura pericárdica única, também com bons resultados.

Couture (6), em 2002, realizou uma extensa revisão da literatura médica na tentativa de descrever os mecanismos responsáveis pelas alterações hemodinâmicas observadas na cirurgia de revascularização do miocárdio sem utilização de CEC. Essas variações podem ser atribuídas à mobilização e estabilização do coração ou à isquemia miocárdica que pode ocorrer durante a oclusão coronariana.

Os efeitos hemodinâmicos variam com os diferentes estabilizadores utilizados, por sucção (Octopus Tissue Stabilizer System, Medtronic Inc., Minneapolis, MN, EUA) ou compressão (CoroNéo Inc., CTS Inc., Cupertino, CA, EUA). O deslocamento anterior do coração em $90^{\circ}$ e a compressão maior do ventrículo direito em relação ao esquerdo são mecanismos responsáveis pelas alterações hemodinâmicas observadas com o uso de estabilizadores do tipo sucção. Por outro lado, os estabilizadores por compressão afetam o ventrículo esquerdo por meio da obstrução de sua via de saída e pela restrição diastólica conseqüente à deformação geométrica (6).

Os dispositivos do tipo “Octopus" permitem a estabilização da parede miocárdica e parecem provocar mínimas alterações hemodinâmicas ou eletrocardiográficas (14). Estes estabilizadores são compostos por duas placas com segmentos maleáveis, que permanecem fixos em um braço articulado preso à mesa 
cirúrgica ou aos afastadores de esterno. Suas placas apresentam seis ventosas, cada uma com capacidade de realizar sucção de até $400 \mathrm{mmHg}$.

Utilizando porcos como modelo animal e o Octopus como estabilizador do miocárdio, Borst et al. (35) não observaram a ocorrência de deterioração hemodinâmica durante as anastomoses distais das artérias descendente anterior (DA) e coronária direita (CD). No entanto, observa-se tendência a diminuição da pressão arterial na abordagem de ramos mais posteriores da parede miocárdica quando ocorre o deslocamento anterior do ápice do coração em atividade (11). Comparativamente, o acesso ao território correspondente à artéria circunflexa $(\mathrm{Cx})$ causa maiores efeitos hemodinâmicos.

A imobilização da parede cardíaca póstero-lateral é possível com a fixação das pás do Octopus diretamente no ventrículo e anteriorização do ápice pela tração deste dispositivo. Com essa manobra, Grundeman et al.(1998) (11) observaram que ocorre diminuição de $26 \%$ na pressão arterial média (PAM), $37 \%$ no débito cardíaco (DC) e 44\% no volume sistólico (VS) biventricular, embora haja aumento na pressão diastólica final de ventrículo direito (VD), mas não de ventrículo esquerdo (VE). A manobra de céfalo-declive em $20^{\circ}$ (Trendelenburg) pode normalizar o débito cardíaco e pressão arterial média.

Grundeman et al.(1999) (12) estudaram, experimentalmente, o mecanismo para a disfunção biventricular utilizando ecocardiografia bidimensional e verificaram que uma porção significativa da parede livre de VD é pressionada contra o septo interventricular resultando em diminuição maior do tamanho do VD em relação ao VE. Ocorre também estreitamento da via de saída de VD, mas não são 
observadas incompetências valvares. O posicionamento em Trendelenburg pode aumentar o retorno venoso e normalizar a pressão arterial média, o volume sistólico e as dimensões do VE, mas corrige apenas parcialmente as dimensões de VD.

Entretanto, as alterações hemodinâmicas da cirurgia de revascularização do miocárdio sem CEC não estão bem caracterizadas nos estudos clínicos. No relato de Jansen et al.(1998) (14), com os resultados dos primeiros 100 pacientes operados utilizando o dispositivo Octopus, foi observada melhor tolerância na exposição das paredes anterior e inferior. A exposição da parede posterior pode ser bem tolerada se o deslocamento cardíaco for realizado lentamente. No entanto, nesses casos, a redistribuição volêmica com a manobra de Trendelenburg e a infusão de dopamina foi necessária em $67 \%$ dos pacientes para manter normal a pressão arterial.

Nierich et al. (2000) (20), em um estudo com 150 pacientes, não observaram deterioração importante na função circulatória global ou disfunção cardíaca de origem isquêmica durante cirurgia com uso do mesmo dispositivo estabilizador. O volume sistólico foi o parâmetro mais afetado durante a revascularização da artéria diagonal (DI) (diminuição de 25\%), fato atribuído à compressão do coração direito entre o ventrículo esquerdo e pericárdio direito. A necessidade de suporte farmacológico com agentes inotrópicos foi $15 \%$ maior nessa situação. Segundo estes autores, a manobra para o posicionamento, mais do que o próprio deslocamento, causa maiores alterações hemodinâmicas, dependendo da artéria a ser abordada. Para qualquer das artérias anastomosadas, o mecanismo de alteração hemodinâmica seria o mesmo: diminuição temporária da ejeção do VD e, 
conseqüentemente, diminuição do débito de VE. A persistência dessa condição sem tratamento adequado impossibilita a realização do enxerto.

Mathison et al. (2000) (16) descreveram detalhadamente a cirurgia de revascularização do miocárdio usando o dispositivo Octopus II. O posicionamento para abordagem da artéria circunflexa resultou em decréscimo de 22,2 $\pm 4,4 \%$ na pressão arterial média e de $28,5 \pm 3,5 \%$ no VS, aumento das pressões atriais esquerda e direita em $59,9 \pm 15,9 \%$ e $166,7 \pm 34,2 \%$, respectivamente, e das pressões diastólicas finais de VE e VD em 59,4 $\pm 16,6 \%$ e $151,4 \pm 9,8 \%$. O posicionamento para revascularização da artéria descendente posterior também resultou em diminuição do VS $(-22,4 \pm 7,9 \%)$ com aumento nas pressões biatriais e diastólica final de VD, mas sem alteração significativa na pressão diastólica final de VE. Na anastomose de artéria descendente anterior, houve a menor alteração hemodinâmica, embora pudesse ser observada diminuição do VS em 17,5 $\pm 5,1 \%$, acompanhada de aumento da pressão de átrio direito e na pressão diastólica final de VD. Utilizando ecocardiografia transesofágica, esses autores puderam observar que, em todos os posicionamentos, o ventrículo direito é o mais afetado pela compressão, porque sua parede é mais fina, sua pressão é relativamente baixa e passível de ser pressionado pelo pericárdio. Desse modo, mesmo que haja compressão do ventrículo esquerdo, os efeitos à direita são maiores. Os aumentos nas pressões atriais podem ser explicados pela observação de que a elevação do ápice cardíaco causa distorção do coração próximo às válvulas atrioventriculares, acarretando obstrução parcial ao fluxo sangüíneo. As pressões nas quatro câmaras cardíacas elevaram-se, enquanto a pressão arterial média, débito cardíaco e volume sistólico decaíram. No entanto, 
diferentemente dos modelos animais, a manobra de Trendelenburg não restaurou esses três últimos parâmetros.

D'Ancona et al. (2000) (7) descreveram uma técnica cirúrgica com sutura única no seio oblíquo do pericárdio para posicionar o coração durante as anastomoses. A tração desta sutura promove elevação e rotação do coração, permitindo a exposição de todas as artérias coronárias a serem abordadas. Utilizando essa técnica e um estabilizador de parede por compressão não foram observadas alterações hemodinâmicas consideráveis nos diversos estágios da cirurgia. O principal fato ressaltado foi que o índice cardíaco não se alterou, mas houve elevação estatisticamente significativa da pressão de oclusão da artéria pulmonar (PoAP) durante o clampeamento e estabilização da artéria coronária circunflexa.

Mishra et al. (2002) (17) não observaram alterações hemodinâmicas significativas durante anastomoses na parede anterior. No entanto, em procedimentos envolvendo a parede posterior, houve diminuição da PAM em $18 \pm 4 \%$ (p $\leq 0,01)$ com aumento concomitante da PVC de $66 \pm 18 \%$ (p $\leq 0,001)$. O VS e índice cardíaco (IC) diminuíram em 35,7 $\pm 11 \%(\mathrm{p} \leq 0,001)$ e $45 \pm 13 \%(\mathrm{p} \leq 0,001)$. As pressões de artéria pulmonar média e ocluída não tiveram elevação significativa apesar da adoção de posição de Trendelenburg e reposição volêmica adicional. À ecocardiografia transesofágica, houve desenvolvimento de alteração de contratilidade em 294 $(59,2 \%)$ dos pacientes com diminuição da função ventricular global em 306 pacientes $(61,2 \%)$. A anastomose na parede inferior se associou a redução significativa de IC e VS, mas dentro de limites aceitáveis. A obstrução da via de saída de VD foi observada nos vários estágios durante o deslocamento vertical do coração. 
O maior comprometimento hemodinâmico foi observado durante o posicionamento do coração para anastomose dos ramos marginais. Houve diminuição significativa da PAM $(18 \pm 4 \%, \mathrm{p} \leq 0,01)$, VS $(35,7 \pm 11 \%, \mathrm{p} \leq 0,01)$ e IC $(45 \pm$ $13 \%, \mathrm{p} \leq 0,001)$ e aumento da PVC $(66 \pm 18 \%, \mathrm{p} \leq 0,001)$. Esses autores atribuíram os efeitos hemodinâmicos observados à compressão ventricular direita resultando em diminuição do débito sistólico de VD. Neste estudo, em alguns pacientes houve redução da PAM e do DC acompanhados de diminuição da PVC e não aumento. O fato poderia ser explicado pela distorção das veias cavas superior e inferior, com conseqüente redução do retorno venoso ao coração.

Já Mueller et al. (2002) (19) demonstraram que, independentemente da artéria a ser abordada, a estabilidade hemodinâmica é preservada durante a revascularização miocárdica sem $\mathrm{CEC}$, desde que técnica adequada de exposição e estabilização seja empregada, de modo a evitar compressão de câmaras cardíacas. Nenhum dos parâmetros analisados em seu estudo teve variação significativa dos valores basais nos três territórios estudados (posterior, anterior e lateral).

A oclusão coronariana, por sua vez, pode representar fator causador de efeitos adicionais na função ventricular esquerda, dependendo do desenvolvimento e do estado da circulação colateral (38). Brown et al. (1999) (39) demonstraram que a oclusão de um vaso com estenose importante (> 90\%) mas com boa circulação colateral acarreta isquemia miocárdica de menor gravidade que a oclusão de um vaso com apenas 60 a $70 \%$ de estenose, mas com menor fluxo colateral. Koh et al. (38), utilizando a ecocardiografia transesofágica em pacientes submetidos a revascularização do miocárdio sem CEC, observaram que, durante a oclusão da 
artéria descendente anterior por até 15 minutos, tanto a função sistólica quanto a diastólica de VE estavam deprimidas nos pacientes sem circulação colateral, em comparação a disfunção diastólica isolada de pacientes com colaterais. Todas essas alterações se normalizaram após 10 minutos de reperfusão. Entretanto, as consequiências hemodinâmicas do deslocamento do coração provavelmente não sofrem influências do grau de estenose coronariana (10).

O posicionamento em Trendelenburg pode, além de normalizar o DC e PAM, restabelecer o fluxo sangüíneo coronariano. Grundeman et al. (1998) (11) demonstraram que o deslocamento cardíaco causa diminuição do fluxo coronariano medido por probe de ultrassom nas artérias descendente anterior, coronária direita e circunflexa em $34 \%, 25 \%$ e $50 \%$ respectivamente, restaurado com o céfalo-declive em $20^{\circ}$ (manobra de Trendelenburg).

\section{A monitorização hemodinâmica durante a RM sem CEC}

A manutenção da estabilidade hemodinâmica durante a luxação cardíaca necessária para acesso às diferentes artérias coronárias depende de acompanhamento rigoroso pelo anestesiologista. Com a mobilização do coração é distorcida a função

de monitores como o eletrocardiograma e a ecocardiografia transesofágica. A monitorização invasiva da pressão arterial não é afetada e é mandatória para assegurar pressão arterial adequada, mas um valor normal não garante débito 
cardíaco ou perfusão tecidual adequados. Neste sentido, a monitorização do DC apresenta-se como instrumento útil para melhor cuidado anestésico e muitos estudos consideram necessário o uso de cateter de artéria pulmonar nessas cirurgias (2). As medidas intermitentes do DC por termodiluição (DCI) tornam-se impraticáveis com as freqüentes e abruptas mudanças da posição do coração. Assim, uma solução ideal compreenderia um monitor confiável e de resposta rápida, como propõe o sistema de débito cardíaco contínuo (DCC) utilizando filamento térmico.

Poli de Figueiredo et al. (1999) (25) procuraram determinar a precisão do monitor de débito cardíaco contínuo durante as alterações hemodinâmicas agudas induzidas por hemorragia e ressuscitação. Em um modelo experimental com cães, foi produzida hemorragia até que fosse atingida PAM de $40 \mathrm{mmHg}$. Esta pressão foi mantida por 30 minutos, o volume retirado foi retransfundido e foi produzida uma segunda hemorragia maciça em 10 minutos. Neste estudo, as medidas de DCC se correlacionaram com o débito cardíaco intermitente e fluxo sangüíneo na artéria pulmonar durante o período basal. No entanto, após perda sangüínea aguda, houve atraso de 20 minutos para que o DCC acompanhasse a diminuição abrupta de DCI e também da saturação venosa mista de oxigênio $\left(\mathrm{SvO}_{2}\right)$. $\mathrm{O}$ mesmo atraso foi observado no início da ressuscitação volêmica, mas este fato foi ainda mais marcante no animal exsangüe, quando o DCC ainda registrava os valores basais.

Singh et al. (2002) (40) compararam as medidas de DC contínuo, no modo STAT (DCS) e intermitente em pacientes submetidos a revascularização coronariana direta minimamente invasiva. Esses autores observaram diminuição estatisticamente significativa dos parâmetros hemodinâmicos durante as anastomoses 
de artéria torácica interna esquerda à DA. A correlação entre DCI e DCC foi significativa $(\mathrm{r}=0,78, \mathrm{p} \leq 0,001)$ com os dados combinados de todos os pacientes, assim como entre DCI e DCS $(r=0,79, p \leq 0,001)$, mas a correlação foi menor entre os métodos durante as anastomoses e no $1^{\circ}$ e $5^{\circ}$ minuto pós-revascularização. Este fato pode ser atribuído ao retardo de resposta de 3 a 6 minutos do DCC, enquanto que a diminuição do DCI foi detectada imediatamente.

Lazor et al. (1997) (41) também compararam as medidas de débito cardíaco durante estabilidade e alteração hemodinâmica aguda, representada por aumento de 10 a $20 \%$ na freqüência de um marcapasso epicárdico. As correlações entre DC contínuo e STAT e entre DC contínuo e intermitente foram boas ( $\mathrm{r}=0,94$ para ambos). O tempo de resposta para alteração significativa de $\mathrm{PAM}_{\mathrm{A}} \mathrm{SvO}_{2}$ foi de 30 segundos e 90 segundos, respectivamente. No entanto, a elevação do DCS foi detectada aos 270 segundos, mas a elevação do DCC não foi estatisticamente significante mesmo após 6 minutos.

Zöllner et al. (2001) (42), estudando dois sistemas de monitorização contínua do DC (IntelliCath catheter, Baxter Edwards Critical-Care, Irvine, CA, EUA e Opti-Q catheter, Abbott Laboratories, Chicago, IL, EUA) não encontraram diferença estatística em relação à concordância entre os valores medidos por DC contínuo e termodiluição em bolus. No entanto, $49 \%$ das medidas com o cateter OptiQ e $46 \%$ com o cateter IntelliCath apresentavam diferença aceitável de $\pm 0,5$ L/min. Os autores concluíram, assim, que a discrepância dos métodos acima de limites aceitáveis clinicamente não permitem que as medidas de DC contínuo substituam o método intermitente. 
O DC também pode ser obtido através da medida do fluxo sangüíneo pela aorta descendente com o uso de monitor com Doppler transesofágico. Este monitor foi desenvolvido como alternativa não-invasiva ao cateter de artéria pulmonar para realização de medida de DC. Ele detecta a velocidade do fluxo sangüíneo aórtico e calcula o volume sistólico e débito cardíaco resultantes (43).

Royse et al. (2003) (44) compararam o DC e o fluxo descendente aórtico medido com ecografia transesofágica durante RM sem CEC de 26 pacientes. Houve pobre correlação dos parâmetros entre os indivíduos, mas as mudanças de DC e fluxo da aorta descendente ocorreram na mesma direção e magnitude (ANOVA com p = 0,062 para interação fator-tempo).

Já Grow et al. (2004) (45) estudaram os três métodos de medida de DC: intermitente, contínuo e por Doppler transesofágico. Enquanto o DCI diminuía $25 \pm$ 2,3\%, o DCC registrava aumento de $4 \pm 4,1 \%$. A velocidade do fluxo aórtico descendente diminuiu $23 \pm 2,9 \%$ e o produto deste com a freqüência cardíaca diminuiu $22 \pm 3,1 \%$, mostrando-se preditor significativo da alteração de DCI. A $\mathrm{SvO}_{2}$ diminuiu $7 \pm 1,3 \%$, correlacionando-se com as alterações de DCI, mas não pode ser considerado indicador completamente preciso e momentâneo das mudanças de débito cardíaco durante a manipulação e estabilização do coração.

O débito cardíaco obtido por termodiluição intermitente com bolus de solução fria foi o método com o qual os novos monitores foram comparados, mas apesar de ser o mais utilizado clinicamente, não pode ser considerado o "gold standard”, já que é uma medida indireta e representa uma média entre três valores obtidos em um intervalo de tempo. No entanto, o DCI se correlaciona bem com 
outros métodos precisos, como o de diluição de corante e de medida do fluxo eletromagnético da aorta $(46,47)$.

Com o uso de monitores hemodinâmicos com variados recursos de medidas é possível reconhecer as alterações cardiocirculatórias que ocorrem no período per-operatório. O emprego destes durante a revascularização do miocárdio sem circulação extracorpórea permite descrever com mais precisão estes eventos e também eleger o método de medida que seria mais eficaz e confiável. 
CASUÍSTICA E MÉTODOS

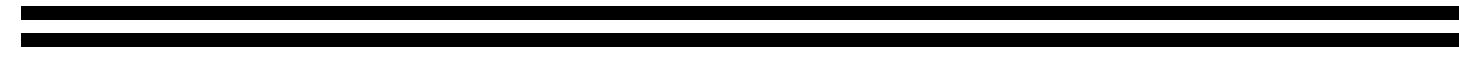




\section{CASUÍSTICA E MÉTODOS}

\subsection{Projeto de pesquisa}

O protocolo de pesquisa foi aprovado pela Comissão Científica e de Ética do Instituto do Coração (InCor) em 17 de outubro de 2002 e pela Comissão de Ética para Análise de Projetos de Pesquisa (CAPPesq) da Diretoria Clínica do Hospital das Clínicas e da Faculdade de Medicina da USP em sessão de 12 de março de 2003. O estudo foi realizado no centro cirúrgico do InCor - HCFMUSP. Para aquisição de materiais de consumo empregados no estudo mas que não faziam parte da rotina cirúrgica, foi obtido auxílio à pesquisa da Fundação de Amparo à Pesquisa do Estado de São Paulo (FAPESP), sob processo de número 03/07092-6, com início da coleta de dados em fevereiro de 2004.

\subsubsection{Critério de seleção dos pacientes}

No período da pesquisa foram avaliados candidatos adultos à cirurgia eletiva de revascularização miocárdica sem CEC, de ambos os sexos. O risco 
cirúrgico foi estratificado segundo os critérios de Higgins (48), sendo admitidos ao estudo somente pacientes com risco mínimo a moderado.

\section{Critérios de inclusão}

- A aceitação voluntária do paciente e capacidade e vontade de ler, entender e assinar termo de consentimento livre e esclarecido;

- Idade inferior a 80 anos;

- Portador de função renal dentro dos limites de normalidade ou creatinina menor que $1,4 \mathrm{mg} / \mathrm{dl}$;

- Função ventricular dentro dos parâmetros normais (fração de ejeção maior ou igual a 50\%) avaliadas pelo ecocardiograma ou ventriculografia.

\section{Critérios de exclusão}

- Recusa em participar do estudo;

- Idade igual ou superior a 80 anos;

- Creatinina sérica igual ou superior a 1,4 mg/dl;

- Fração de ejeção do ventrículo esquerdo inferior a 50\%;

- Reoperação;

- Presença de valvopatias associadas;

- Diagnóstico de doença pulmonar obstrutiva crônica. 


\subsubsection{Termo de consentimento livre e esclarecido}

Após definição da indicação cirúrgica eletiva e avaliação dos critérios de inclusão e exclusão, os pacientes foram convidados a participar do estudo. Após esclarecimento dos objetivos gerais do estudo, assinaram o termo de consentimento livre e esclarecido.

\subsection{Casuística}

Para se detectar diferenças de medidas entre os grupos com nível de significância de 0,05 , foi estabelecido que 20 pacientes seriam estudados, considerando-se que, em média, seriam realizadas três anastomoses coronarianas em cada paciente.

A decisão para realização do procedimento cirúrgico sem a utilização de CEC, das artérias a serem abordadas e da ordem de revascularização foi estabelecida pelo cirurgião cardíaco. Os procedimentos foram realizados por duas equipes de cirurgiões cardíacos.

Quando houve mudança de conduta durante a cirurgia, indicando-se a utilização de CEC, o paciente foi excluído do estudo. No total, 29 pacientes foram recrutados e assinaram o termo de consentimento, mas nove foram excluídos porque 
foram submetidos ao procedimento com CEC. Este estudo se refere aos 20 pacientes que finalizaram a avaliação.

As anastomoses coronarianas foram agrupadas segundo a localização do procedimento: na parede anterior (anastomoses distais das artérias coronárias descendente anterior - DA e diagonal - DI), lateral (anastomose distal da artéria marginal esquerda) ou posterior (anastomose distal da artéria coronária direita ou de seus ramos posteriores).

\subsection{Métodos}

O estudo foi iniciado com a entrevista dos pacientes antes da cirurgia, quando se obteve a autorização para sua inclusão e assinatura do termo de consentimento.

Foi determinado um período mínimo de jejum alimentar de 8 horas e a medicação pré-anestésica consistiu de midazolam na dose de 0,1 a $0,2 \mathrm{mg} / \mathrm{kg}$ por via oral, 30 minutos antes da operação, até a dose máxima de 15 mg.

Ao serem admitidos na sala de cirurgia, os pacientes foram monitorizados com eletrocardiografia nas derivações DII e V5, com análise contínua de segmento ST, e oximetria de pulso.

Após venóclise periférica com cateter de calibre $16 \mathrm{G}$, a monitorização invasiva da pressão arterial foi realizada pela punção da artéria radial com cateter 
20G, utilizando-se transdutor de pressão e verificando-se a obtenção da curva de pressão (monitor Siemens Infinity SC 9000 XL, Munique, Alemanha).

Após a pré-oxigenação, a indução da anestesia geral foi realizada com a administração titulada de sufentanil até dose de $0,5 \mu \mathrm{g} / \mathrm{kg}$ e propofol (até a perda dos reflexos) ou etomidato $(0,2 \mathrm{mg} / \mathrm{kg})$.

O relaxamento muscular foi obtido com brometo de pancurônio na dose de 0,1 a $0,2 \mathrm{mg} / \mathrm{kg}$ ou atracúrio $0,5 \mathrm{mg} / \mathrm{kg}$. Aplicou-se ventilação manual sob máscara e intubação traqueal com tubo de diâmetro adequado, instalando-se a seguir ventilação controlada mecânica (respirador Cícero EM, Drager Medical, Lübeck, Alemanha), em modo volume controlado, com volume corrente de $8 \mathrm{ml} / \mathrm{kg}$, freqüência respiratória de 10 a 12 por minuto, relação $\mathrm{I}: \mathrm{E}=1: 2, \mathrm{FiO}_{2}=0,6$ (oxigênio e ar comprimido) e PEEP de $5 \mathrm{~cm} \mathrm{H}_{2} \mathrm{O}$. A ventilação foi ajustada conforme monitorização do $\mathrm{ETCO}_{2}$, pressões de vias aéreas e gasometria arterial. Após a indução anestésica, realizou-se sondagem vesical para avaliação de diurese.

A anestesia foi mantida com concentrações variáveis de isoflurano $(0,7$ a $0,9 \%$ ) e bolus intermitentes de sufentanil.

Após a intubação traqueal, foi realizada a punção da veia jugular interna direita para passagem de cateter de artéria pulmonar calibre 7,5F com filamento térmico (CCO catheter, Baxter Edwards Critical Care, Irvine, CA, EUA), através de introdutor 8,5F. O cateter foi então conectado ao monitor Vigilance (Baxter Edwards Critical Care, Irvine, CA, EUA). Após o posicionamento do cateter na artéria pulmonar, foi colhida amostra de sangue venoso misto para realização de exame de gasometria e calibração do monitor de saturação venosa contínua. 
Foi introduzida, por via oral, uma sonda esofágica com transdutores de Doppler e ecografia em modo M (Hemosonic 100, Arrow International Inc., Reading, PA, EUA), protegida com camisa descartável própria. A profundidade e rotação dos transdutores em relação à aorta torácica descendente foram adequadas buscando-se o traçado Doppler característico do fluxo sanguíneo aórtico e a imagem das paredes da aorta na ecografia (Figura 1).

No período antes do início das anastomoses coronarianas, foi realizado ajuste da volemia com $10 \mathrm{ml} / \mathrm{kg}$ de solução de hidroxietilamido 130/0,4 a $6 \%$ (Voluven, Fresenius Kabi, Bad Homburg, Alemanha) e solução de Ringer lactato até atingir estabilização hemodinâmica, com obtenção de valores normais de índice cardíaco intermitente, pressão venosa central e pressão de oclusão de artéria pulmonar.

O agente inotrópico de escolha para os casos em que, apesar da otimização volêmica, os valores de índice cardíaco permanecessem diminuídos foi a dobutamina. Quando necessária vasodilatação, infusões contínuas de soluções de nitroprussiato ou nitroglicerina poderiam ser utilizadas. Para ajustes rápidos da pressão arterial, era administrado um bolus de $4 \mu \mathrm{g}$ de noradrenalina em caso de hipotensão ou $200 \mu \mathrm{g}$ de nitroglicerina em caso de hipertensão arterial. 
Figura 1. Tela de monitorização do Hemosonic 100

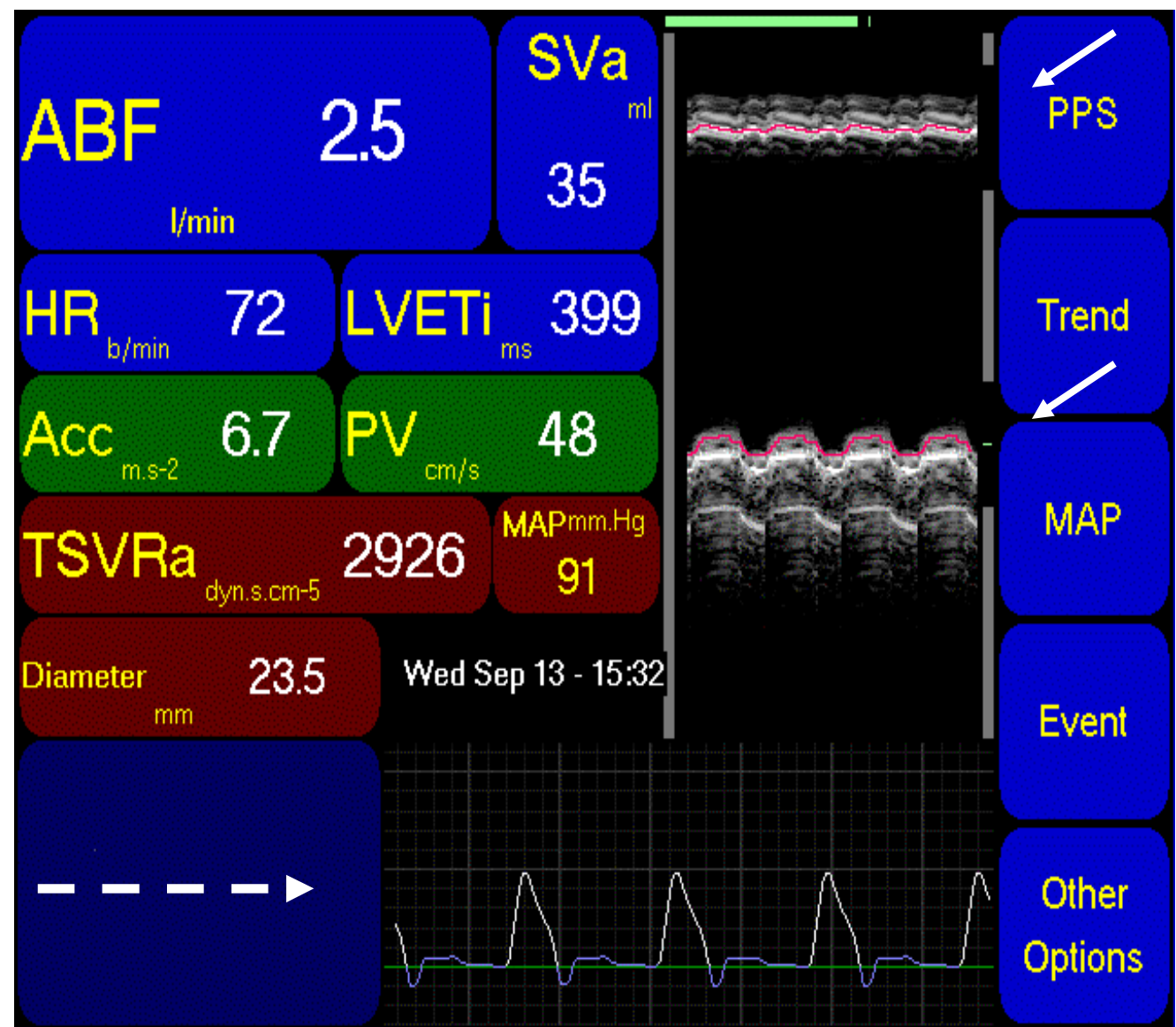

Legenda: setas brancas cheias - ecografia em modo $\mathrm{M}$ das paredes anterior $\mathrm{e}$ posterior da aorta torácica descendente; seta tracejada - gráfico Doppler de velocidade do fluxo aórtico x tempo

Parâmetros: ABF - fluxo sangüíneo aórtico; Acc - aceleração máxima; Diameter diâmetro da aorta; HR - frequiência cardíaca; LVETi - tempo de ejeção de ventrículo esquerdo indexado; PV - pico de velocidade; SVa - volume sistólico aórtico. 
Foram registrados os seguintes parâmetros hemodinâmicos:

FC - frequiência cardíaca;

PAM - pressão arterial média;

PAPm - pressão de artéria pulmonar média;

PVC - pressão venosa central;

PoAP - pressão de oclusão de artéria pulmonar;

$\mathrm{SvO}_{2}$ - saturação venosa mista de oxigênio;

DCI - débito cardíaco intermitente (método de termodiluição);

$\mathrm{DC}_{\mathrm{STAT}}$ - débito cardíaco obtido no modo STAT do monitor Vigilance;

VDF - volume diastólico final de ventrículo direito;

$\mathrm{DC}_{\mathrm{DE}}$ - débito cardíaco obtido por Doppler esofágico;

TEVEc - tempo de ejeção de ventrículo esquerdo corrigido;

PV - pico de velocidade do fluxo sangüíneo aórtico;

AMáx - aceleração máxima do fluxo sangüíneo aórtico.

A avaliação hemodinâmica foi realizada nos seguintes momentos da cirurgia (Figura 2):

- após a indução anestésica e com o tórax ainda fechado;

-BASAL (0) - após esternotomia, estabilização cardiovascular e otimização da volemia, sendo considerada como medida basal para a primeira anastomose e repetida antes de cada anastomose, antes do posicionamento do coração; 
- INÍCIO DA ANASTOMOSE (I) - no início da anastomose coronariana, com o dispositivo estabilizador da parede miocárdica Octopus (Medtronic, Inc., Minneapolis, MN, EUA) posicionado;

-FINAL DA ANASTOMOSE (F) - após 5 minutos do início da anastomose, próximo à finalização da mesma e antes da retirada do Octopus.

Figura 2. Delineamento do estudo - exemplo de coletas de dados em um caso com 3 anastomoses coronarianas distais

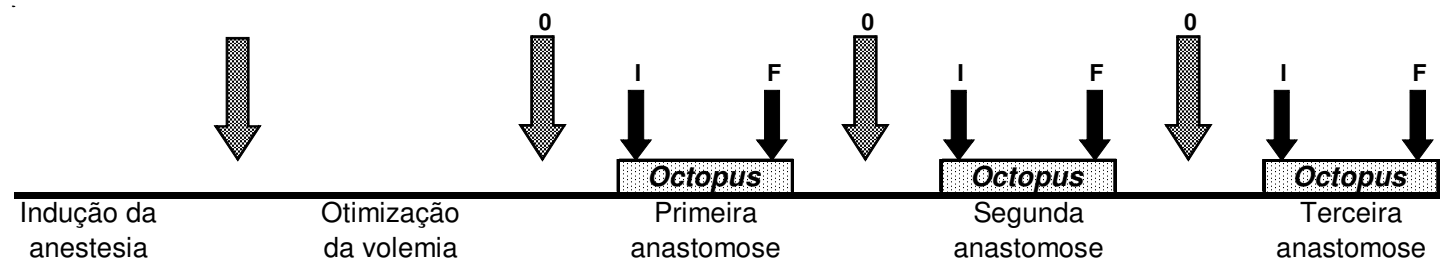

Legenda: setas - momentos de coleta, 0 - basal, I - no início da anastomose ou F no final da anastomose

No momento da avaliação, os valores de índice cardíaco e volume diastólico final indexado indicados pelo monitor Vigilance no modo STAT foram registrados. Em seguida, foram realizadas as medidas de débito cardíaco por termodiluição utilizando injeção de bolus de $10 \mathrm{~mL}$ de solução de glicose a $5 \%$ em temperatura ambiente. As curvas de termodiluição foram avaliadas e o resultado registrado considerou a média de três medidas consecutivas. 


\subsection{Análise estatística}

Para a análise descritiva das medidas hemodinâmicas obtidas, foram calculadas as suas médias aritméticas, desvios-padrão e amplitude de variações. As variáveis foram analisadas com os testes de Levene e Kolmogorov-Smirnov para verificação de homogeneidade das variâncias e aderência à curva de normalidade.

A análise de variância (ANOVA) de duplo fator com repetição foi utilizada para verificar diferenças dos parâmetros hemodinâmicos nos diferentes grupos de anastomoses coronarianas. O método de ANOVA incluiu o fator grupo (anastomoses nas paredes lateral, anterior ou posterior), tempo (basal, inicial ou final) e a interação entre tempo e grupo. Para aqueles testes em que houve diferença significativa, seguiram-se os testes de Newman-Keuls para comparações múltiplas entre os tempos e de Tukey para comparações múltiplas entre os grupos.

As diferenças observadas durante as análises foram consideradas estatisticamente significativas quando a probabilidade de erro tipo 1 foi menor que $0,05(5 \%)$.

Para comparação das medidas de índice cardíaco obtidas pelos métodos STAT ou por Doppler transesofágico com o método de termodiluição intermitente, foram realizados testes de correlação e foram calculadas as diferenças médias e seus limites de concordância, definidos como média \pm 1,96 desvios-padrão. Os intervalos de confiança de $95 \%$ foram relatados para possibilitar a generalização a outras populações. Segundo Bland e Altman (49), os métodos comparados podem ser 
considerados intercambiáveis se os limites de concordância não demonstrarem importância clínica. 


\section{RESULTADOS}

\subsection{Características clínicas}

Vinte pacientes submetidos a cirurgia de revascularização do miocárdio sem circulação extracorpórea foram incluídos no estudo. Os dados antropométricos são apresentados na Tabela 1 . O risco cirúrgico de cada paciente foi avaliado seguindo os critérios propostos por Higgins (48). Nesta avaliação, alguns dos fatores que poderiam representar alta mortalidade pós-operatória já faziam parte dos critérios de exclusão do estudo.

Duas a quatro anastomoses coronarianas distais foram realizadas em cada paciente. Dentre as artérias tratadas, houve um maior número de procedimentos sobre aquelas que compunham o grupo ANTERIOR, 19 da descendente anterior (DA) e 13 da diagonal (DI). O grupo LATERAL foi composto por 14 anastomoses nas artérias marginais (Mg e Mg2) e o POSTERIOR por 11 anastomoses em ramos posteriores das artérias coronárias direita (CD) ou ventriculares posteriores (VP). Um paciente teve o procedimento de anastomose repetido sobre a mesma artéria do grupo posterior.

As anastomoses coronarianas duraram em média 5,7 \pm 1,6 minutos e os intervalos entre elas variaram de 6 a 79 minutos, tempo necessário para o 
posicionamento do coração para o procedimento seguinte ou para a realização das anastomoses proximais. A ordem de realização das anastomoses não foi uniforme e seguiu a indicação estabelecida pela equipe cirúrgica para cada caso. 
Tabela 1. Dados antropométricos, risco cirúrgico e anastomoses coronarianas realizadas

\begin{tabular}{|c|c|}
\hline & $\mathrm{n}$ \\
\hline $\operatorname{Sexo}(\mathrm{M} / \mathrm{F})$ & $15 / 5$ \\
\hline Idade (média \pm DP) & $\begin{array}{c}61,7 \pm 10,4 \\
{[39 \text { a } 79]}\end{array}$ \\
\hline Superfície corpórea (média \pm DP) & $1,76 \pm 0,19$ \\
\hline \multicolumn{2}{|l|}{ Risco cirúrgico } \\
\hline Mínimo & 9 \\
\hline Baixo & 11 \\
\hline \multicolumn{2}{|l|}{ Anastomoses coronarianas } \\
\hline \multicolumn{2}{|l|}{2 artérias } \\
\hline $\mathrm{DA}+\mathrm{Mg}$ & 3 \\
\hline $\mathrm{DA}+\mathrm{DI}$ & 3 \\
\hline $\mathrm{DA}+\mathrm{CD}$ & 1 \\
\hline \multicolumn{2}{|l|}{3 artérias } \\
\hline $\mathrm{DA}+\mathrm{DI}+\mathrm{Mg}$ & 4 \\
\hline $\mathrm{DA}+\mathrm{DI}+\mathrm{VP}$ da CD & 3 \\
\hline $\mathrm{DA}+\mathrm{Mg}+\mathrm{CD}$ & 1 \\
\hline $\mathrm{Mg}+\mathrm{Mg} 2+\mathrm{CD}$ & 1 \\
\hline \multicolumn{2}{|l|}{4 artérias } \\
\hline $\mathrm{DA}+\mathrm{DI}+\mathrm{Mg}+\mathrm{VP}$ da CD & 3 \\
\hline $\mathrm{DA}+\mathrm{Mg}+\mathrm{VP} / \mathrm{CD}+\mathrm{VP}$ da $\mathrm{CD}$ & 1 \\
\hline
\end{tabular}




\subsection{Ajuste de volemia e uso de fármacos vasoativos}

No período antes do início das anastomoses coronarianas, foi realizado ajuste da volemia administrando-se a todos os pacientes $10 \mathrm{ml} / \mathrm{kg}$ de solução de hidroxietilamido 130/0,4 a 6\% (média e desvio-padrão de 720 e 145,4 ml) e $2560 \pm$ 99,7 ml de solução de Ringer lactato. Durante a realização das anastomoses, foram infundidos 360,4 $\pm 226,3 \mathrm{ml}$ de solução de Ringer lactato, sendo que nos procedimentos sobre a parede anterior este volume foi de $375 \pm 262,4 \mathrm{ml}$, sobre a lateral de $500 \pm 141,4 \mathrm{ml}$ e sobre a posterior de $450 \pm 201,2 \mathrm{ml}$.

O posicionamento em Trendelemburg foi adotado para todos os pacientes submetidos a anastomoses em parede lateral e posterior e a $65 \%$ dos pacientes com procedimentos sobre as artérias descendente anterior e diagonal (parede anterior).

Foi instalada infusão contínua de solução de dobutamina em velocidade de 2 a $5 \mu \mathrm{g} / \mathrm{Kg} / \mathrm{min}$ durante $45,6 \%$ dos procedimentos de anastomose coronariana em 17 das 32 anastomoses da parede anterior, em 6 das 14 da parede lateral e em 3 das 11 da parede posterior. A velocidade de infusão de dobutamina não foi alterada após o início da anastomose.

Vasodilatadores foram utilizados quando houve necessidade de redução de pressão arterial em momentos específicos da cirurgia e foram interrompidos durante as anastomoses coronarianas distais. 


\subsection{Freqüência cardíaca}

A Tabela 2 apresenta a análise descritiva das medidas de frequiência cardíaca (variável FC) por grupos de estudo e tempos. Foi possível observar pelo teste de ANOVA de duplo fator para medidas repetidas que não houve diferenças entre grupos $(p=0,76)$ e nem entre tempos $(p=0,31)$.

Tabela 2. Análise descritiva da variável FC (freqüência cardíaca, expressa em batimentos por minuto) por tempo e grupo de estudo e resultados de ANOVA de duplo fator

\begin{tabular}{|c|c|c|c|}
\hline & $\begin{array}{c}\text { Grupo } \\
\text { ANTERIOR }\end{array}$ & $\begin{array}{c}\text { Grupo } \\
\text { LATERAL }\end{array}$ & $\begin{array}{c}\text { Grupo } \\
\text { POSTERIOR }\end{array}$ \\
\hline & $\mathrm{n}=32$ & $\mathrm{n}=14$ & $\mathrm{n}=11$ \\
\hline \multicolumn{4}{|l|}{$\mathrm{FC}_{\text {BASAL }}$} \\
\hline Média \pm DP & $74,09 \pm 13,11$ & $71,36 \pm 9,64$ & $73,27 \pm 11,59$ \\
\hline Mínimo - Máximo & $50-117$ & $49-84$ & $48-90$ \\
\hline \multicolumn{4}{|l|}{$\mathrm{FC}_{\text {INÍCIO DA ANASTOMOSE }}$} \\
\hline Média \pm DP & $76,09 \pm 11,79$ & $75,07 \pm 12,29$ & $74,45 \pm 12,30$ \\
\hline Mínimo - Máximo & $55-103$ & $53-104$ & $46-90$ \\
\hline \multicolumn{4}{|l|}{ FC $_{\text {FINAL DA ANASTOMOSE }}$} \\
\hline Média \pm DP & $76,00 \pm 10,73$ & $73,21 \pm 10,26$ & $73,64 \pm 11,31$ \\
\hline Mínimo - Máximo & $53-100$ & $47-90$ & $46-83$ \\
\hline ANOVA & & $\mathbf{p}$ & Significância \\
\hline Entre grupos & & 0,76 & $\mathrm{NS}$ \\
\hline Entre tempos & & 0,31 & NS \\
\hline Interação grupo x tempo & & 0,96 & NS \\
\hline
\end{tabular}




\subsection{Pressão arterial média}

A Tabela 3 apresenta a análise descritiva das medidas de pressão arterial média (variável PAM) por grupos de estudo e tempos. Foi possível observar pelo teste de ANOVA de duplo fator para medidas repetidas que não houve diferenças entre grupos $(p=0,47)$ e nem entre tempos $(p=0,46)$.

Tabela 3. Análise descritiva da variável PAM (pressão arterial média, expressa em $\mathrm{mmHg}$ ) por tempo e grupo de estudo e resultados de ANOVA de duplo fator

\begin{tabular}{|c|c|c|c|}
\hline & $\begin{array}{c}\text { Grupo } \\
\text { ANTERIOR }\end{array}$ & $\begin{array}{c}\text { Grupo } \\
\text { LATERAL }\end{array}$ & $\begin{array}{c}\text { Grupo } \\
\text { POSTERIOR }\end{array}$ \\
\hline & $\mathrm{n}=32$ & $\mathrm{n}=14$ & $\mathrm{n}=11$ \\
\hline $\begin{array}{l}\text { PAM }_{\text {BASAL }} \\
\text { Média } \pm \text { DP } \\
\text { Mínimo - Máximo }\end{array}$ & $\begin{array}{c}69,59 \pm 9,86 \\
52-92\end{array}$ & $\begin{array}{c}69,21 \pm 9,15 \\
57-85\end{array}$ & $\begin{array}{c}68,55 \pm 11,61 \\
46-85\end{array}$ \\
\hline $\begin{array}{l}\text { PAM }{ }_{\text {INÍCIO DA ANASTOMOSE }} \\
\text { Média } \pm \text { DP } \\
\text { Mínimo - Máximo }\end{array}$ & $\begin{array}{c}71,28 \pm 9,02 \\
56-89\end{array}$ & $\begin{array}{c}66,50 \pm 5,36 \\
57-73\end{array}$ & $\begin{array}{c}73,36 \pm 8,95 \\
57-84\end{array}$ \\
\hline $\begin{array}{l}\text { PAM }_{\text {FINAL DA ANASTOMOSE }} \\
\text { Média } \pm \text { DP } \\
\text { Mínimo - Máximo }\end{array}$ & $\begin{array}{c}69,06 \pm 8,61 \\
51-88\end{array}$ & $\begin{array}{c}66,93 \pm 8,40 \\
52-83\end{array}$ & $\begin{array}{c}70,36 \pm 7,72 \\
58-83\end{array}$ \\
\hline ANOVA & & $\mathbf{p}$ & Significância \\
\hline $\begin{array}{l}\text { Entre grupos } \\
\text { Entre tempos } \\
\text { Interação grupo x tempo }\end{array}$ & & $\begin{array}{l}0,47 \\
0,46 \\
0,37\end{array}$ & $\begin{array}{l}\text { NS } \\
\text { NS } \\
\text { NS }\end{array}$ \\
\hline
\end{tabular}




\subsection{Pressão média de artéria pulmonar}

A Tabela 4 apresenta a análise descritiva das medidas de pressão média de artéria pulmonar (variável PAPm) por grupos de estudo e tempos. Foi possível observar pelo teste de ANOVA de duplo fator para medidas repetidas que não houve diferenças entre grupos $(p=0,79)$ e nem entre tempos $(p=0,09)$.

Tabela 4. Análise descritiva da variável PAPm (pressão média de artéria pulmonar, expressa em $\mathrm{mmHg}$ ) por tempo e grupo de estudo e resultados de ANOVA de duplo fator

\begin{tabular}{|c|c|c|c|}
\hline & $\begin{array}{c}\text { Grupo } \\
\text { ANTERIOR }\end{array}$ & $\begin{array}{c}\text { Grupo } \\
\text { LATERAL }\end{array}$ & $\begin{array}{c}\text { Grupo } \\
\text { POSTERIOR }\end{array}$ \\
\hline & $\mathrm{n}=32$ & $\mathrm{n}=14$ & $\mathrm{n}=11$ \\
\hline $\begin{array}{l}\text { PAPm } \\
\text { Média } \pm \text { DP } \\
\text { Mínimo - Máximo }\end{array}$ & $\begin{array}{c}26,00 \pm 5,75 \\
15-42\end{array}$ & $\begin{array}{c}24,71 \pm 5,68 \\
15-34\end{array}$ & $\begin{array}{c}25,36 \pm 5,30 \\
18-35\end{array}$ \\
\hline $\begin{array}{l}\text { PAPmINÍCIO DA ANASTOMOSE } \\
\text { Média } \pm \text { DP } \\
\text { Mínimo - Máximo }\end{array}$ & $\begin{array}{c}26,63 \pm 6,52 \\
16-43\end{array}$ & $\begin{array}{c}25,50 \pm 6,02 \\
14-34\end{array}$ & $\begin{array}{c}27,73 \pm 8,05 \\
15-48\end{array}$ \\
\hline $\begin{array}{l}\text { PAPm } \text { FINAL DA ANASTOMOSE } \\
\text { Média } \pm \text { DP } \\
\text { Mínimo - Máximo }\end{array}$ & $\begin{array}{c}27,06 \pm 5,66 \\
17-46\end{array}$ & $\begin{array}{c}26,00 \pm 5,49 \\
15-33\end{array}$ & $\begin{array}{c}26,55 \pm 4,61 \\
18-35\end{array}$ \\
\hline ANOVA & & $\mathbf{p}$ & Significância \\
\hline $\begin{array}{l}\text { Entre grupos } \\
\text { Entre tempos } \\
\text { Interação grupo x tempo }\end{array}$ & & $\begin{array}{l}0,79 \\
0,09 \\
0,78\end{array}$ & $\begin{array}{l}\mathrm{NS} \\
\mathrm{NS} \\
\mathrm{NS}\end{array}$ \\
\hline
\end{tabular}




\subsection{Pressão de oclusão de artéria pulmonar}

A Tabela 5 apresenta a análise descritiva das medidas de pressão de oclusão de artéria pulmonar (variável PoAP) por grupos de estudo e tempos. Foi possível observar pelo teste de ANOVA de duplo fator para medidas repetidas que não houve diferenças entre grupos $(\mathrm{p}=0,22)$, mas houve diferença estatisticamente significativa entre tempos $(\mathrm{p}<0,001)$. Pelo teste de comparações múltiplas de Newman-Keuls (Tabela 6), foi possível observar que a diferença ocorreu do tempo BASAL para o tempo INICIAL $(\mathrm{p}<0,001)$ e para o tempo FINAL $(\mathrm{p}<0,001)$.

Tabela 5. Análise descritiva da variável PoAP (pressão de oclusão de artéria pulmonar, expressa em $\mathrm{mmHg}$ ) por tempo e grupo de estudo e resultados de ANOVA de duplo fator

\begin{tabular}{|c|c|c|c|}
\hline & $\begin{array}{c}\text { Grupo } \\
\text { ANTERIOR }\end{array}$ & $\begin{array}{c}\text { Grupo } \\
\text { LATERAL }\end{array}$ & $\begin{array}{c}\text { Grupo } \\
\text { POSTERIOR }\end{array}$ \\
\hline & $\mathrm{n}=32$ & $\mathrm{n}=14$ & $\mathrm{n}=11$ \\
\hline $\begin{array}{l}\text { PoAP }{ }_{\mathrm{BASAL}} \\
\text { Média } \pm \mathrm{DP} \\
\text { Mínimo - Máximo }\end{array}$ & $\begin{array}{c}17,72 \pm 5,95 \\
6-30\end{array}$ & $\begin{array}{c}16,71 \pm 6,58 \\
6-26\end{array}$ & $\begin{array}{c}18,64 \pm 6,04 \\
11-30\end{array}$ \\
\hline $\begin{array}{l}\text { PoAP INí́cIO DA ANASTOMOSE } \\
\text { Média } \pm \text { DP } \\
\text { Mínimo - Máximo }\end{array}$ & $\begin{array}{c}18,88 \pm 6,09 \\
9-30\end{array}$ & $\begin{array}{c}17,21 \pm 5,98 \\
6-25\end{array}$ & $\begin{array}{c}22,55 \pm 7,39 \\
11-40\end{array}$ \\
\hline $\begin{array}{l}\text { PoAP } \\
\text { Média } \pm \text { DP } \\
\text { Mínimo - Máximo }\end{array}$ & $\begin{array}{c}18,78 \pm 5,57 \\
8-29\end{array}$ & $\begin{array}{c}18,07 \pm 5,76 \\
7-27\end{array}$ & $\begin{array}{c}22,64 \pm 6,00 \\
15-36\end{array}$ \\
\hline
\end{tabular}




\section{ANOVA}

p

Significância

Entre grupos

0,22

NS

Entre tempos

$<0,001$

*

Interação grupo x tempo

0,09

NS

Tabela 6. Resultados do pós-teste de Newman-Keuls

\begin{tabular}{lc}
\hline & $\mathbf{p}$ \\
\hline BASAL x INÍCIO & $<0,001^{*}$ \\
DA ANASTOMOSE & \\
BASAL x FINAL & $<0,001^{*}$ \\
DA ANASTOMOSE & \\
INÍCIO x FINAL & 0,56 \\
DA ANASTOMOSE &
\end{tabular}

Figura 3. Valores médios e erros-padrões de PoAP por grupo de estudo

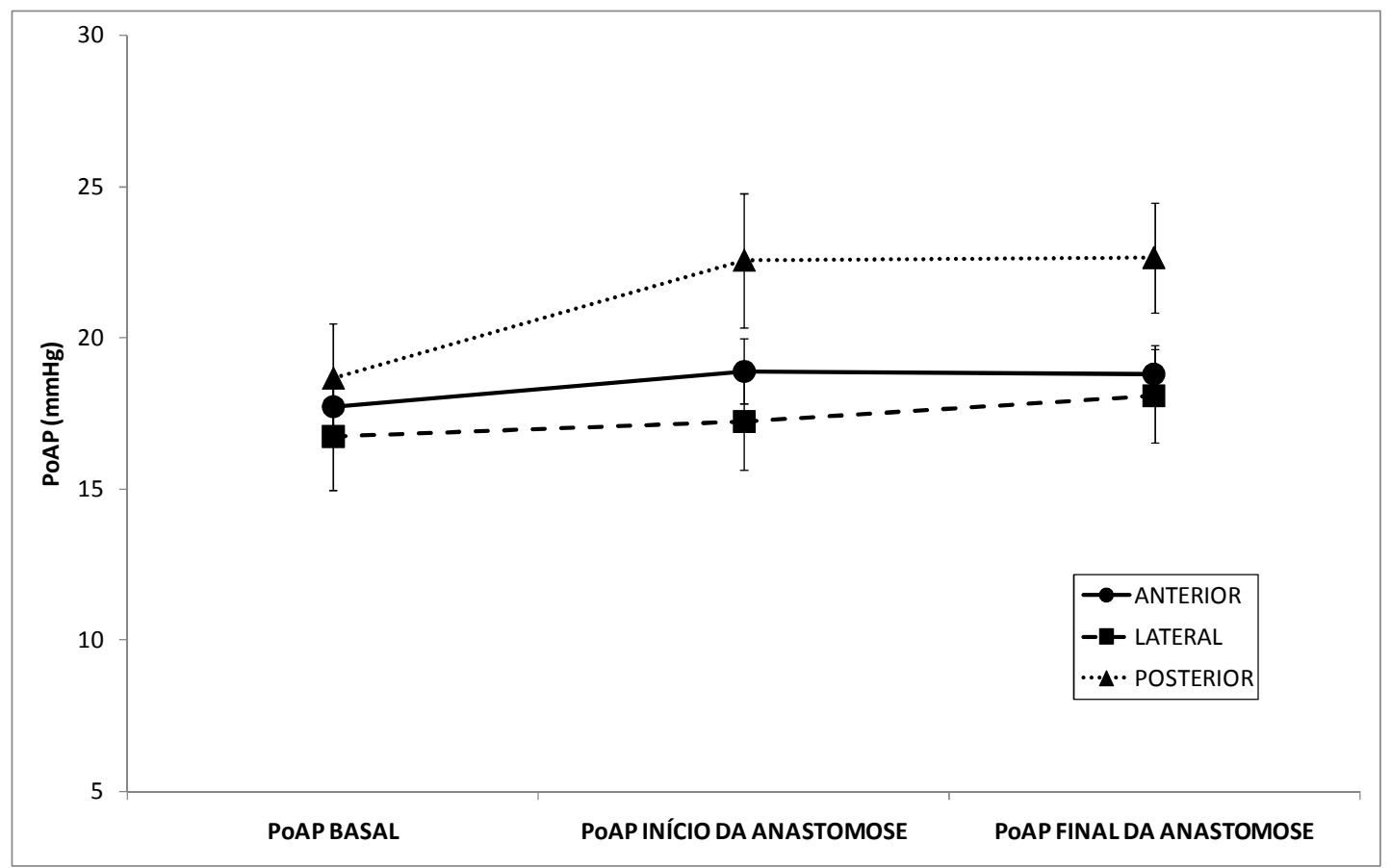




\subsection{Pressão venosa central}

A Tabela 7 apresenta a análise descritiva das medidas de pressão venosa central (variável PVC) por grupos de estudo e tempos. Foi possível observar pelo teste de ANOVA de duplo fator para medidas repetidas que não houve diferenças entre grupos $(p=0,10)$, mas houve diferença estatisticamente significativa entre tempos $(p=0,009)$. Pelo teste de comparações múltiplas de Newman-Keuls (Tabela 8), foi possível observar que a diferença ocorreu do tempo BASAL para o tempo $\operatorname{INICIAL~}(p=0,007)$ e para o tempo FINAL $(p=0,006)$.

Tabela 7. Análise descritiva da variável PVC (pressão venosa central, expressa em $\mathrm{mmHg}$ ) por tempo e grupo de estudo e resultados de ANOVA de duplo fator

\begin{tabular}{|c|c|c|c|}
\hline & $\begin{array}{c}\text { Grupo } \\
\text { ANTERIOR }\end{array}$ & $\begin{array}{c}\text { Grupo } \\
\text { LATERAL }\end{array}$ & $\begin{array}{c}\text { Grupo } \\
\text { POSTERIOR }\end{array}$ \\
\hline & $\mathrm{n}=32$ & $\mathrm{n}=14$ & $\mathrm{n}=11$ \\
\hline $\begin{array}{l}\mathrm{PVC}_{\mathrm{BASAL}} \\
\text { Média } \pm \mathrm{DP} \\
\text { Mínimo - Máximo }\end{array}$ & $\begin{array}{c}13,09 \pm 4,99 \\
4-22\end{array}$ & $\begin{array}{c}13,93 \pm 6,06 \\
6-27\end{array}$ & $\begin{array}{c}16,18 \pm 5,62 \\
6-24\end{array}$ \\
\hline $\begin{array}{l}\mathrm{PVC}_{\mathrm{INÍCIO}} \text { DA ANASTOMOSE } \\
\text { Média } \pm \text { DP } \\
\text { Mínimo - Máximo }\end{array}$ & $\begin{array}{c}13,72 \pm 5,02 \\
6-26\end{array}$ & $\begin{array}{c}14,86 \pm 7,08 \\
6-27\end{array}$ & $\begin{array}{c}18,36 \pm 6,07 \\
4-25\end{array}$ \\
\hline $\begin{array}{l}\text { PVC }{ }_{\text {FINAL DA ANASTOMOSE }} \\
\text { Média } \pm \text { DP } \\
\text { Mínimo - Máximo }\end{array}$ & $\begin{array}{c}14,00 \pm 5,02 \\
6-31\end{array}$ & $\begin{array}{c}14,93 \pm 6,90 \\
6-26\end{array}$ & $\begin{array}{c}18,55 \pm 6,98 \\
4-29\end{array}$ \\
\hline
\end{tabular}




\section{ANOVA}

Entre grupos

p

0,10

$<0,01$

Significância

Entre tempos

0,69

*

Interação grupo x tempo

NS

Tabela 8. Resultados do pós-teste de Newman-Keuls

\begin{tabular}{ll}
\hline & $\mathbf{p}$ \\
\hline BASAL x INÍCIO & \\
DA ANASTOMOSE & $0,007^{*}$ \\
BASAL x FINAL & \\
DA ANASTOMOSE & $0,008^{*}$ \\
$\begin{array}{l}\text { INÍCIO x FINAL } \\
\text { DA ANASTOMOSE }\end{array}$ & 0,69 \\
\hline
\end{tabular}

Figura 4. Valores médios e erros-padrões de PVC por grupo de estudo

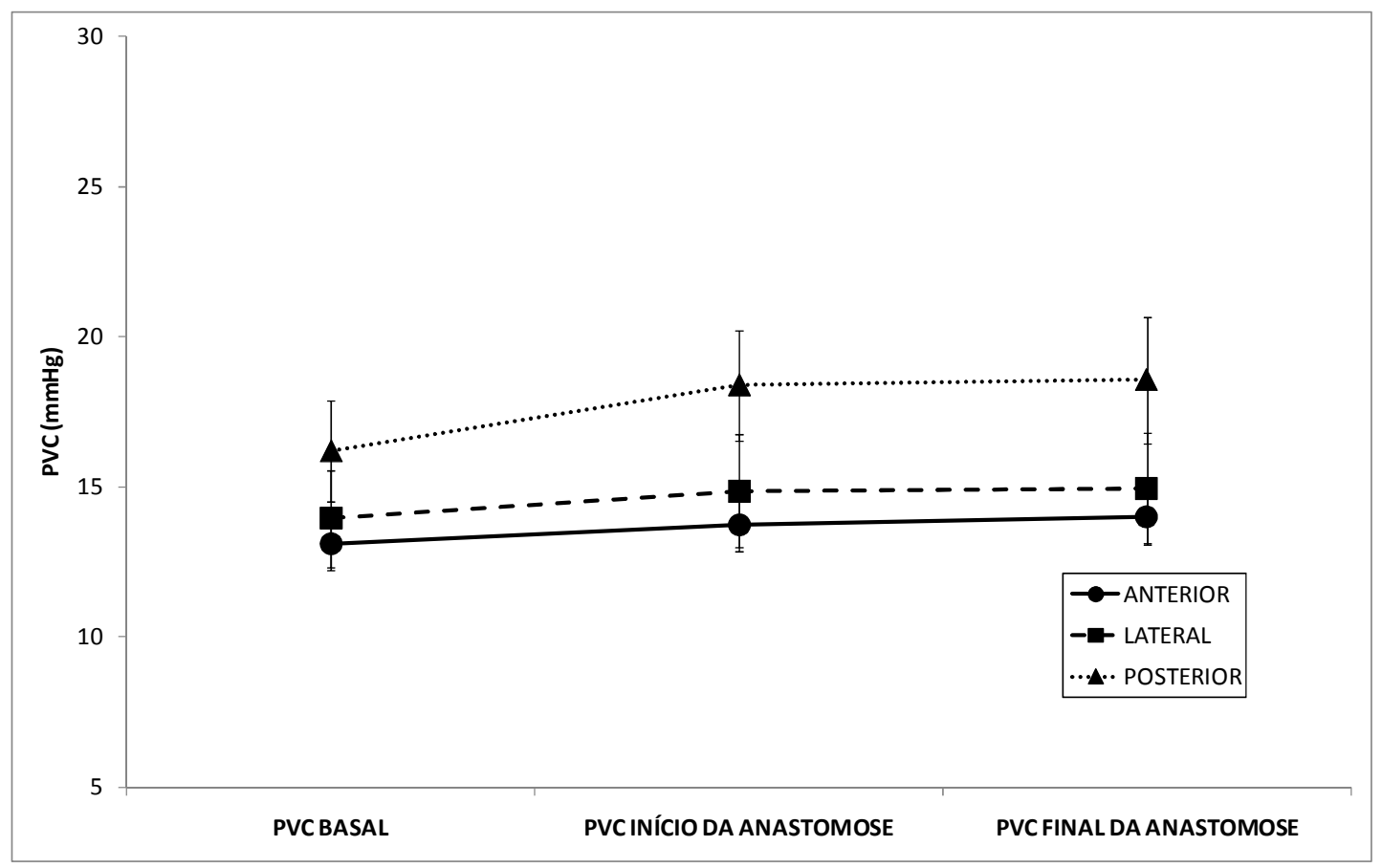




\subsection{Saturação venosa mista de oxigênio}

A Tabela 9 apresenta a análise descritiva das medidas de saturação venosa mista de oxigênio (variável $\mathrm{SvO}_{2}$ ) por grupos de estudo e tempos. Foi possível observar pelo teste de ANOVA de duplo fator para medidas repetidas que não houve diferenças entre grupos $(\mathrm{p}=0,89)$ e nem entre tempos $(\mathrm{p}=0,08)$.

Tabela 9. Análise descritiva da variável $\mathrm{SvO}_{2}$ (saturação venosa mista de oxigênio, expressa em porcentagem) por tempo e grupo de estudo e resultados de ANOVA de duplo fator

\begin{tabular}{|c|c|c|c|}
\hline & $\begin{array}{c}\text { Grupo } \\
\text { ANTERIOR }\end{array}$ & $\begin{array}{c}\text { Grupo } \\
\text { LATERAL }\end{array}$ & $\begin{array}{c}\text { Grupo } \\
\text { POSTERIOR }\end{array}$ \\
\hline & $\mathrm{n}=30$ & $\mathrm{n}=14$ & $\mathrm{n}=11$ \\
\hline \multicolumn{4}{|l|}{$\mathrm{SvO}_{2 \text { BASAL }}$} \\
\hline Média \pm DP & $75,13 \pm 8,82$ & $78,86 \pm 6,77$ & $75,82 \pm 9,89$ \\
\hline Mínimo - Máximo & $53-91$ & $66-89$ & $52-88$ \\
\hline \multicolumn{4}{|l|}{$\mathrm{SvO}_{2}$ INÍCIO DA ANASTOMOSE } \\
\hline Média \pm DP & $74,83 \pm 8,77$ & $75,50 \pm 9,85$ & $76,73 \pm 8,63$ \\
\hline Mínimo - Máximo & $55-91$ & $59-88$ & $65-88$ \\
\hline \multicolumn{4}{|l|}{$\mathrm{SvO}_{2}$ FINAL DA ANASTOMOSE } \\
\hline Média \pm DP & $74,67 \pm 9,25$ & $73,71 \pm 10,92$ & $75,27 \pm 10,47$ \\
\hline Mínimo - Máximo & $55-91$ & $57-87$ & $60-88$ \\
\hline ANOVA & & $\mathbf{p}$ & Significância \\
\hline Entre grupos & & 0,89 & $\mathrm{NS}$ \\
\hline Entre tempos & & 0,08 & NS \\
\hline Interação grupo $\mathrm{x}$ tempo & & 0,16 & NS \\
\hline
\end{tabular}




\subsection{Débito cardíaco intermitente}

A Tabela 10 apresenta a análise descritiva das medidas de débito cardíaco obtidas por termodiluição com bolus intermitente de solução fria (variável DCI), por grupos de estudo e tempos. Foi possível observar pelo teste de ANOVA de duplo fator para medidas repetidas que não houve diferenças entre grupos $(p=0,90)$, mas houve diferença estatisticamente significativa entre tempos $(\mathrm{p}<0,001)$. Pelo teste de comparações múltiplas de Newman-Keuls (Tabela 11), foi possível observar que a diferença ocorreu do tempo BASAL para o tempo INÍCIO DA ANASTOMOSE ( $\mathrm{p}<$ 0,001) e para o tempo FINAL DA ANASTOMOSE $(\mathrm{p}<0,001)$.

Tabela 10. Análise descritiva da variável DCI (débito cardíaco intermitente, expresso em $1 / \mathrm{min}$ ) por tempo e grupo de estudo e resultados de ANOVA de duplo fator

\begin{tabular}{lccc}
\hline & $\begin{array}{c}\text { Grupo } \\
\text { ANTERIOR }\end{array}$ & $\begin{array}{c}\text { Grupo } \\
\text { LATERAL }\end{array}$ & $\begin{array}{c}\text { Grupo } \\
\text { POSTERIOR }\end{array}$ \\
\hline & $\mathrm{n}=32$ & $\mathrm{n}=14$ & $\mathrm{n}=11$ \\
DCI $_{\mathrm{BASAL}}$ & & & \\
Média \pm DP & $4,46 \pm 1,267$ & $5,13 \pm 1,72$ & $4,82 \pm 1,49$ \\
Mínimo - Máximo & $2,3-8,8$ & $2,0-7,7$ & $1,8-6,9$ \\
& & & \\
& & & \\
DCI & & \\
Médício DA ANASTOMOSE \pm DP & $4,36 \pm 1,12$ & $4,01 \pm 1,61$ & $2,8-5,7$ \\
Mínimo - Máximo & $2,3-6,4$ & $1,3-6,8$ & \\
& & & $4,06 \pm 1,08$ \\
DCI & & & $2,5-5,7$ \\
Média \pm DP ANASTOMOSE & $4,26 \pm 1,08$ & $4,42 \pm 1,80$ & \\
Mínimo - Máximo & $2,6-6,4$ & $1,3-7,9$ & \\
\hline
\end{tabular}




\section{ANOVA}

Entre grupos

p

0,90

Significância

Entre tempos

$<0,001$

NS

Interação grupo x tempo

0,07

NS

Tabela 11. Resultados do pós-teste de Newman-Keuls

\begin{tabular}{lc}
\hline & p \\
\hline BASAL x INÍCIO & $<0,001^{*}$ \\
DA ANASTOMOSE & \\
BASAL x FINAL & $<0,001^{*}$ \\
DA ANASTOMOSE & \\
INÍCIO x FINAL & 0,60 \\
DA ANASTOMOSE &
\end{tabular}

Figura 5. Valores médios e erros-padrões de DCI por grupo de estudo

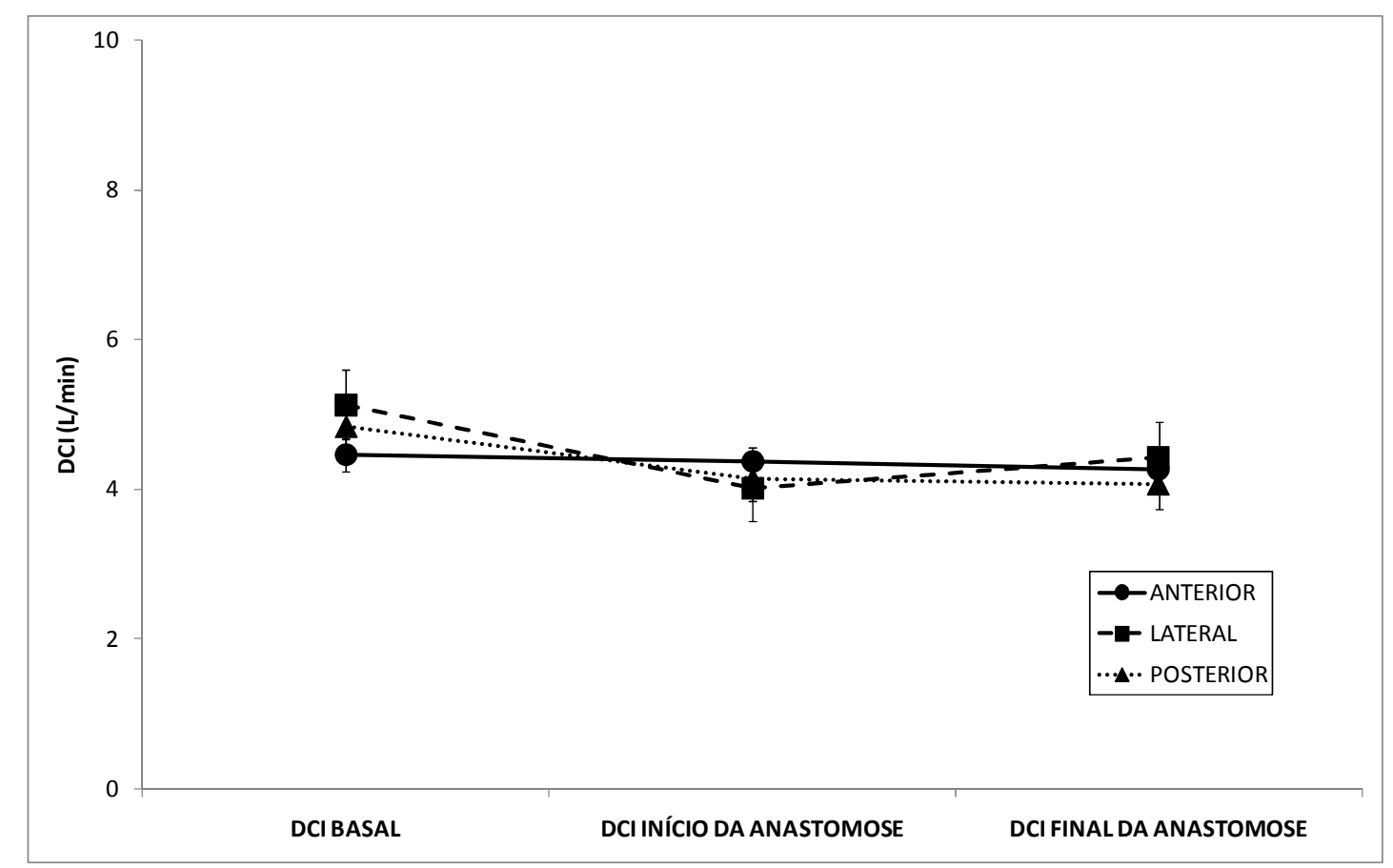




\subsection{Débito cardíaco em modo STAT}

A Tabela 12 apresenta a análise descritiva das medidas de débito cardíaco obtidas por termodiluição contínua, em modo STAT (variável $\mathrm{DC}_{\mathrm{STAT}}$ ), por grupos de estudo e tempos. Foi possível observar pelo teste de ANOVA de duplo fator para medidas repetidas que não houve diferenças entre grupos $(p=0,66)$ e nem entre tempos $(\mathrm{p}=0,07)$.

Tabela 12. Análise descritiva da variável $\mathrm{DC}_{\mathrm{STAT}}$ (débito cardíaco em modo $S T A T$, em 1/min) por tempo e grupo de estudo e resultados de ANOVA de duplo fator

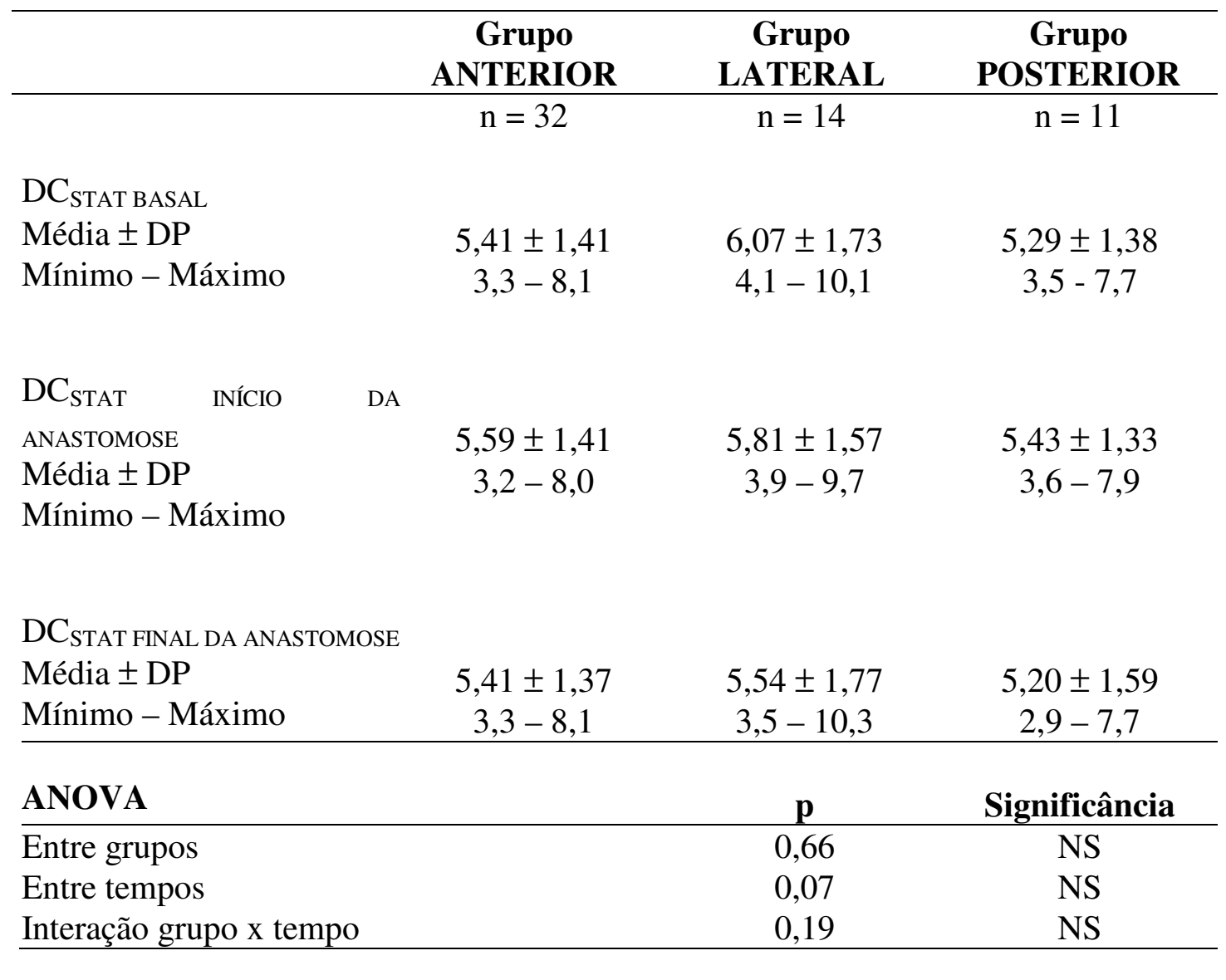




\subsection{Débito cardíaco medido por ecodoppler transesofágico}

A Tabela 13 apresenta a análise descritiva das medidas de débito cardíaco obtidas por Doppler esofágico (variável $\mathrm{DC}_{\mathrm{DE}}$ ) por grupos de estudo e tempos. Foi possível observar pelo teste de ANOVA de duplo fator para medidas repetidas que houve interação tempo x grupo significativa $(\mathrm{p}=0,02)$. Pelo teste de comparações múltiplas de Newman-Keuls (Tabela 14), foi possível observar que a diferença ocorreu no grupo LATERAL, em que o tempo BASAL diferiu do tempo INÍCIO DA ANASTOMOSE $(p=0,02)$ e do tempo FINAL DA ANASTOMOSE $(p=0,02)$.

Tabela 13. Análise descritiva da variável $\mathrm{DC}_{\mathrm{DE}}$ (débito cardíaco obtido por ecodoppler transesofágico, expresso em 1/min) por tempo e grupo de estudo e resultados de ANOVA de duplo fator

\begin{tabular}{|c|c|c|c|}
\hline & $\begin{array}{c}\text { Grupo } \\
\text { ANTERIOR }\end{array}$ & $\begin{array}{c}\text { Grupo } \\
\text { LATERAL }\end{array}$ & $\begin{array}{c}\text { Grupo } \\
\text { POSTERIOR }\end{array}$ \\
\hline & $\mathrm{n}=32$ & $\mathrm{n}=14$ & $\mathrm{n}=11$ \\
\hline \multicolumn{4}{|l|}{$\mathrm{DC}_{\mathrm{DE} \text { BASAL }}$} \\
\hline Média \pm DP & $4,03 \pm 1,48$ & $4,08 \pm 1,99$ & $3,59 \pm 1,62$ \\
\hline Mínimo - Máximo & $1,3-8,2$ & $1,1-8,7$ & $0,9-5,6$ \\
\hline \multicolumn{4}{|c|}{ DC $_{\text {DE INÍCIO DA ANASTOMOSE }}$} \\
\hline Média \pm DP & $4,08 \pm 1,44$ & $2,84 \pm 1,81$ & $3,61 \pm 1,66$ \\
\hline Mínimo - Máximo & $2,0-7,2$ & $1,3-7,4$ & $1,4-6,7$ \\
\hline \multicolumn{4}{|c|}{ DC $_{\text {DE FINAL DA ANASTOMOSE }}$} \\
\hline Média \pm DP & $4,29 \pm 1,86$ & $2,86 \pm 1,73$ & $3,71 \pm 1,56$ \\
\hline Mínimo - Máximo & $1,9-8,2$ & $1,0-6,9$ & $1,7-6,7$ \\
\hline
\end{tabular}


ANOVA

Entre grupos

Entre tempos

Interação grupo x tempo

\section{p}

0,15

0,19

0,02
Significância

NS

NS

Tabela 14. Resultados do pós-teste de Newman-Keuls

\begin{tabular}{cccc}
\hline & $\begin{array}{c}\text { Grupo } \\
\text { ANTERIOR }\end{array}$ & $\begin{array}{c}\text { Grupo } \\
\text { LATERAL }\end{array}$ & $\begin{array}{c}\text { Grupo } \\
\text { POSTERIOR }\end{array}$ \\
\hline BASAL x INÍCIO & $\mathrm{p}=0,99$ & $\mathrm{p}=0,02^{*}$ & $\mathrm{p}=0,94$ \\
DA ANASTOMOSE & $\mathrm{NS}$ & & $\mathrm{NS}$ \\
BASAL x FINAL & $\mathrm{p}=0,90$ & $\mathrm{p}=0,02^{*}$ & $\mathrm{p}=0,95$ \\
DA ANASTOMOSE & $\mathrm{NS}$ & & $\mathrm{NS}$ \\
INÍCIO x FINAL & $\mathrm{p}=0,58$ & $\mathrm{p}=0,96$ & $\mathrm{p}=0,81$ \\
DA ANASTOMOSE & $\mathrm{NS}$ & $\mathrm{NS}$ & $\mathrm{NS}$ \\
\hline
\end{tabular}

Figura 6. Valores médios e erros-padrões de $\mathrm{DC}_{\mathrm{DE}}$ por grupo de estudo

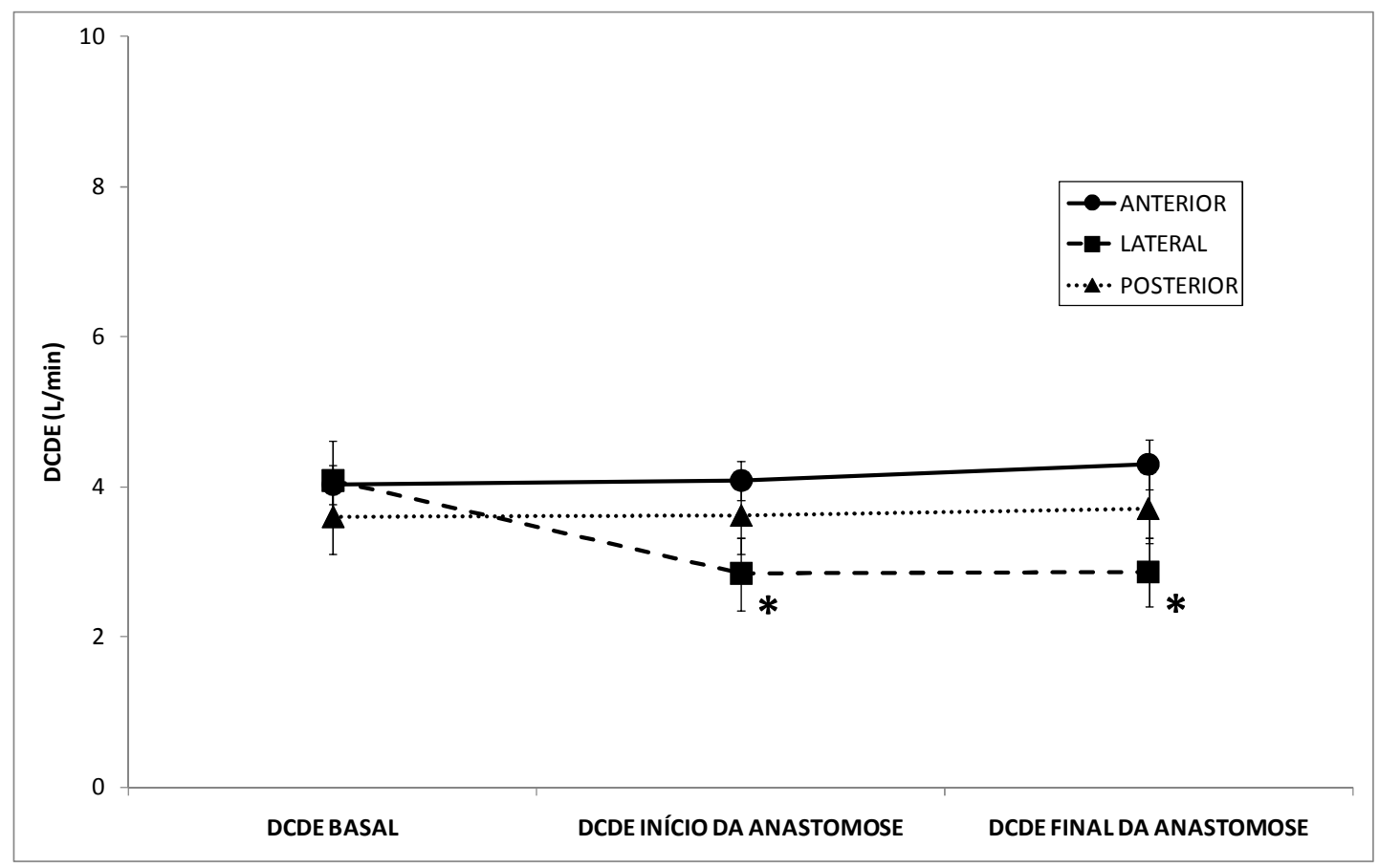




\subsection{Volume diastólico final de ventrículo direito}

A Tabela 15 apresenta a análise descritiva das medidas do volume diastólico final de ventrículo direito (variável VDF) por grupos de estudo e tempos. Foi possível observar pelo teste de ANOVA de duplo fator para medidas repetidas que não houve diferenças entre grupos $(\mathrm{p}=0,44)$ e nem entre tempos $(\mathrm{p}=0,56)$.

Tabela 15. Análise descritiva da variável VDF (volume diastólico final, expresso por $\mathrm{mL}$ ) por tempo e grupo de estudo e resultados de ANOVA de duplo fator

\begin{tabular}{lccc}
\hline & $\begin{array}{c}\text { Grupo } \\
\text { ANTERIOR }\end{array}$ & $\begin{array}{c}\text { Grupo } \\
\text { LATERAL }\end{array}$ & $\begin{array}{c}\text { Grupo } \\
\text { POSTERIOR }\end{array}$ \\
\hline VDF $_{\text {BASAL }}$ & $\mathrm{n}=30$ & $\mathrm{n}=13$ & $\mathrm{n}=11$ \\
Média \pm DP & & & \\
Mínimo - Máximo & $219,04 \pm 51,37$ & $256,83 \pm 75,13$ & $224,85 \pm 68,57$ \\
& $114-311$ & $187-403$ & $134-360$ \\
VDF & & & \\
Média \pm DP & & & \\
Mínimo - Máximo & $217,07 \pm 48,93$ & $238,07 \pm 75,76$ & $240,21 \pm 88,58$ \\
& $126-326$ & $158-435$ & $132-412$ \\
VDF & & & \\
Média \pm DP & & & \\
Mínimo - Máximo & $219,13 \pm 49,29$ & $231,04 \pm 57,39$ & $224,98 \pm 76,19$ \\
& $138-368$ & $158-339$ & $144-364$ \\
ANOVA & & $\mathbf{p}$ & Significância \\
\hline Entre grupos & & 0,44 & NS \\
Entre tempos & & 0,56 & NS \\
Interação grupo x tempo & & 0,08 & NS \\
\hline
\end{tabular}




\subsection{Fluxo sangüíneo aórtico}

A Tabela 16 apresenta a análise descritiva das medidas de fluxo sangüíneo aórtico (variável FSA) por grupos de estudo e tempos. Foi possível observar pelo teste de ANOVA de duplo fator para medidas repetidas que houve interação tempo $\mathrm{x}$ grupo significativa $(\mathrm{p}=0,02)$. Pelo teste de comparações múltiplas de Newman-Keuls (Tabela 17), foi possível observar que a diferença ocorreu no grupo LATERAL, em que o tempo BASAL diferiu do tempo INÍCIO DA ANASTOMOSE $(p=0,02)$ e do tempo FINAL DA ANASTOMOSE $(p=0,02)$.

Tabela 16. Análise descritiva da variável FSA (fluxo sangüíneo aórtico, expresso por 1/min) por tempo e grupo de estudo e resultados de ANOVA de duplo fator

\begin{tabular}{lccc}
\hline & $\begin{array}{c}\text { Grupo } \\
\text { ANTERIOR }\end{array}$ & $\begin{array}{c}\text { Grupo } \\
\text { LATERAL }\end{array}$ & $\begin{array}{c}\text { Grupo } \\
\text { POSTERIOR }\end{array}$ \\
\hline & $\mathrm{n}=32$ & $\mathrm{n}=14$ & $\mathrm{n}=11$ \\
FSA $_{\text {BASAL }}$ & & & \\
Média \pm DP & $2,82 \pm 1,03$ & $2,85 \pm 1,39$ & $2,51 \pm 1,13$ \\
Mínimo - Máximo & $0,90-5,70$ & $0,80-6,10$ & $0,60-3,90$ \\
& & & \\
FSA & & & \\
MédiácIO DA ANASTOMOSE & & & \\
Mínimo - Máximo & $2,88 \pm 1,01$ & $1,99 \pm 1,26$ & $2,53 \pm 1,16$ \\
& $1,40-5,00$ & $0,90-5,20$ & $1,00-4,70$ \\
& & & \\
FSA & & & $2,59 \pm 1,09$ \\
Média \pm DP & & & $1,20-4,70$ \\
Mínimo - Máximo & $3,00 \pm 1,30$ & $2,00 \pm 1,21$ & \\
\hline
\end{tabular}


ANOVA

p

Entre grupos

0,16

Significância

Entre tempos

0,19

NS

Interação grupo x tempo

0,01

NS

Tabela 17. Resultados do pós-teste de Newman-Keuls

\begin{tabular}{cccc}
\hline & $\begin{array}{c}\text { Grupo } \\
\text { ANTERIOR }\end{array}$ & $\begin{array}{c}\text { Grupo } \\
\text { LATERAL }\end{array}$ & $\begin{array}{c}\text { Grupo } \\
\text { POSTERIOR }\end{array}$ \\
\hline BASAL x INÍCIO & $\mathrm{p}=0,99$ & $\mathrm{p}=0,02^{*}$ & $\mathrm{p}=0,94$ \\
DA ANASTOMOSE & $\mathrm{NS}$ & & $\mathrm{NS}$ \\
BASAL x FINAL & $\mathrm{p}=0,90$ & $\mathrm{p}=0,02^{*}$ & $\mathrm{p}=0,95$ \\
DA ANASTOMOSE & $\mathrm{NS}$ & & $\mathrm{NS}$ \\
INÍCIO x FINAL & $\mathrm{p}=0,58$ & $\mathrm{p}=0,96$ & $\mathrm{p}=0,81$ \\
DA ANASTOMOSE & $\mathrm{NS}$ & $\mathrm{NS}$ & $\mathrm{NS}$ \\
\hline
\end{tabular}

Figura 7. Valores médios e erros-padrões de FSA por grupo de estudo

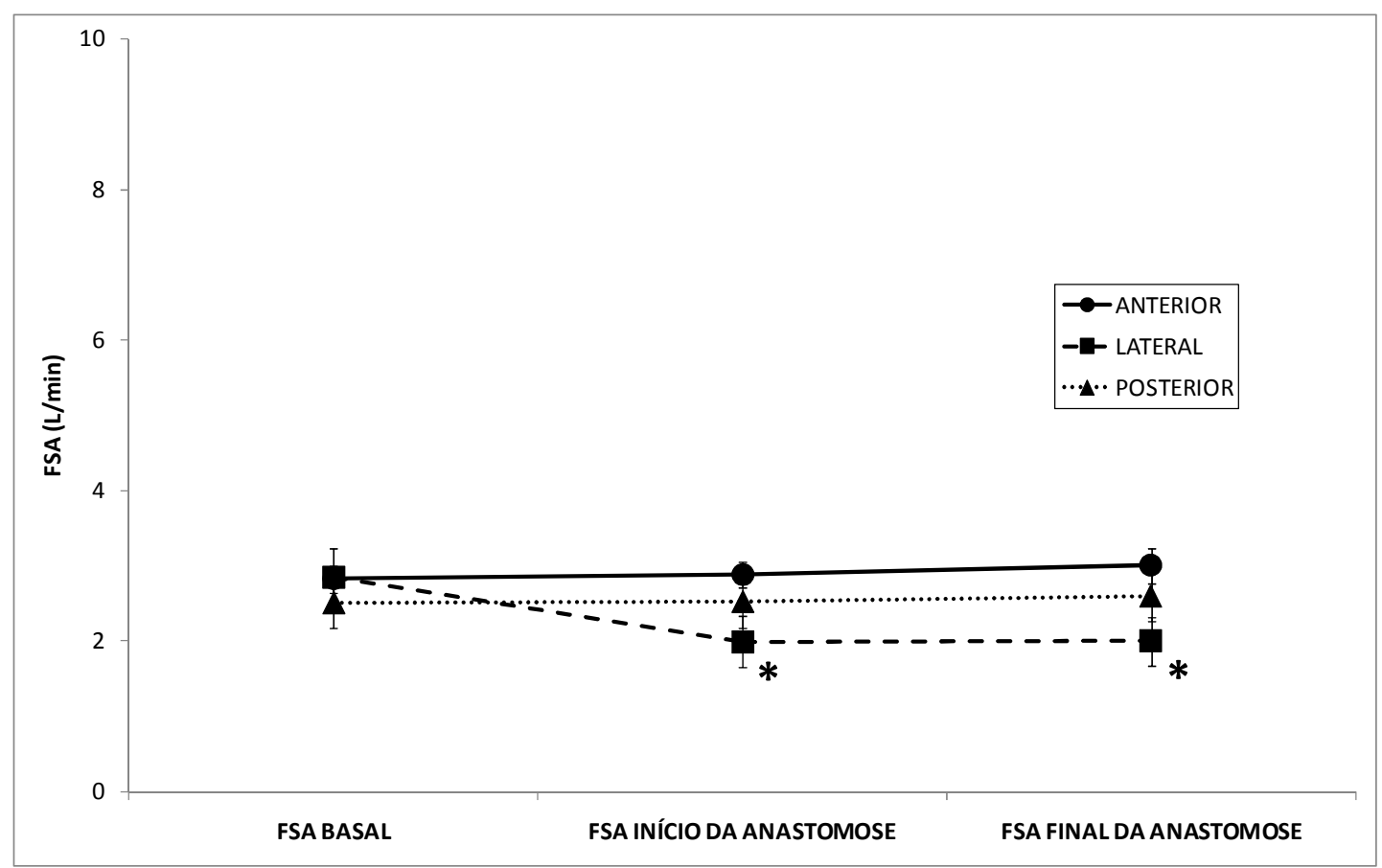




\subsection{Tempo de ejeção de ventrículo esquerdo corrigido}

A Tabela 18 apresenta a análise descritiva das medidas de tempo de ejeção de ventrículo esquerdo corrigido (variável TEVEc) por grupos de estudo e tempos. Foi possível observar pelo teste de ANOVA de duplo fator para medidas repetidas que não houve diferenças entre grupos $(p=0,60)$ e nem entre tempos $(p=$ $0,07)$.

Tabela 18. Análise descritiva da variável TEVEc (tempo de ejeção de ventrículo esquerdo corrigido, expresso em milissegundos) por tempo e grupo de estudo e resultados de ANOVA de duplo fator

\begin{tabular}{|c|c|c|c|}
\hline & $\begin{array}{c}\text { Grupo } \\
\text { ANTERIOR }\end{array}$ & $\begin{array}{c}\text { Grupo } \\
\text { LATERAL }\end{array}$ & $\begin{array}{c}\text { Grupo } \\
\text { POSTERIOR }\end{array}$ \\
\hline & $\mathrm{n}=32$ & $\mathrm{n}=14$ & $\mathrm{n}=11$ \\
\hline \multicolumn{4}{|l|}{$\mathrm{TEVEc}_{\mathrm{BASAL}}$} \\
\hline Média \pm DP & $339,34 \pm 63,74$ & $349,14 \pm 55,72$ & $326,82 \pm 65,93$ \\
\hline Mínimo - Máximo & $180-491$ & $246-454$ & $220-449$ \\
\hline \multicolumn{4}{|l|}{ TEVEc ${ }_{\text {INÍCIO DA ANASTOMOSE }}$} \\
\hline Média \pm DP & $341,50 \pm 48,78$ & $330,07 \pm 69,18$ & $324,73 \pm 69,86$ \\
\hline Mínimo - Máximo & $221-427$ & $203-421$ & $225-437$ \\
\hline \multicolumn{4}{|l|}{ TEVEc$_{\text {FINAL DA ANASTOMOSE }}$} \\
\hline Média \pm DP & $363,50 \pm 62,73$ & $356,14 \pm 77,38$ & $341,36 \pm 42,08$ \\
\hline Mínimo - Máximo & $220-535$ & $180-491$ & $280-411$ \\
\hline ANOVA & & $\mathbf{p}$ & Significância \\
\hline$\overline{\text { Entre grupos }}$ & & 0,60 & $\mathrm{NS}$ \\
\hline Entre tempos & & 0,07 & NS \\
\hline Interação grupo $\mathrm{x}$ tempo & & 0,86 & NS \\
\hline
\end{tabular}




\subsection{Pico de velocidade}

A Tabela 19 apresenta a análise descritiva das medidas de pico de velocidade (variável PV) por grupos de estudo e tempos. Foi possível observar pelo teste de ANOVA de duplo fator para medidas repetidas que houve interação tempo $\mathrm{x}$ grupo significativa $(\mathrm{p}=0,02)$. No entanto, pelo teste de comparações múltiplas de Newman-Keuls (Tabela 20), não foi possível detectar diferenças entre grupos ou tempos.

Tabela 17. Análise descritiva da variável PV (pico de velocidade, expresso em $\mathrm{cm} / \mathrm{seg}$ ) por tempo e grupo de estudo e resultados de ANOVA de duplo fator

\begin{tabular}{lccc}
\hline & $\begin{array}{c}\text { Grupo } \\
\text { ANTERIOR }\end{array}$ & $\begin{array}{c}\text { Grupo } \\
\text { LATERAL }\end{array}$ & $\begin{array}{c}\text { Grupo } \\
\text { POSTERIOR }\end{array}$ \\
\hline & $\mathrm{n}=32$ & $\mathrm{n}=14$ & $\mathrm{n}=11$ \\
PV & & & \\
Média \pm DP & $42,75 \pm 13,39$ & $49,43 \pm 17,10$ & $41,82 \pm 13,43$ \\
Mínimo - Máximo & $21-73$ & $17-85$ & $26-61$ \\
& & & \\
PV & & & \\
Médící \pm DA ANASTOMOSE & $42,53 \pm 13,45$ & $41,57 \pm 16,17$ & $47,55 \pm 15,04$ \\
Mínimo - Máximo & $22-82$ & $17-69$ & $27-76$ \\
& & & \\
PV & & & \\
Média \pm DP & & & \\
Mínimo - Máximo & $41,56 \pm 13,91$ & $41,43 \pm 16,68$ & $45,45 \pm 11,15$ \\
\end{tabular}


ANOVA

Entre grupos

p

0,81

Significância

Entre tempos

0,50

Interação grupo x tempo

0,02

NS

NS

Tabela 20. Resultados do pós-teste de Newman-Keuls

\begin{tabular}{cccc}
\hline & $\begin{array}{c}\text { Grupo } \\
\text { ANTERIOR }\end{array}$ & $\begin{array}{c}\text { Grupo } \\
\text { LATERAL }\end{array}$ & $\begin{array}{c}\text { Grupo } \\
\text { POSTERIOR }\end{array}$ \\
\hline BASAL x INÍCIO & $\mathrm{p}=0,94$ & $\mathrm{p}=0,07$ & $\mathrm{p}=0,22$ \\
DA ANASTOMOSE & $\mathrm{NS}$ & $\mathrm{NS}$ & $\mathrm{NS}$ \\
BASAL x FINAL & $\mathrm{p}=0,99$ & $\mathrm{p}=0,09$ & $\mathrm{p}=0,54$ \\
DA ANASTOMOSE & $\mathrm{NS}$ & $\mathrm{NS}$ & $\mathrm{NS}$ \\
INÍCIO x FINAL & $\mathrm{p}=0,98$ & $\mathrm{p}=0,99$ & $\mathrm{p}=0,44$ \\
DA ANASTOMOSE & $\mathrm{NS}$ & $\mathrm{NS}$ & $\mathrm{NS}$ \\
\hline
\end{tabular}

Figura 8. Valores médios e erros-padrões de PV por grupo de estudo

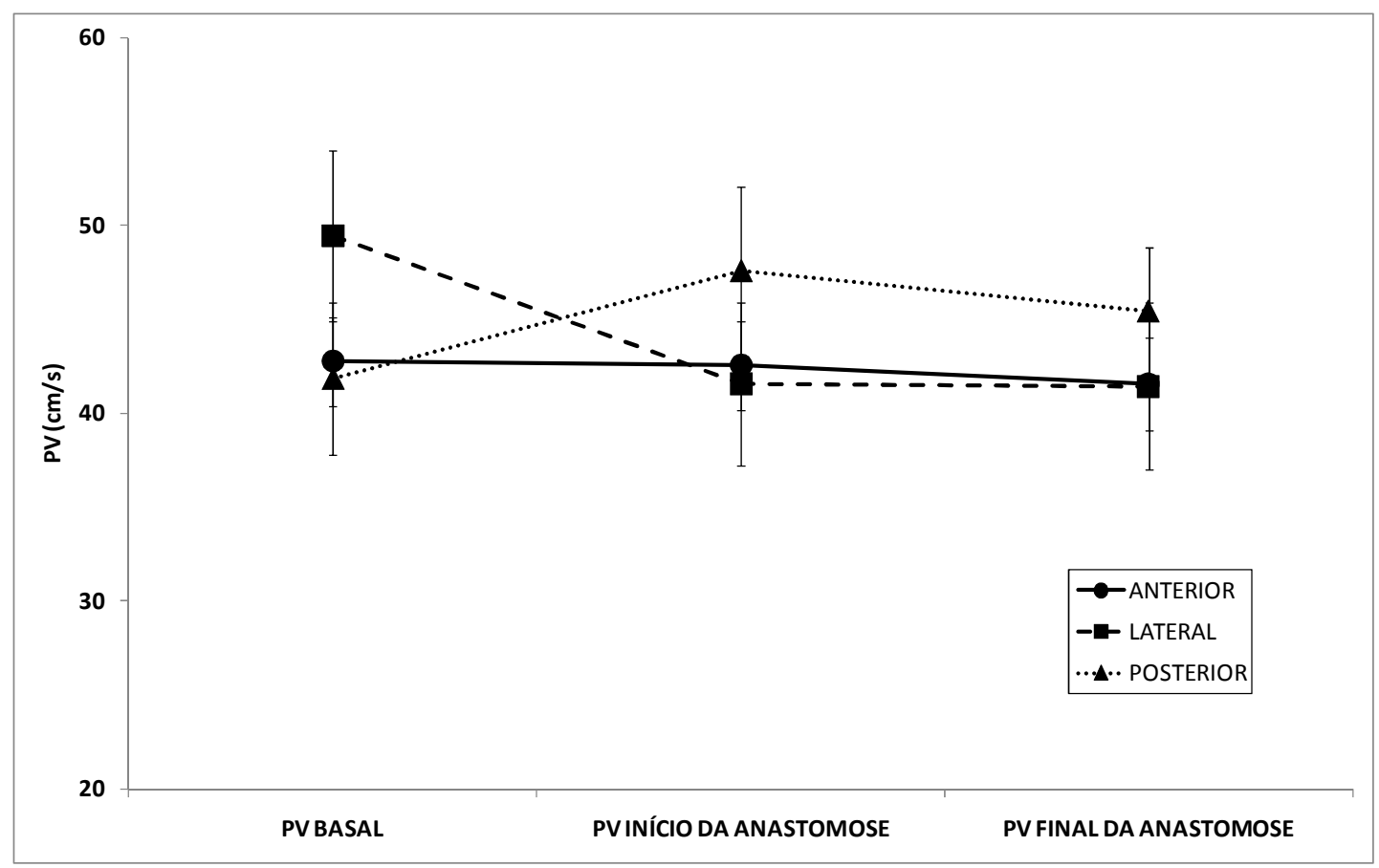




\subsection{Aceleração máxima}

A Tabela 21 apresenta a análise descritiva das medidas de aceleração máxima (variável AMáx) por grupos de estudo e tempos. Foi possível observar pelo teste de ANOVA de duplo fator para medidas repetidas que não houve diferenças entre grupos $(p=0,95)$ e nem entre tempos $(p=0,12)$.

Tabela 21. Análise descritiva da variável AMáx (aceleração máxima, expressa em $\mathrm{m} / \mathrm{seg}^{2}$ ) por tempo e grupo de estudo e resultados de ANOVA de duplo fator

\begin{tabular}{|c|c|c|c|}
\hline & $\begin{array}{c}\text { Grupo } \\
\text { ANTERIOR } \\
\end{array}$ & $\begin{array}{c}\text { Grupo } \\
\text { LATERAL }\end{array}$ & $\begin{array}{c}\text { Grupo } \\
\text { POSTERIOR }\end{array}$ \\
\hline & $\mathrm{n}=32$ & $\mathrm{n}=14$ & $\mathrm{n}=11$ \\
\hline \multicolumn{4}{|l|}{ AMáx ${ }_{\text {BASAL }}$} \\
\hline Média \pm DP & $9,98 \pm 4,97$ & $11,70 \pm 6,28$ & $8,60 \pm 5,16$ \\
\hline Mínimo - Máximo & $3,60-23,10$ & $3,30-24,20$ & $3,60-21,50$ \\
\hline \multicolumn{4}{|l|}{ AMáx INÍCIO DA ANASTOMOSE } \\
\hline Média \pm DP & $9,62 \pm 4,39$ & $9,42 \pm 5,38$ & $11,66 \pm 6,75$ \\
\hline Mínimo - Máximo & $2,50-20,20$ & $3,70-21,60$ & $5,00-21,90$ \\
\hline \multicolumn{4}{|l|}{ AMáx } \\
\hline Média \pm DP & $8,97 \pm 4,27$ & $8,56 \pm 4,97$ & $9,17 \pm 3,91$ \\
\hline Mínimo - Máximo & $2,70-21,50$ & $2,70-22,40$ & $5,50-19,70$ \\
\hline ANOVA & & p & Significância \\
\hline Entre grupos & & 0,95 & NS \\
\hline Entre tempos & & 0,12 & NS \\
\hline Interação grupo x tempo & & 0,08 & NS \\
\hline
\end{tabular}




\subsection{Comparação das medidas de débito cardíaco}

As medidas de débito cardíaco obtidas por termodiluição contínua em modo STAT e através do monitor de ecodoppler transesofágico foram comparadas com o método de termodiluição com bolus intermitente de solução fria em três diferentes tempos cirúrgicos: BASAL, INÍCIO e FINAL DA ANASTOMOSE.

Os coeficientes de correlação intraclasse (CCI), diferenças médias entre métodos e seus limites de concordância são apresentados na Tabela 22, junto com os intervalos de confiança de $95 \%$. 
Tabela 22. Resultados da análise de concordância dos métodos de medida de débito cardíaco em modo STAT $\left(\mathrm{DC}_{\mathrm{STAT}}\right)$ ou por ecodoppler transesofágico $\left(\mathrm{DC}_{\mathrm{DE}}\right)$ com o método intermitente (DCI), expressos em 1/min

\begin{tabular}{lcccc}
\hline DC & & & \\
\hline STAT & DCI & CCI & $\begin{array}{c}\text { Diferença média } \\
\text { [IC 95\%] }\end{array}$ & \multicolumn{2}{c}{$\begin{array}{c}\text { Limites de concordância } \\
\text { [IC 95\%] }\end{array}$} \\
\hline BASAL & 0,25 & 0,85 & $-2,41$ & 4,12 \\
& & {$[0,41$ a 1,29$]$} & {$[-3,18$ a $-1,65]$} & {$[3,35$ a 4,88$]$} \\
INÍCIO DA & 0,08 & 1,38 & $-1,53$ & 4,29 \\
ANASTOMOSE & & {$[0,99$ a 1,77$]$} & {$[-2,21$ a $-0,85]$} & {$[3,61$ a 4,97$]$} \\
FINAL DA & 0,39 & 1,14 & $-1,23$ & 3,51 \\
ANASTOMOSE & & {$[0,82$ a 1,46$]$} & {$[-1,78$ a $-0,67]$} & {$[2,95$ a 4,06$]$} \\
\hline
\end{tabular}

$\underline{D_{\text {DE }} \times \text { DCI }}$

\begin{tabular}{lcccc}
\hline & CCI & $\begin{array}{c}\text { Diferença média } \\
{[\mathbf{I C ~ 9 5 \% ]}}\end{array}$ & \multicolumn{2}{c}{$\begin{array}{c}\text { Limites de concordância } \\
\text { [IC 95\%] }\end{array}$} \\
\hline BASAL & 0,37 & $-0,74$ & $-3,89$ & 2,40 \\
& & {$[-1,17 \mathrm{a}-0,32]$} & {$[-4,63 \mathrm{a}-3,15]$} & {$[1,67 \mathrm{a} 3,14]$} \\
INÍCIO DA & 0,37 & $-0,54$ & $-3,61$ & 2,52 \\
ANASTOMOSE & & {$[-0,96 \mathrm{a}-0,13]$} & {$[-4,33 \mathrm{a}-2,89]$} & {$[1,80 \mathrm{a} 3,24]$} \\
FINAL DA & 0,44 & $-0,44$ & $-3,66$ & 2,78 \\
ANASTOMOSE & & {$[-0,87 \mathrm{a} 0,00]$} & {$[-4,42 \mathrm{a}-2,90]$} & {$[2,03$ a 3,54$]$} \\
\hline
\end{tabular}

Pela análise dos $\mathrm{CCI}$, tanto o método $\mathrm{DC}_{\mathrm{STAT}}$ quanto o $\mathrm{DC}_{\mathrm{DE}}$ não apresentaram correlação significativa com o método DCI em quaisquer dos tempos estudados. Observando as diferenças médias e os limites de concordância entre os métodos e em cada momento de coleta (Figuras 9 e 10), também é possível constatar que as diferenças detectadas não são aceitáveis clinicamente. 
Figura 9. Gráfico das diferenças entre os débitos cardíacos medidos em modo STAT e por termodiluição intermitente $\left(\mathrm{DC}_{\mathrm{STAT}} \mathrm{e} \mathrm{DCI}\right)$ em relação às medidas médias, nos momentos BASAL, INÍCIO e FINAL DA ANASTOMOSE, expressos em 1/min. Os limites de concordância equivalem à diferença média $\pm 1,96$ desvios-padrões

BASAL

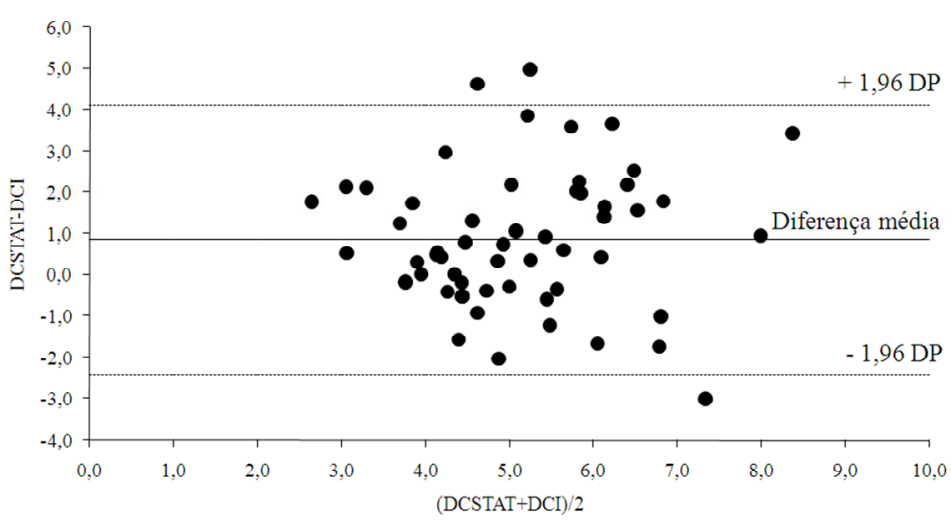

INÍCIO DAANASTOMOSE

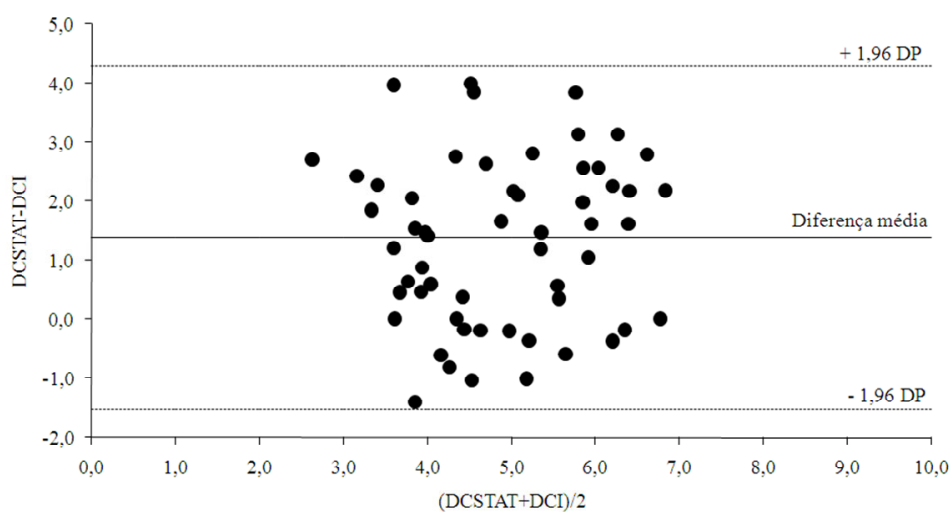

FINAL DA ANASTOMOSE

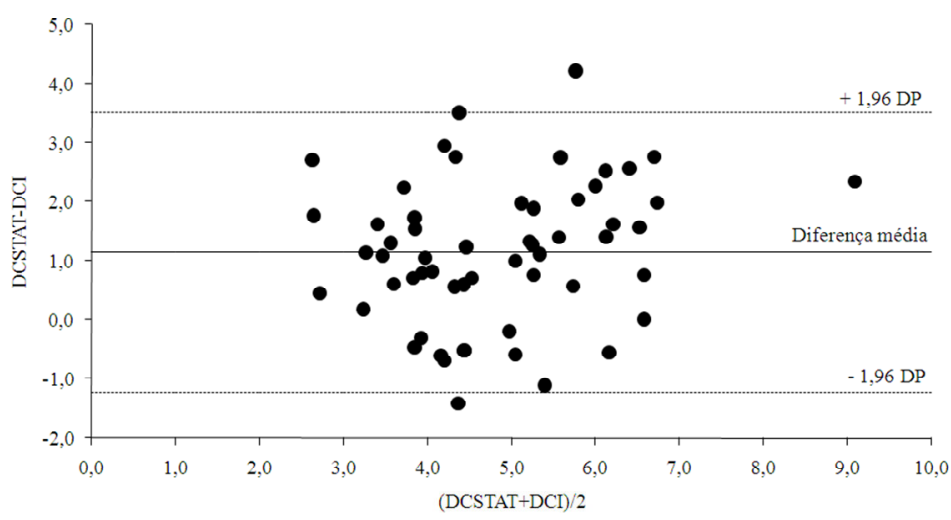


Figura 10. Gráfico das diferenças entre os débitos cardíacos medidos com ecodoppler transesofágico e por termodiluição intermitente $\left(\mathrm{DC}_{\mathrm{DE}} \mathrm{e} \mathrm{DCI}\right)$ em relação às medidas médias, nos momentos BASAL, INÍCIO e FINAL DA ANASTOMOSE, expressos em $1 /$ min. Os limites de concordância equivalem à diferença média $\pm 1,96$ desviospadrões

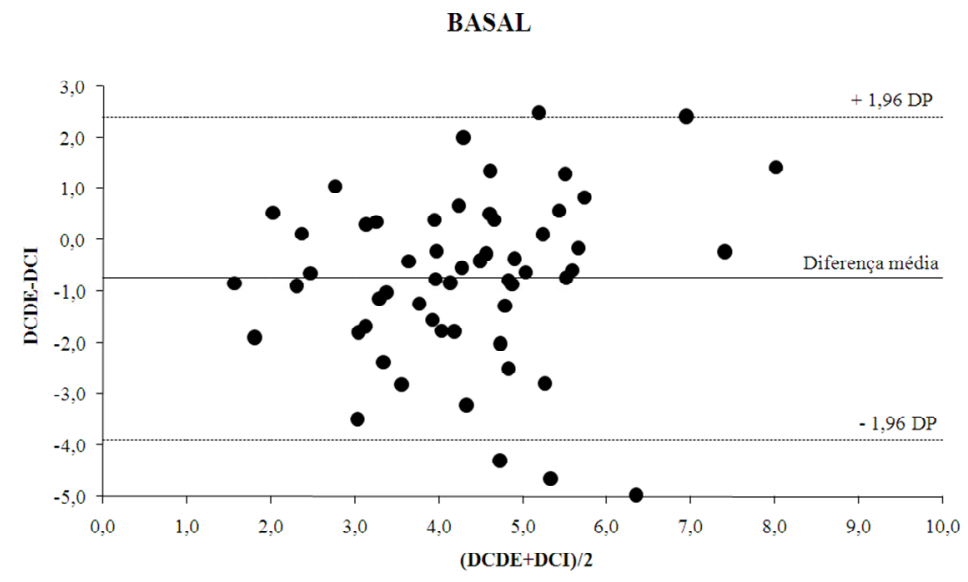

INÍCIO DA ANASTOMOSE

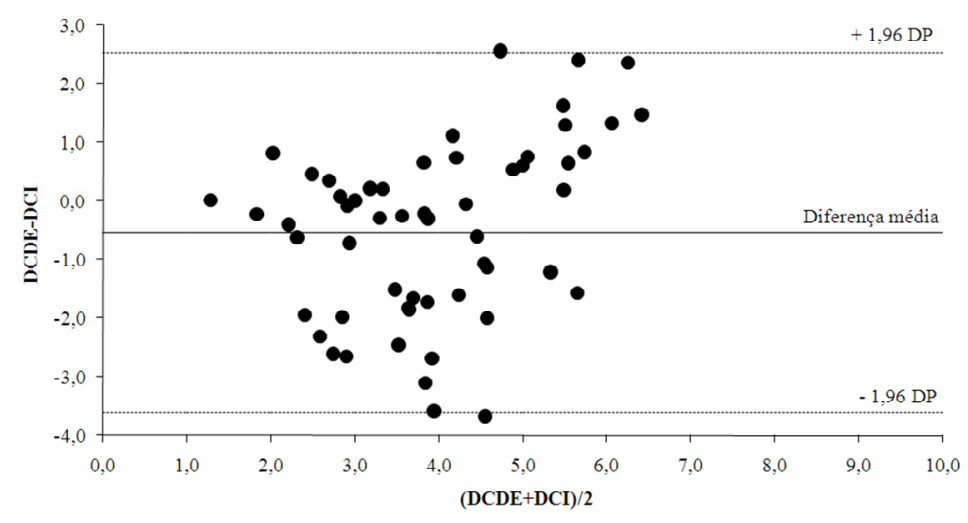

FINAL DA ANASTOMOSE

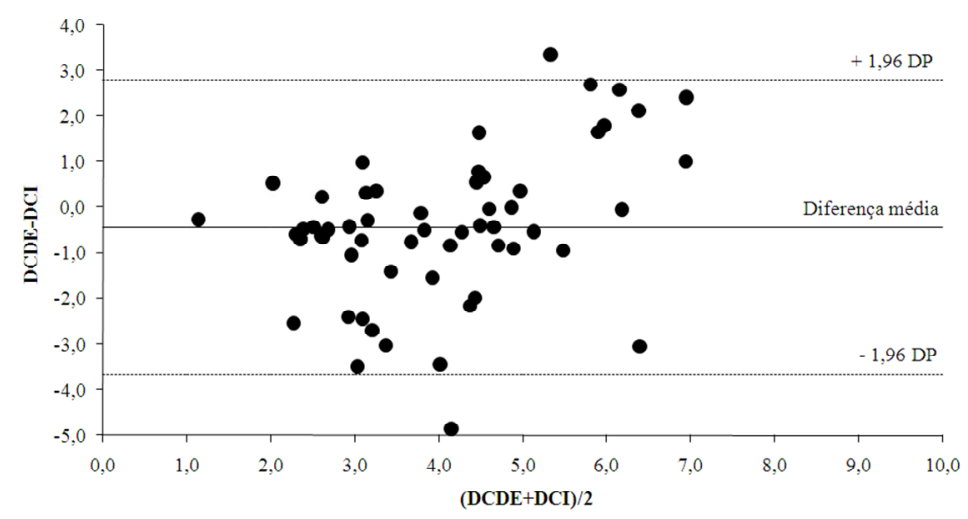




\subsection{Comparação das medidas de débito cardíaco na parede anterior}

As medidas de $\mathrm{DC}_{\mathrm{STAT}}$ e $\mathrm{DC}_{\mathrm{DE}}$ registradas durante os procedimentos sobre a parede anterior foram comparadas ao DCI do mesmo momento (Tabela 23).

Observando os CCI, não há correlação entre DC $_{\text {STAT }}$ e DCI ou entre $\mathrm{DC}_{\mathrm{DE}}$ e DCI. Realizando a análise pelo método proposto por Bland e Altman (Figuras 11 e 12) pode-se observar também que em todas as comparações realizadas as diferenças médias e os seus limites de concordância permanecem muito amplos e, na prática clínica, os métodos STAT e ecodoppler transesofágicos não poderiam substituir o método de termodiluição intermitente. 
Tabela 23. Resultados da análise de concordância dos métodos de medida de débito cardíaco em modo STAT $\left(\mathrm{DC}_{\mathrm{STAT}}\right)$ ou por ecodoppler transesofágico $\left(\mathrm{DC}_{\mathrm{DE}}\right)$ com o método intermitente (DCI), expressos em 1/min, na parede anterior

\section{DC}

\begin{tabular}{|c|c|c|c|c|}
\hline \multirow[b]{2}{*}{ BASAL } & \multirow{2}{*}{$\begin{array}{l}\text { CCI } \\
0,13\end{array}$} & \multirow{2}{*}{$\begin{array}{c}\text { Diferença média } \\
\text { [IC 95\%] } \\
0,95 \\
{[0,36 \text { a } 1,53]}\end{array}$} & \multicolumn{2}{|c|}{$\begin{array}{c}\text { Limites de concordância } \\
\text { [IC 95\%] }\end{array}$} \\
\hline & & & $\begin{array}{c}-2,23 \\
{[-2,99 \mathrm{a}-1,47]}\end{array}$ & $\begin{array}{c}4,13 \\
{[3,37 \text { a } 4,89]}\end{array}$ \\
\hline INÍCIO DA & 0,08 & 1,23 & $-1,67$ & 4,13 \\
\hline ANASTOMOSE & & {$[0,70$ a 1,76$]$} & {$[-2,36$ a $-0,98]$} & {$[3,44$ a 4,82$]$} \\
\hline FINAL DA & 0,19 & 1,15 & $-1,40$ & 3,70 \\
\hline ANASTOMOSE & & {$[0,68$ a 1,62$]$} & {$[-2,01 \mathrm{a}-0,79]$} & {$[3,09$ a 4,30$]$} \\
\hline \multicolumn{5}{|l|}{$\underline{\text { DC }_{\text {DE }} \times \text { DCI }}$} \\
\hline & CCI & $\begin{array}{c}\text { Diferença média } \\
\text { [IC 95\%] }\end{array}$ & \multicolumn{2}{|c|}{$\begin{array}{c}\text { Limites de concordância } \\
\text { [IC 95\%] }\end{array}$} \\
\hline BASAL & 0,31 & $\begin{array}{c}-0,44 \\
{[-1,01 \text { a } 0,14]}\end{array}$ & $\begin{array}{c}-3,56 \\
{[-4,30 \mathrm{a}-2,81]}\end{array}$ & $\begin{array}{c}2,68 \\
{[1,94 \text { a } 3,43]}\end{array}$ \\
\hline INÍCIO DA & 0,43 & $-0,28$ & $-2,99$ & 2,43 \\
\hline ANASTOMOSE & & {$[-0,79$ a 0,22$]$} & {$[-3,64 \mathrm{a}-2,34]$} & {$[1,78$ a 3,07$]$} \\
\hline FINAL DA & 0,59 & 0,02 & $-2,71$ & 2,76 \\
\hline ANASTOMOSE & & {$[-0,48$ a 0,53$]$} & {$[-3,36 \mathrm{a}-2,06]$} & {$[2,11$ a 3,41$]$} \\
\hline
\end{tabular}


Figura 11. Gráfico das diferenças entre os débitos cardíacos medidos em modo STAT e por termodiluição intermitente $\left(\mathrm{DC}_{\mathrm{STAT}} \mathrm{e} \mathrm{DCI}\right)$ na parede anterior em relação às medidas médias, nos momentos BASAL, INÍCIO e FINAL DA ANASTOMOSE, expressos em $1 / \mathrm{min}$. Os limites de concordância equivalem à diferença média $\pm 1,96$ desvios-padrões

BASAL

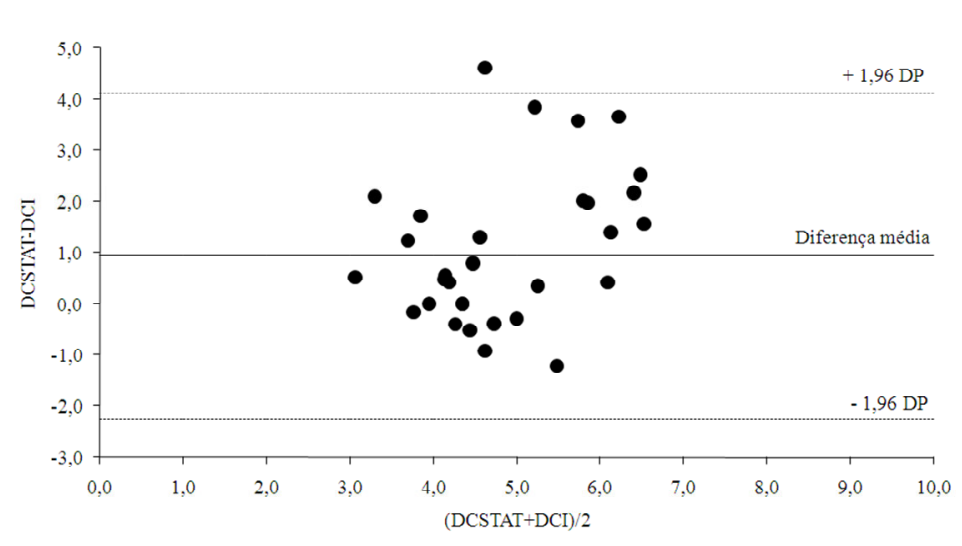

INÍCIO DAANASTOMOSE

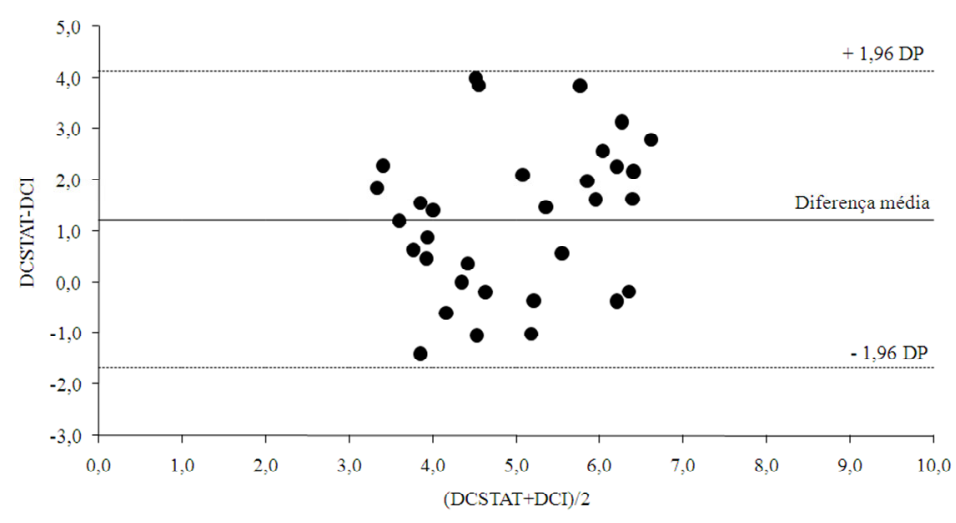

FINAL DAANASTOMOSE

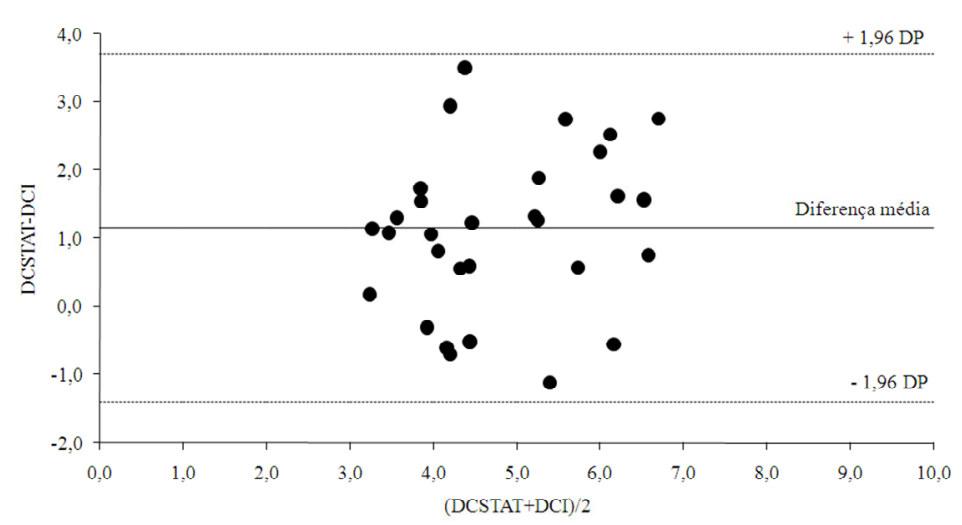


Figura 12. Gráfico das diferenças entre os débitos cardíacos medidos com ecodoppler transesofágico e por termodiluição intermitente $\left(\mathrm{DC}_{\mathrm{DE}} \mathrm{e} \mathrm{DCI}\right)$ na parede anterior em relação às medidas médias, nos momentos BASAL, INÍCIO e FINAL DA ANASTOMOSE, expressos em $1 / \mathrm{min}$. Os limites de concordância equivalem à diferença média $\pm 1,96$ desvios-padrões

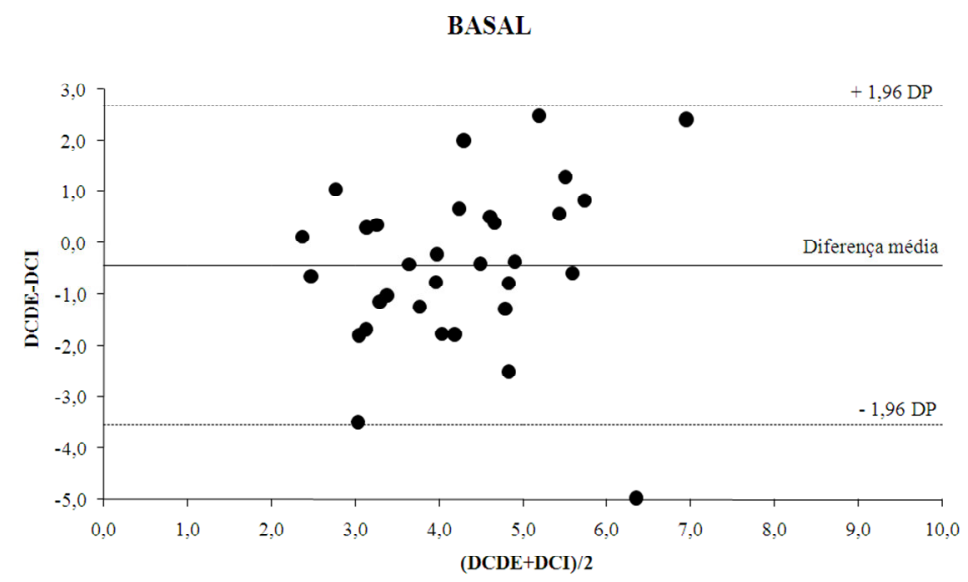

INÍCIO DA ANASTOMOSE

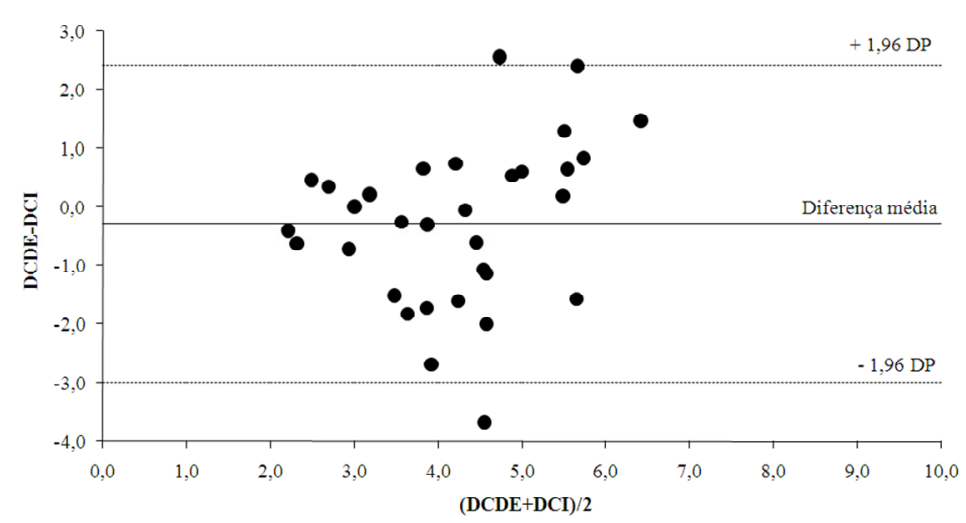

FINAL DAANASTOMOSE

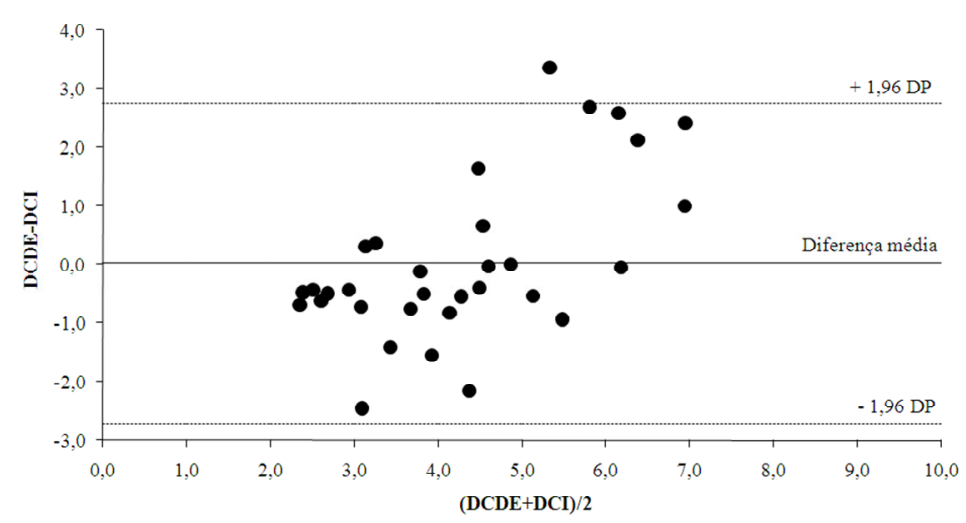




\section{DISCUSSÃO}

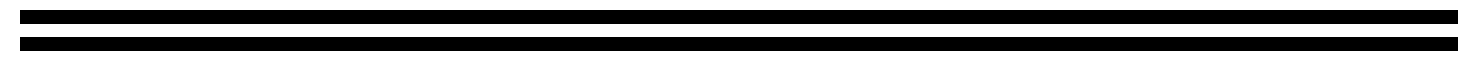




\section{DISCUSSÃO}

No estudo do comportamento hemodinâmico durante a realização da revascularização do miocárdio sem utilização de CEC, os resultados demonstraram que houve alteração hemodinâmica significativa representada por aumento da pressão de oclusão de artéria pulmonar e pressão venosa central e diminuição do débito cardíaco intermitente, independentemente da parede ventricular avaliada. Já nas medidas de débito cardíaco por Doppler esofágico e fluxo sanguíneo aórtico, a redução dos parâmetros ocorreu somente na parede lateral.

Comparando as medidas de débito cardíaco obtidas pelos diferentes modos de monitorização empregados, por cateter de artéria pulmonar com filamento térmico e por sonda de ecodoppler transesofágico, as diferenças observadas para ambos os métodos foram muito amplas para que se pudesse considerar as medidas obtidas concordantes, em quaisquer das condições hemodinâmicas estudadas.

A análise dos parâmetros hemodinâmicos obtidos pelo cateter de artéria pulmonar não entram em conflito com os resultados apresentados em diversos trabalhos publicados na literatura médica, ao demonstrar o aumento das pressões atriais e diastólicas finais ventriculares e diminuição do débito cardíaco $(6,7,11,14$, $16,17,20,35)$. No entanto, em sua maioria apontam maior alteração hemodinâmica nos procedimentos realizados sobre as artérias das paredes póstero-laterais do coração. Mueller et al. (2002) (19), em seu trabalho realizado com técnica que enucleava o coração, evitando a compressão de qualquer cavidade cardíaca, não 
detectou alterações hemodinâmicas significativas nas diferentes paredes, mas a parede lateral parecia sofrer maior impacto hemodinâmico, embora sem significância estatística.

Neste estudo, com o uso do monitor de ecodoppler transesofágico, não foram observadas outras alterações hemodinâmicas exceto no débito cardíaco e fluxo sangüíneo aórtico, quando avaliada a parede lateral.

No entanto, as variáveis hemodinâmicas que sofrem alterações nestes diversos estudos variam e isto pode ser explicado pelo fato de que a evolução da técnica cirúrgica e do conhecimento do comportamento hemodinâmico nessas situações permitiram minimizar os prejuízos circulatórios que eram tão freqüentes no desenvolver das cirurgias sem CEC. Nas publicações mais recentes e principalmente em estudos clínicos é menor o relato de diminuições significativas de pressão arterial média, já que manobras para normalização da mesma, como o posicionamento em Trendelemburg e a infusão de fármacos inotrópicos já se estabeleceram como condutas de rotina nestas cirurgias.

O aumento de freqüência cardíaca, que seria esperado frente a manipulação do coração, não é fato descrito na literatura recente e nem foi observado neste estudo. A justificativa para isso também pode estar tanto na evolução da técnica como na rotina de implantação de fármacos betabloqueadores já no período préoperatório.

O aumento das pressões atriais durante a manipulação cirúrgica pode ser explicado pela distorção anatômica do coração luxado, principalmente próximo às válvulas atrioventriculares, acarretando em obstrução parcial ao fluxo sangüíneo ou 
em insuficiências valvares. Também poderia ser explicado pela migração do cateter para um posicionamente inadequado detectando pressões errôneas. Deve ser lembrado que as medidas de pressões atriais sofrem grandes influências também da complacência das câmaras, que pode ter sido alterada pela maior alteração do eixo cardíaco nestas situações.

Outras variáveis indicadoras de pré-carga cardíaca foram analisadas, o volume diastólico final de ventrículo direito (VDF) e o tempo de ejeção de ventrículo esquerdo corrigido (TEVEc). Esses índices não apresentaram alterações entre os grupos estudados ou no decorrer do procedimento. Essas observações poderiam corroborar com a eficácia das manobras de ajuste volêmico, já que ambos os métodos se demonstraram superiores às medidas de pressões atriais para refletir o enchimento cardíaco direito ou esquerdo $(50,51,52)$.

O pico de velocidade e aceleração máxima do fluxo sangüíneo aórtico, medidos pelo monitor de ecodoppler transesofágico, não se alteraram no decorrer do procedimento em qualquer das paredes estudadas. Esses parâmetros são indicadores de contratilidade miocárdica que se correlacionam bem com o índice de $\mathrm{dP} / \mathrm{dt} \mathrm{VE}$ obtido por cateterização de ventrículo esquerdo (53).

O débito cardíaco obtido por termodiluição intermitente registrou diminuição significativa independente de parede. Essa alteração não foi observada no DC em modo STAT. Já na monitorização com Doppler esofágico, essa alteração hemodinâmica foi registrada somente na parede lateral.

Apesar de observarmos os comportamentos diferentes entre as medidas de débito cardíaco obtidas pelos três monitores, para se comparar os métodos é 
recomendada a análise proposta por Bland e Altman (49). Foram estudadas as diferenças entre os débitos cardíacos obtidos por termodiluição semi-contínua em modo STAT e por ecodoppler transesofágico, em relação ao de termodiluição intermitente com bolus de solução fria, que é o método mais utilizado na prática clínica.

Estudos anteriores comparando estes diferentes monitores de débito cardíaco mostraram correlação significativa entre DCI e DCC $(40,41,42)$ e concordância entre DCI e $\mathrm{DC}_{\mathrm{DE}}(54)$, mas sempre em momentos de estabilidade hemodinâmica. No entanto, adotando o método proposto por Bland e Altman (49), Zollner (2001) (42) também encontrou discrepância entre os métodos maior que 0,5 L/min, que está acima de limites aceitáveis clinicamente. Durante a instabilidade, representada por choque hipovolêmico (25) ou taquicardia induzida por marcapasso epicárdico (41), os monitores de débito cardíaco contínuo e semi-contínuo apresentaram menor correlação devido ao atraso de medida. O mesmo ocorreu na comparação DCI e $\mathrm{DC}_{\mathrm{DE}}$, mas as mudanças ocorriam na mesma direção $(44,45)$.

A concordância entre os métodos foi buscada também em situações específicas da revascularização do miocárdio sem CEC e não somente durante a estabilidade hemodinâmica. O estudo tinha como intuito buscar a possibilidade destes métodos novos substituírem o cateter de artéria pulmonar convencional nestas cirurgias, por serem alternativas automáticas ou menos invasivas, nos casos do modo STAT e ecodoppler transesofágico, respectivamente.

A termodiluição intermitente com bolus de solução fria foi o método com o qual os monitores novos foram comparados. No entanto, deve-se considerar que 
erros de medida com o cateter de artéria pulmonar podem ocorrer com a manipulação do coração, principalmente com sua elevação e rotação. Nessas situações, pode ocorrer mistura inadequada do bolus indicador, movimentação do cateter, regurgitação tricúspide e arritmias, sendo que todos estes fatores podem interferir nos valores calculados como débito cardíaco. Essas interferências seriam observadas também na termodiluição contínua com uso de filamento térmico.

Por outro lado, a análise do débito cardíaco esquerdo, através da análise do fluxo sangüíneo aórtico com ecodoppler, poderia fornecer o valor do fluxo efetivamente direcionado para a perfusão de órgãos-alvo. Neste sentido, seria possível considerar que o valor fidedigno de débito cardíaco seria aquele obtido pelo ecodoppler transesofágico e não pela termodiluição com bolus.

Entretanto, apesar da mobilização do coração representar para esse monitor menor influência direta no fluxo aórtico, manipulações com instrumentais cirúrgicos causavam movimentações em todo o campo cirúrgico, eventualmente comprimindo ou deslocando a aorta, principalmente durante os procedimentos sobre as paredes póstero-laterais do coração. Havia assim uma interferência no posicionamento ideal da sonda de ecodoppler transesofágico, que requer paralelismo da aorta com o esôfago, para que tanto a medida do diâmetro aórtico com ecografia quanto a obtenção do sinal Doppler do fluxo aórtico fossem adequadas (55).

Por esse motivo, nas comparações entre débitos cardíacos foi feita a opção por uma nova análise considerando apenas a parede anterior, que estaria livre de torções do coração ou de manipulações no mediastino posterior. 
Mesmo com esta nova análise, as diferenças entre os valores obtidos por cada método mostraram-se muito amplos para se considerar os métodos intercambiáveis no uso clínico.

Deve ser ressaltado também que o cateter de artéria pulmonar permite obter o valor de débito cardíaco direito, enquanto que o ecodoppler mede por via transesofágica o fluxo aórtico descendente, que equivale a $70 \%$ do débito cardíaco esquerdo, mesmo em situações de choque circulatório (56). A manipulação sobre o coração com conseqüentes insuficiências valvares e o represamento de sangue na pequena circulação poderiam explicar em parte a discrepância entre as medidas de DC por cateter de artéria pulmonar e ecodoppler transesofágico.

A técnica cirúrgica varia entre os cirurgiões e entre as rotinas de cada serviço. Assim, a análise das alterações hemodinâmicas deste estudo se aplica às condutas adotadas pelos cirurgiões envolvidos.

Os dados hemodinâmicos de interesse foram coletados em dois momentos diferentes: imediatamente após o posicionamento cirúrgico e decorridos aproximadamente cinco minutos. A justificativa para a escolha desses dois momentos foi a de que a primeira medida identificaria a instabilidade hemodinâmica inicial e a segunda, uma relativa estabilização dos parâmetros na posição instalada.

Os três grupos de estudo classificavam diferentes locais de anastomose coronariana. No entanto, os procedimentos dentro de cada grupo também podiam variar, se realizados em posições mais proximais ou distais em uma mesma artéria coronária. No caso de anastomoses sobre a artéria coronária direita, classificadas dentro do grupo posterior, uma abordagem mais proximal poderia justificar sua 
inclusão no grupo da parede anterior. Também houve o agrupamento em anterior das anastomoses da artéria diagonal e descendente anterior, mas algumas operações sobre a primeira eram acompanhadas de maior lateralização do coração do que sobre a última. Além disso, a ordem de realização das anastomoses não era uniforme, mas estabelecida pela equipe cirúrgica. A condição hemodinâmica durante a anastomose prévia poderia influenciar as medidas subseqüentes. Houve neste estudo a tentativa de minimizar esse fator com a coleta de medidas basais antes de cada anastomose, mas não foi possível precisar se o tempo para recuperação hemodinâmica teria sido suficiente.

Esta foi uma pesquisa clínica sem interferência no tratamento ou na técnica cirúrgica. Poderia haver contribuição com maior significado se o trabalho tivesse sido realizado em situações mais homogêneas ou controladas. No entanto, dificilmente encontraríamos pacientes com lesões nas mesmas artérias coronarianas e com comprometimentos similares.

Este estudo procurou descrever as alterações cardiocirculatórias que ocorrem especificamente durante a revascularização do miocárdio sem CEC, utilizando-se de variados recursos de medida que os monitores hemodinâmicos podem oferecer. Com essa análise, comparou-se também os diferentes métodos de obtenção de débito cardíaco, no intuito de buscar um método que pudesse substituir o de termodiluição com injeção de bolus de solução fria. A comparação entre as medidas de DC permitiu afirmar que os métodos não são intercambiáveis, o que estimula o desenvolvimento e aperfeiçoamento da tecnologia de monitores de DC. 
A cirurgia de revascularização do miocárdio sem CEC vem se aperfeiçoando, tanta em relação a técnica, desenvolvimento de materiais, habilidade dos cirurgiões quanto em relação ao manejo anestésico, com o conhecimento da cirurgia e adoção de monitores precisos. Assim, os estudos neste tema continuam, buscando o desenvolvimento da cirurgia com menores prejuízos aos pacientes. Outros monitores de resposta rápida e menos invasivos também estão sendo estudados, como por análise do contorno da onda de pulso ou do gás carbônico expirado.

Apesar da presença dos fatores que interferem na monitorização hemodinâmica durante a cirurgia de revascularização do miocárdio sem utilização de CEC, as alterações circulatórias devem ser esperadas, acompanhadas e adequadamente avaliadas pelo anestesiologista, para guiar o melhor tratamento a ser adotado. 
CONCLUSÕES

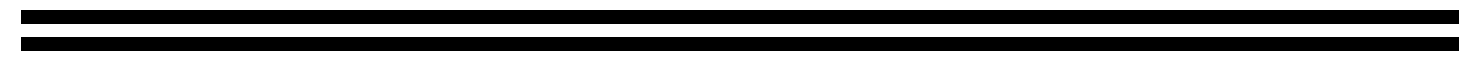




\section{CONCLUSÕES}

Os resultados obtidos pela avaliação hemodinâmica durante a realização das anastomoses coronarianas distais na revascularização do miocárdio sem utilização de circulação extracorpórea permitem concluir que:

houve aumento da PoAP e PVC e diminuição do DCI, em todas as paredes operadas;

houve diminuição do $\mathrm{DC}_{\mathrm{DE}}$ e FSA na parede lateral;

as medidas de DC obtidas pelos métodos STAT e Doppler esofágico não são concordantes com aquela obtida por termodiluição intermitente. 
REFERÊNCIAS BIBLIOGRÁFICAS

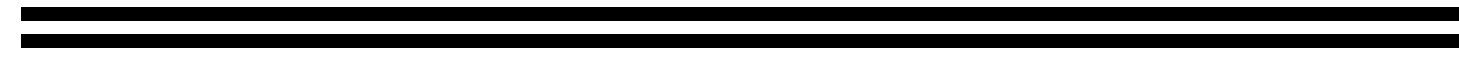




\section{REFERÊNCIAS BIBLIOGRÁFICAS}

1. Jansen EW, Lahpor JR, Borst C, Grundeman PF, Bredee JJ. Off-pump coronary bypass grafting: how to use the Octopus Tissue Stabilizer. Ann Thorac Surg 1998;66(2):576-9.

2. Chassot PG, van der Linden P, Zaugg M, Mueller XM, Spahn DR. Off-pump coronary artery bypass surgery: physiology and anaesthetic management. $\mathrm{Br} \mathrm{J}$ Anaesth 2004;92(3):400-13.

3. Michelsen LG, Horswell J. Anesthesia for off-pump coronary artery bypass grafting. Semin Thorac Cardiovasc Surg 2003;15(1):71-82.

4. Novitzky D, Bowen TE, Larsen A, Powe J, Ebra G. Aiming towards complete myocardial revascularization without cardiopulmonary bypass: a systematic approach. Heart Surg Forum 2002;5(3):214-20.

5. Buffolo E, Andrade JC, Succi JE. Revascularização direta do miocárdio sem circulação extracorpórea: descrição da técnica e resultados iniciais. Arq Bras Cardiol $1982 ; 38: 365-73$

6. Couture P, Denault A, Limoges P, Sheridan P, Babin D, Cartier R. Mechanisms of hemodynamic changes during off-pump coronary artery bypass surgery. Can $\mathrm{J}$ Anaesth 2002;49(8):835-49.

7. D'Ancona G, Karamanoukian H, Lima R, Ricci M, Bergsland J, Rossman J, et al. Hemodynamic effects of elevation and stabilization of the heart during off-pump coronary surgery. J Card Surg 2000;15(6):385-91.

8. de Jaegere PP, Suyker WJ. Off-pump coronary artery bypass surgery. Heart 2002;88(3):313-8. 
9. Do QB, Goyer C, Chavanon O, Couture P, Denault A, Cartier R. Hemodynamic changes during off-pump CABG surgery. Eur J Cardiothorac Surg 2002;21(3):38590 .

10. Eldrup N, Rasmussen NH, Yndgaard S, Bigler D, Berthelsen PG. Impact of offpump coronary artery surgery on myocardial performance and beta-adrenoceptor function. J Cardiothorac Vasc Anesth 2001;15(4):428-32.

11. Grundeman PF, Borst C, van Herwaarden JA, Verlaan CW, Jansen EW. Vertical displacement of the beating heart by the octopus tissue stabilizer: influence on coronary flow. Ann Thorac Surg 1998;65(5):1348-52.

12. Grundeman PF, Borst C, Verlaan CW, Meijburg H, Moues CM, Jansen EW. Exposure of circumflex branches in the tilted, beating porcine heart: echocardiographic evidence of right ventricular deformation and the effect of right or left heart bypass. J Thorac Cardiovasc Surg 1999;118:316-323.

13. Hart JC. Maintaining hemodynamic stability and myocardial performance during off-pump coronary bypass surgery. Ann Thorac Surg 2003;75(2):S740-4.

14. Jansen EW, Borst C, Lahpor JR, Grundeman PF, Eefting FD, Nierich A, et al. Coronary artery bypass grafting without cardiopulmonary bypass using the octopus method: results in the first one hundred patients. J Thorac Cardiovasc Surg 1998;116(1):60-7.

15. Kwak YL, Oh YJ, Jung SM, Yoo KJ, Lee JH, Hong YW. Change in right ventricular function during off-pump coronary artery bypass graft surgery. Eur $\mathrm{J}$ Cardiothorac Surg 2004;25(4):572-7.

16. Mathison M, Edgerton JR, Horswell JL, Akin JJ, Mack MJ. Analysis of hemodynamic changes during beating heart surgical procedures. Ann Thorac Surg 2000;70(4):1355-60; discussion 1360-1.

17. Mishra M, Malhotra R, Mishra A, Meharwal ZS, Trehan N. Hemodynamic changes during displacement of the beating heart using epicardial stabilization for off-pump coronary artery bypass graft surgery. J Cardiothorac Vasc Anesth 2002;16(6):685-90. 
18. Mishra M, Shrivastava S, Dhar A, Bapna R, Mishra A, Meharwal ZS, et al. A prospective evaluation of hemodynamic instability during off-pump coronary artery bypass surgery. J Cardiothorac Vasc Anesth 2003;17(4):452-8.

19. Mueller XM, Chassot PG, Zhou J, Eisa KM, Chappuis C, Tevaearai HT, et al. Hemodynamics optimization during off-pump coronary artery bypass: the 'no compression' technique. Eur J Cardiothorac Surg 2002;22(2):249-54.

20. Nierich AP, Diephuis J, Jansen EW, Borst C, Knape JT. Heart displacement during off-pump CABG: how well is it tolerated? Ann Thorac Surg 2000;70(2):46672.

21. Torracca L, Schreuder JJ, Quarti A, Ismeno G, Franze V, Alfieri O. Acute effects of beating heart coronary surgery on left ventricular performance. Ann Thorac Surg 2002;74(4):S1348-52.

22. Velissaris T, Tang A, Jonas M, Ohri S. Haemodynamic changes during off-pump surgery. Eur J Cardiothorac Surg 2002;22(5):852; author reply 853.

23. Watters MP, Ascione R, Ryder IG, Ciulli F, Pitsis AA, Angelini GD. Haemodynamic changes during beating heart coronary surgery with the 'Bristol Technique'. Eur J Cardiothorac Surg 2001;19(1):34-40.

24. Singer M. Esophageal Doppler monitoring of aortic blood flow: beat-by-beat cardiac output monitoring. Int Anesthesiol Clin 1993;31(3):99-125.

25. Poli de Figueiredo LF, Malbouisson LM, Varicoda EY, Carmona MJ, Auler JO, Jr., Rocha e Silva M. Thermal filament continuous thermodilution cardiac output delayed response limits its value during acute hemodynamic instability. J Trauma 1999;47(2):288-93.

26. Matata BM, Sosnowski AW, Galinanes M. Off-pump bypass graft operation significantly reduces oxidative stress and inflammation. Ann Thorac Surg 2000;69(3):785-91.

27. Kolessov VI. Mammary artery-coronary artery anastomosis as method of treatment for angina pectoris. J Thorac Cardiovasc Surg 1967;54:535-544. 
28. Menasche P. The systemic factor: the comparative roles of cardiopulmonary bypass and off-pump surgery in the genesis of patient injury during and following cardiac surgery. Ann Thorac Surg 2001;72(6):S2260-5; discussion S2265-6, S226770 .

29. Stamou SC, Dangas G, Hill PC, Pfister AJ, Dullum MK, Boyce SW, et al. Atrial fibrillation after beating heart surgery. Am J Cardiol 2000;86(1):64-7.

30. Bainbridge D, Martin J, Cheng D. Off pump coronary artery bypass graft surgery versus conventional coronary artery bypass graft surgery: a systematic review of the literature. Semin Cardiothorac Vasc Anesth 2005;9(1):105-11.

31. Trapp WG, Bisarya R. Placement of coronary artery bypass graft without pump oxigenator. Ann Thorac Surg 1975;19:1-9.

32. Benetti FJ. Direct coronary surgery with saphenous vein bypass without either cardiopulmonary bypass or cardiac arrest. J Cardiovasc Surg 1985;26:217-222.

33. Calafiore AM, Giammarco GD, Teodori G, Bosco G, D'Annunzio E, Barsotti A, et al. Left anterior descending coronary artery grafting via left anterior small thoracotomy without cardiopulmonary bypass. Ann Thorac Surg 1996;61(6):165863; discussion 1664-5.

34. Boonstra PW, Grandjean JG, Mariani MA. Local immobilization of the left anterior descending artery for minimally invasive coronary bypass grafting. Ann Thorac Surg 1997;63(6 Suppl):S76-8.

35. Borst C, Jansen EW, Tulleken CA, Grundeman PF, Mansvelt Beck HJ, van Dongen JW, et al. Coronary artery bypass grafting without cardiopulmonary bypass and without interruption of native coronary flow using a novel anastomosis site restraining device ("Octopus"). J Am Coll Cardiol 1996;27(6):1356-64.

36. Thanikachalam M, Lombardi P, Tehrani HY, Katariya K, Salerno TA. The History and Development of Direct Coronary Surgery without Cardiopulmonary Bypass*. J Card Surg 2004;19(6):516-9. 
37. Lima RdC. Padronizaçäo técnica de revascularizaçäo miocárdica da artéria circunflexa e seus ramos sem circulaçäo extracorpórea. [Technical regulation of the myocardial revascularization the circumflex arteries without use of extracorporeal circulation]. [doutorado - tese]. São Paulo: Universidade Federal de São Paulo. Escola Paulista de Medicina; 1999.

38. Koh TW, Carr-White GS, DeSouza AC, Ferdinand FD, Pepper JR, Gibson DG. Effect of coronary occlusion on left ventricular function with and without collateral supply during beating heart coronary artery surgery. Heart 1999;81(3):285-91.

39. Brown PM, Jr., Kim VB, Boyer BJ, Lust RM, Chitwood WR, Jr., Elbeery JR. Regional left ventricular systolic function in humans during off-pump coronary bypass surgery. Circulation 1999;100(19 Suppl):II125-7.

40. Singh A, Juneja R, Mehta Y, Trehan N. Comparison of continuous, stat, and intermittent cardiac output measurements in patients undergoing minimally invasive direct coronary artery bypass surgery. J Cardiothorac Vasc Anesth 2002;16(2):18690 .

41. Lazor MA, Pierce ET, Stanley GD, Cass JL, Halpern EF, Bode RH, Jr. Evaluation of the accuracy and response time of STAT-mode continuous cardiac output. J Cardiothorac Vasc Anesth 1997;11(4):432-6.

42. Zollner C, Goetz AE, Weis M, Morstedt K, Pichler B, Lamm P, et al. Continuous cardiac output measurements do not agree with conventional bolus thermodilution cardiac output determination. Can J Anaesth 2001;48(11):1143-7.

43. Gan TJ, Arrowsmith JE. The oesophageal Doppler monitor. Bmj 1997;315(7113):893-4.

44. Royse CF, Royse AG, Soeding PF, Mathieson EM. Descending aortic pulsed wave Doppler can predict changes in cardiac output during off-pump coronary artery bypass surgery. Ann Thorac Cardiovasc Surg 2003;9(5):314-8.

45. Grow MP, Singh A, Fleming NW, Young N, Watnik M. Cardiac output monitoring during off-pump coronary artery bypass grafting. J Cardiothorac Vasc Anesth 2004;18(1):43-6. 
46. Woog RH, McWilliam DB. A comparison of methods of cardiac output measurement. Anaesth Intensive Care 1983;11(2):141-6.

47. Merjavy JP, Hahn JW, Barner HB. Comparison of thermodilution cardiac output and electromagnetic flowmeter. Surg Forum 1974;25(0):145-7.

48. Higgins TL, Estafanous FG, Loop FD, Beck GJ, Blum JM, Paranandi L. Stratification of morbidity and mortality outcome by preoperative risk factors in coronary artery bypass patients. A clinical severity score. Jama 1992;267(17):2344-8.

49. Bland JM, Altman DG. Statistical methods for assessing agreement between two methods of clinical measurement. Lancet 1986;1(8476):307-10.

50. Diebel LN, Wilson RF, Tagett MG, Kline RA. End-diastolic volume. A better indicator of preload in the critically ill. Arch Surg 1992;127(7):817-21; discussion 821-2.

51. Reuse C, Vincent JL, Pinsky MR. Measurements of right ventricular volumes during fluid challenge. Chest 1990;98(6):1450-4.

52. Pinsky MR. Assessment of indices of preload and volume responsiveness. Curr Opin Crit Care 2005;11(3):235-9.

53. Saeian K, Wann LS, Sagar KB. Doppler echocardiographic evaluation of left ventricular function. Echocardiography 1990;7(1):21-25.

54. Chand R, Mehta Y, Trehan N. Cardiac output estimation with a new Doppler device after off-pump coronary artery bypass surgery. J Cardiothorac Vasc Anesth 2006;20(3):315-9.

55. Tortoli P, Bambi G, Guidi F, Muchada R. Toward a better quantitative measurement of aortic flow. Ultrasound Med Biol 2002;28(2):249-57.

56. Dumans-Nizard V, Nizard J, Payen D, Cholley BP. Redistribution of cardiac output during hemorrhagic shock in sheep. Crit Care Med 2006;34(4):1147-51. 
APÊNDICES

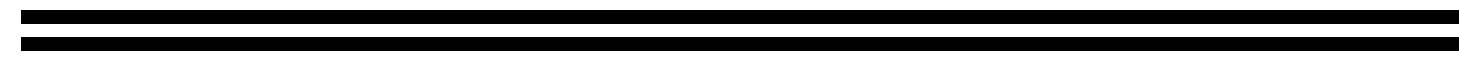




\section{APÊNDICES}

\section{I- Dados Individuais}

\begin{tabular}{|c|c|c|c|c|c|c|c|c|c|c|}
\hline caso paciente & \multicolumn{2}{|c|}{ RGHC } & \multicolumn{2}{|c|}{ data } & sexo & idade & peso & altura & IMC & $\begin{array}{ll}\text { SC } & \text { Higgins } \\
\end{array}$ \\
\hline $1 \mathrm{MS}$ & \multicolumn{2}{|c|}{$55380566 \mathrm{~A}$} & \multicolumn{2}{|c|}{$7 / a b r / 04$} & $M$ & 64 & 69,0 & 1,62 & 26,3 & 1,74 mínimo \\
\hline $2 \mathrm{CCP}$ & \multicolumn{2}{|c|}{$55387370 \mathrm{~J}$} & \multicolumn{2}{|c|}{ 10/ago/04 } & $\mathrm{F}$ & 66 & 59,0 & 1,51 & 25,9 & 1,54 baixo \\
\hline $3 \mathrm{EAC}$ & \multicolumn{2}{|c|}{ 55387452J } & \multicolumn{2}{|c|}{ 11/ago/04 } & M & 64 & 70,0 & 1,75 & 22,9 & 1,84 mínimo \\
\hline 4 ICMS & \multicolumn{2}{|c|}{ 55414715B } & \multicolumn{2}{|c|}{$30 /$ set/04 } & $\mathrm{F}$ & 64 & 56,0 & 1,50 & 24,9 & 1,50 baixo \\
\hline 5 SZS & \multicolumn{2}{|c|}{$55412755 \mathrm{~K}$} & \multicolumn{2}{|c|}{ 1/out/04 } & M & 54 & 86,0 & 1,70 & 29,8 & 1,97 baixo \\
\hline 6 OT & \multicolumn{2}{|c|}{$55417927 G$} & \multicolumn{2}{|c|}{$1 / \mathrm{dez} / 04$} & M & 56 & 57,0 & 1,58 & 22,8 & 1,57 mínimo \\
\hline 7 ASB & \multicolumn{2}{|c|}{$55419554 G$} & \multicolumn{2}{|c|}{ 11/jan/05 } & $M$ & 60 & 59,0 & 1,60 & 23,0 & 1,62 mínimo \\
\hline $8 \mathrm{MM}$ & \multicolumn{2}{|c|}{$5117111 \mathrm{C}$} & \multicolumn{2}{|c|}{ 16/jan/05 } & M & 74 & 68,0 & 1,72 & 23,0 & 1,80 baixo \\
\hline 9 JGA & \multicolumn{2}{|c|}{$55424428 B$} & \multicolumn{2}{|c|}{ 16/mar/05 } & $M$ & 47 & 99,6 & 1,69 & 34,9 & 2,10 baixo \\
\hline $10 \mathrm{FC}$ & \multicolumn{2}{|c|}{$55390420 \mathrm{~F}$} & \multicolumn{2}{|c|}{ 8/mar/05 } & M & 79 & 78,6 & 1,67 & 28,2 & 1,88 baixo \\
\hline 11 TJCR & \multicolumn{2}{|c|}{$55427939 \mathrm{G}$} & $11 /$ & $\mathrm{mai} / 05$ & $\mathrm{~F}$ & 75 & 48,0 & 1,52 & 20,8 & 1,42 baixo \\
\hline $12 \mathrm{VC}$ & 553905 & & $17 /$ & $\mathrm{mai} / 05$ & M & 39 & 78,0 & 1,70 & 27,0 & 1,88 mínimo \\
\hline 13 ILMG & 528518 & & & 7/jul/05 & $\mathrm{F}$ & 61 & 83,5 & 1,59 & 33,0 & 1,86 mínimo \\
\hline $14 \mathrm{RB}$ & 553964 & $\mathrm{OH}$ & $11 /$ & ago/05 & M & 65 & 98,3 & 1,63 & 37,0 & 2,03 baixo \\
\hline 15 MERC & 553970 & $4 \mathrm{H}$ & $16 /$ & ago/05 & $\mathrm{F}$ & 55 & 53,0 & 1,50 & 23,6 & 1,47 mínimo \\
\hline 16 EGM & 441000 & $31 \mathrm{~B}$ & $24 /$ & ago/05 & M & 66 & 69,0 & 1,65 & 25,3 & 1,74 baixo \\
\hline 17 ENS & 553971 & $3 \mathrm{H}$ & $29 /$ & ago/05 & M & 59 & 69,0 & 1,59 & 27,3 & 1,75 mínimo \\
\hline 18 SLC & 553192 & $37 \mathrm{C}$ & & /out/05 & M & 44 & 84,4 & 1,72 & 28,5 & 1,98 mínimo \\
\hline 19 ADF & 528814 & & $27 /$ & nov/05 & M & 69 & 71,4 & 1,71 & 24,4 & 1,83 baixo \\
\hline 20 JJS & 335840 & & & jan/06 & M & 67 & 67,0 & 1,66 & 24,3 & 1,75 baixo \\
\hline caso paciente & RM1 & & te1 & RM2 & ponte2 & RM3 & ponte3 & RM4 & ponte4 & \\
\hline $1 \mathrm{MS}$ & $\mathrm{DI}$ & PV & & $\overline{D A}$ & $\mathrm{MaD}$ & $\mathrm{CD}$ & PVS & & & \\
\hline $2 \mathrm{CCP}$ & DI & PV & & DA & $\mathrm{Ma}$ & & & & & \\
\hline 3 EAC & Mg2 & $\mathrm{Ma}$ & & DI & Ma & DA & $\mathrm{Ma}$ & $\mathrm{VP}(\mathrm{CD})$ & gastroepi & \\
\hline 4 ICMS & MgE & epi & astr & DI & Ma & DA & $\mathrm{Ma}$ & & & \\
\hline 5 SZS & VP & PV & & VP & PVS & $\mathrm{DA}$ & $\mathrm{MaE}$ & $\mathrm{MgE}$ & PVS & \\
\hline 6 OT & DI & epi & astr & DA & $\mathrm{Ma}$ & $\mathrm{VP}(C D)$ & $\mathrm{Rd}$ & & & \\
\hline 7 ASB & $\mathrm{MgE}$ & PV & & DA & $\mathrm{Ma}$ & & & & & \\
\hline $8 \mathrm{MM}$ & $\mathrm{MgE}$ & $\mathrm{Rd}$ & & DI & $\mathrm{Rd}$ & DA & $\mathrm{Ma}$ & & & \\
\hline 9 JGA & DI & $\mathrm{Rd}$ & & DA & $\mathrm{Ma}$ & & & & & \\
\hline $10 \mathrm{FC}$ & DI & PV & & $\mathrm{Mg}$ & PVS & DA & $\mathrm{Ma}$ & & & \\
\hline 11 TJCR & $\mathrm{MgE}$ & PV & & DA & $\mathrm{Ma}$ & & & & & \\
\hline 12 VC & $\mathrm{MgE}$ & $P V$ & & DA & $\mathrm{Ma}$ & & & & & \\
\hline 13 ILMG & $\mathrm{DA}$ & $\mathrm{Ma}$ & & CD & PVS & & & & & \\
\hline $14 \mathrm{RB}$ & $\mathrm{MgE}$ & $P V$ & & DI & PVS & $C D$ & PVS & DA & $\mathrm{Ma}$ & \\
\hline 15 MERC & $\mathrm{DA}$ & $\mathrm{Ma}$ & & $\mathrm{MgE}$ & PVS & CD & PVS & & & \\
\hline 16 EGM & $\mathrm{MgE}$ & $\mathrm{Ma}$ & & DI & $\mathrm{Ma}$ & DA & $\mathrm{Ma}$ & $C D$ & gastroepi & \\
\hline 17 ENS & $\mathrm{MgE}$ & $\mathrm{Ma}$ & & DI & Ma & DA & Ma & & & \\
\hline 18 SLC & VP & $\mathrm{Ma}$ & & $\mathrm{MgE}$ & $\mathrm{Ma}$ & Mg2 & $\mathrm{Ma}$ & & & \\
\hline 19 ADF & CD & $\mathrm{Ma}$ & & DI & $\mathrm{Ma}$ & $\mathrm{DA}$ & $\mathrm{Ma}$ & & & \\
\hline $20 \mathrm{JJS}$ & DI & $\mathrm{Ma}$ & & DA & $\mathrm{Ma}$ & & & & & \\
\hline
\end{tabular}




\begin{tabular}{|c|c|c|c|c|c|c|c|c|c|c|}
\hline CASO & RM & FC 0 & FC I & FCF & PAM 0 & PAM I & PAM F & PAPm 0 & PAPm I & $\overline{\text { PAPm F }}$ \\
\hline MS & DA2 & 77 & 75 & 74 & 63 & 70 & 64 & 28 & 28 & 25 \\
\hline $\mathrm{CCP}$ & DA2 & 60 & 60 & 95 & 62 & 62 & 51 & 19 & 19 & 19 \\
\hline EAC & DA3 & 76 & 74 & 73 & 79 & 79 & 73 & 21 & 19 & 18 \\
\hline ICMS & DA3 & 81 & 82 & 74 & 63 & 64 & 62 & 28 & 33 & 30 \\
\hline SZS & DA3 & 73 & 55 & 53 & 80 & 80 & 73 & 34 & 34 & 32 \\
\hline OT & DA2 & 75 & 70 & 70 & 66 & 72 & 68 & 30 & 31 & 28 \\
\hline ASB & DA2 & 80 & 81 & 83 & 72 & 65 & 72 & 30 & 26 & 31 \\
\hline MM & DA3 & 75 & 75 & 75 & 58 & 57 & 74 & 20 & 20 & 24 \\
\hline JGA & DA2 & 65 & 72 & 72 & 81 & 84 & 88 & 24 & 22 & 22 \\
\hline $\mathrm{FC}$ & DA3 & 117 & 103 & 71 & 76 & 67 & 66 & 34 & 27 & 32 \\
\hline TJCR & DA2 & 71 & 71 & 75 & 60 & 62 & 58 & 22 & 24 & 24 \\
\hline VC & DA2 & 74 & 72 & 68 & 70 & 74 & 72 & 27 & 26 & 27 \\
\hline ILMG & DA1 & 66 & 80 & 77 & 79 & 76 & 78 & 21 & 26 & 25 \\
\hline $\mathrm{RB}$ & DA4 & 79 & 83 & 81 & 60 & 71 & 68 & 18 & 21 & 22 \\
\hline MERC & DA1 & 102 & 102 & 94 & 83 & 82 & 64 & 31 & 39 & 31 \\
\hline EGM & DA3 & 91 & 82 & 90 & 79 & 80 & 80 & 25 & 33 & 32 \\
\hline ENS & DA3 & 89 & 87 & 86 & 75 & 82 & 76 & 34 & 38 & 35 \\
\hline ADF & DA3 & 59 & 59 & 59 & 67 & 66 & 70 & 21 & 23 & 23 \\
\hline JJS & DA2 & 68 & 74 & 77 & 60 & 74 & 63 & 22 & 27 & 28 \\
\hline MS & DI1 & 81 & 95 & 73 & 60 & 67 & 55 & 15 & 16 & 17 \\
\hline CCP & DI1 & 65 & 80 & 78 & 64 & 78 & 74 & 32 & 26 & 28 \\
\hline EAC & DI2 & 85 & 80 & 81 & 73 & 69 & 63 & 28 & 29 & 28 \\
\hline ICMS & DI2 & 60 & 73 & 75 & 61 & 63 & 66 & 27 & 28 & 30 \\
\hline OT & DI1 & 67 & 73 & 74 & 52 & 64 & 63 & 18 & 23 & 24 \\
\hline MM & DI2 & 50 & 58 & 57 & 92 & 79 & 84 & 26 & 21 & 30 \\
\hline JGA & DI1 & 69 & 98 & 100 & 60 & 65 & 75 & 27 & 25 & 30 \\
\hline FC & DI1 & 72 & 77 & 73 & 62 & 68 & 74 & 24 & 22 & 22 \\
\hline RB & DI2 & 70 & 69 & 91 & 64 & 70 & 71 & 27 & 24 & 25 \\
\hline EGM & DI2 & 80 & 74 & 82 & 89 & 89 & 81 & 42 & 43 & 46 \\
\hline ENS & DI2 & 62 & 64 & 62 & 76 & 57 & 66 & 23 & 19 & 22 \\
\hline ADF & DI2 & 63 & 68 & 69 & 76 & 56 & 53 & 29 & 23 & 25 \\
\hline JJS & DI1 & 69 & 69 & 70 & 65 & 89 & 65 & 25 & 37 & 31 \\
\hline EAC & Mg21 & 60 & 53 & 65 & 61 & 64 & 64 & 34 & 32 & 32 \\
\hline ICMS & $\mathrm{MgE} 1$ & 71 & 71 & 70 & 60 & 65 & 59 & 21 & 20 & 19 \\
\hline SZS & $\mathrm{MgE} 4$ & 49 & 60 & 47 & 65 & 67 & 66 & 29 & 33 & 32 \\
\hline ASB & MgE1 & 72 & 66 & 69 & 57 & 65 & 62 & 25 & 34 & 31 \\
\hline MM & MgE1 & 64 & 73 & 71 & 85 & 68 & 69 & 17 & 30 & 28 \\
\hline $\mathrm{FC}$ & MgE2 & 63 & 67 & 67 & 71 & 58 & 67 & 28 & 24 & 27 \\
\hline TJCR & $\mathrm{MgE} 1$ & 76 & 72 & 74 & 73 & 61 & 58 & 31 & 31 & 33 \\
\hline VC & $\mathrm{MgE} 1$ & 76 & 104 & 75 & 70 & 65 & 68 & 24 & 23 & 22 \\
\hline RB & $\mathrm{MgE} 1$ & 72 & 78 & 74 & 62 & 72 & 67 & 27 & 23 & 23 \\
\hline MERC & MgE2 & 84 & 82 & 79 & 75 & 57 & 52 & 29 & 23 & 26 \\
\hline EGM & $\mathrm{MgE} 1$ & 76 & 80 & 90 & 82 & 73 & 83 & 27 & 29 & 29 \\
\hline ENS & $\mathrm{MgE} 1$ & 72 & 85 & 78 & 57 & 71 & 68 & 17 & 22 & 27 \\
\hline SLC & MgE2 & 83 & 82 & 81 & 79 & 72 & 72 & 22 & 14 & 15 \\
\hline SLC & Mg23 & 81 & 78 & 85 & 72 & 73 & 82 & 15 & 19 & 20 \\
\hline MS & CD3 & 69 & 70 & 65 & 62 & 75 & 68 & 23 & 31 & 29 \\
\hline EAC & $\mathrm{VP}(C D) 4$ & 73 & 72 & 73 & 73 & 82 & 83 & 18 & 30 & 26 \\
\hline SZS & VP1 & 63 & 46 & 46 & 65 & 57 & 63 & 27 & 28 & 35 \\
\hline SZS & VP2 & 73 & 73 & 73 & 46 & 81 & 70 & 35 & 48 & 32 \\
\hline OT & $\mathrm{VP}(C D) 3$ & 80 & 76 & 79 & 85 & 71 & 72 & 29 & 26 & 28 \\
\hline ILMG & CD2 & 66 & 81 & 81 & 76 & 84 & 75 & 24 & 24 & 25 \\
\hline RB & CD3 & 82 & 86 & 83 & 70 & 78 & 70 & 25 & 29 & 28 \\
\hline MERC & CD3 & 79 & 82 & 82 & 52 & 68 & 58 & 26 & 27 & 24 \\
\hline EGM & CD4 & 90 & 81 & 81 & 80 & 71 & 67 & 32 & 25 & 24 \\
\hline SLC & DP1 & 83 & 90 & 82 & 73 & 80 & 83 & 22 & 22 & 23 \\
\hline ADF & CD1 & 48 & 62 & 65 & 72 & 60 & 65 & 18 & 15 & 18 \\
\hline
\end{tabular}




\begin{tabular}{|c|c|c|c|c|c|c|c|c|c|c|}
\hline CASO & RM & POAP 0 & POAP I & PoAP F & PVC 0 & PVC I & PVCF & Sv02 0 & SvO2I & Sv02 F \\
\hline$\overline{M S}$ & DA2 & 11 & 17 & 15 & 16 & 22 & 18 & 73 & 67 & 66 \\
\hline $\mathrm{CCP}$ & DA2 & 10 & 10 & 10 & 6 & 6 & 6 & 74 & 74 & 63 \\
\hline EAC & DA3 & 15 & 14 & 16 & 11 & 10 & 16 & 81 & 81 & 81 \\
\hline ICMS & DA3 & 18 & 22 & 19 & 15 & 15 & 14 & 74 & 73 & 74 \\
\hline SZS & DA3 & 30 & 30 & 28 & 21 & 18 & 31 & 59 & 59 & 55 \\
\hline OT & DA2 & 24 & 25 & 24 & 19 & 18 & 18 & 73 & 75 & 77 \\
\hline ASB & DA2 & 21 & 21 & 24 & 7 & 10 & 10 & 71 & 73 & 67 \\
\hline MM & DA3 & 15 & 15 & 17 & 10 & 10 & 11 & 59 & 59 & 55 \\
\hline JGA & DA2 & 6 & 13 & 14 & 10 & 9 & 13 & 80 & 78 & 77 \\
\hline FC & DA3 & 24 & 20 & 24 & 20 & 14 & 16 & 83 & 88 & 81 \\
\hline TJCR & DA2 & 14 & 14 & 15 & 4 & 7 & 6 & 77 & 77 & 75 \\
\hline VC & DA2 & 21 & 19 & 13 & 14 & 18 & 15 & 76 & 74 & 72 \\
\hline ILMG & DA1 & 13 & 17 & 18 & 8 & 13 & 14 & 82 & 82 & 81 \\
\hline $\mathrm{RB}$ & DA4 & 15 & 15 & 17 & 9 & 10 & 12 & 70 & 73 & 75 \\
\hline MERC & DA1 & 27 & 30 & 29 & 22 & 26 & 18 & 78 & 83 & 81 \\
\hline EGM & DA3 & 24 & 27 & 24 & 18 & 17 & 16 & 86 & 83 & 84 \\
\hline ENS & DA3 & 25 & 27 & 25 & 7 & 7 & 7 & 76 & 83 & 77 \\
\hline ADF & DA3 & 15 & 16 & 16 & 10 & 11 & 10 & 76 & 76 & 75 \\
\hline JJS & DA2 & 14 & 15 & 11 & 20 & 21 & 16 & 66 & 66 & 73 \\
\hline MS & DI1 & 8 & 9 & 8 & 9 & 7 & 7 & 82 & 72 & 74 \\
\hline CCP & DI1 & 22 & 20 & 19 & 17 & 10 & 11 & 80 & 83 & 86 \\
\hline EAC & DI2 & 14 & 15 & 18 & 12 & 14 & 15 & 84 & 81 & 81 \\
\hline ICMS & DI2 & 24 & 22 & 24 & 18 & 19 & 19 & 83 & 77 & 73 \\
\hline OT & DI1 & 8 & 10 & 10 & 12 & 15 & 17 & 53 & 55 & 56 \\
\hline MM & DI2 & 15 & 13 & 15 & 16 & 12 & 13 & - & - & - \\
\hline JGA & DI1 & 17 & 16 & 20 & 10 & 12 & 10 & 91 & 91 & 91 \\
\hline FC & DI1 & 16 & 18 & 17 & 15 & 14 & 14 & 65 & 72 & 76 \\
\hline RB & DI2 & 20 & 22 & 24 & 17 & 18 & 18 & 78 & 83 & 86 \\
\hline EGM & DI2 & 25 & 29 & 26 & 9 & 9 & 10 & 67 & 65 & 87 \\
\hline ENS & DI2 & 16 & 15 & 16 & 6 & 10 & 10 & 87 & 79 & 76 \\
\hline ADF & DI2 & 21 & 18 & 19 & 14 & 16 & 17 & 70 & 63 & 65 \\
\hline JJS & DI1 & 19 & 30 & 26 & 17 & 21 & 20 & - & - & - \\
\hline EAC & Mg21 & 26 & 22 & 22 & 21 & 17 & 17 & 83 & 82 & 80 \\
\hline ICMS & $\mathrm{MgE} 1$ & 10 & 9 & 7 & 9 & 8 & 8 & 77 & 78 & 80 \\
\hline SZS & $\mathrm{MgE} 4$ & 24 & 25 & 27 & 27 & 27 & 26 & 66 & 68 & 67 \\
\hline ASB & MgE1 & 10 & 20 & 18 & 19 & 21 & 23 & 76 & 60 & 58 \\
\hline MM & $\mathrm{MgE} 1$ & 6 & 22 & 21 & 9 & 23 & 22 & 67 & 59 & 57 \\
\hline $\mathrm{FC}$ & MgE2 & 13 & 12 & 14 & 10 & 7 & 7 & 86 & 86 & 87 \\
\hline TJCR & $\mathrm{MgE} 1$ & 24 & 23 & 25 & 10 & 15 & 15 & 79 & 67 & 61 \\
\hline VC & MgE1 & 18 & 19 & 18 & 18 & 18 & 17 & 80 & 68 & 67 \\
\hline RB & $\mathrm{MgE} 1$ & 18 & 17 & 16 & 11 & 13 & 12 & 76 & 71 & 75 \\
\hline MERC & MgE2 & 22 & 20 & 23 & 19 & 19 & 21 & 78 & 78 & 79 \\
\hline EGM & $\mathrm{MgE} 1$ & 24 & 22 & 22 & 16 & 21 & 20 & 89 & 82 & 84 \\
\hline ENS & $\mathrm{MgE} 1$ & 14 & 10 & 15 & 11 & 7 & 7 & 76 & 88 & 65 \\
\hline SLC & MgE2 & 16 & 6 & 9 & 9 & 6 & 6 & 85 & 85 & 87 \\
\hline SLC & Mg23 & 9 & 14 & 16 & 6 & 6 & 8 & 86 & 85 & 85 \\
\hline MS & CD3 & 11 & 21 & 21 & 17 & 25 & 24 & 70 & 66 & 62 \\
\hline EAC & $\mathrm{VP}(\mathrm{CD}) 4$ & 16 & 26 & 24 & 16 & 18 & 16 & 81 & 83 & 83 \\
\hline SZS & VP1 & 21 & 24 & 29 & 23 & 21 & 29 & 77 & 65 & 62 \\
\hline SZS & VP2 & 30 & 40 & 36 & 24 & 23 & 22 & 52 & 65 & 60 \\
\hline OT & $\mathrm{VP}(C D) 3$ & 21 & 20 & 22 & 18 & 18 & 21 & 79 & 78 & 79 \\
\hline ILMG & CD2 & 12 & 16 & 16 & 10 & 16 & 14 & 72 & 71 & 68 \\
\hline RB & CD3 & 20 & 25 & 23 & 17 & 23 & 22 & 69 & 81 & 85 \\
\hline MERC & CD3 & 23 & 25 & 24 & 21 & 24 & 24 & 79 & 78 & 75 \\
\hline EGM & CD4 & 24 & 23 & 22 & 16 & 17 & 16 & 84 & 82 & 81 \\
\hline SLC & DP1 & 16 & 17 & 17 & 10 & 13 & 12 & 88 & 87 & 85 \\
\hline ADF & CD1 & 11 & 11 & 15 & 6 & 4 & 4 & 83 & 88 & 88 \\
\hline
\end{tabular}




\begin{tabular}{|c|c|c|c|c|c|c|c|c|c|c|}
\hline CASO & RM & $\mathrm{DCl} 0$ & $\mathrm{DCII}$ & $\mathrm{DClF}$ & DCS 0 & DCS I & DCS F & VDF 0 & VDFI & VDFF \\
\hline MS & DA2 & 5,7 & 4,7 & 4,9 & 7,3 & 7,8 & 7,1 & 238 & 228 & 228 \\
\hline $\mathrm{CCP}$ & DA2 & 3,1 & 3,7 & 2,9 & 4,3 & 4,2 & 4,0 & 253 & 251 & 242 \\
\hline EAC & DA3 & 3,9 & 4,2 & 4,0 & 4,4 & 4,6 & 4,6 & 213 & 178 & 175 \\
\hline ICMS & DA3 & 2,3 & 3,0 & 3,5 & 4,4 & 4,2 & 4,5 & 165 & 173 & 164 \\
\hline SZS & DA3 & 5,3 & 5,3 & 5,3 & 7,5 & 7,5 & 8,1 & 232 & 244 & 238 \\
\hline OT & DA2 & 3,0 & 3,5 & 4,1 & 4,7 & 4,1 & 3,8 & 193 & 195 & 188 \\
\hline ASB & DA2 & 3,9 & 2,3 & 2,9 & 4,4 & 4,5 & 4,2 & 225 & 232 & 237 \\
\hline MM & DA3 & 4,9 & 4,9 & 4,9 & 6,8 & 6,8 & 7,4 & 212 & 223 & 218 \\
\hline$J G A$ & DA2 & 5,9 & 4,6 & 4,6 & 6,3 & 6,1 & 5,9 & 311 & 298 & 271 \\
\hline $\mathrm{FC}$ & DA3 & 3,9 & 5,3 & 4,3 & 3,9 & 5,8 & 6,2 & - & - & - \\
\hline TJCR & DA2 & 4,0 & 2,4 & 2,7 & 4,4 & 4,3 & 3,8 & 212 & 206 & 209 \\
\hline VC & DA2 & 8,8 & 6,4 & 5,5 & 5,8 & 6,0 & 6,0 & 203 & 207 & 209 \\
\hline ILMG & DA1 & 3,9 & 5,4 & 6,0 & 5,2 & 5,0 & 4,8 & 249 & 186 & 264 \\
\hline $\mathrm{RB}$ & DA4 & 4,5 & 4,5 & 4,5 & 4,1 & 3,9 & 3,9 & 114 & 126 & 138 \\
\hline MERC & DA1 & 5,1 & 5,1 & 4,6 & 4,9 & 6,8 & 5,9 & 263 & 275 & 368 \\
\hline EGM & DA3 & 4,7 & 5,0 & 4,7 & 4,2 & 4,0 & 4,2 & 162 & 153 & 153 \\
\hline ENS & DA3 & 3,9 & 3,5 & 4,6 & 3,7 & 4,4 & 3,9 & 179 & 182 & 175 \\
\hline ADF & DA3 & 3,3 & 3,8 & 3,7 & 7,1 & 7,7 & 7,9 & 271 & 264 & 258 \\
\hline JJS & DA2 & 2,8 & 4,6 & 3,2 & 3,3 & 3,2 & 3,3 & 167 & 245 & 238 \\
\hline MS & DI1 & 4,4 & 5,2 & 5,7 & 4,4 & 8,0 & 7,3 & 233 & 243 & 249 \\
\hline CCP & DI1 & 5,1 & 3,1 & 3,1 & 4,2 & 4,6 & 4,6 & 232 & 237 & 241 \\
\hline EAC & DI2 & 4,8 & 6,4 & 6,4 & 6,8 & 6,3 & 5,9 & 234 & 211 & 229 \\
\hline ICMS & DI2 & 4,9 & 4,7 & 4,1 & 4,5 & 4,5 & 4,7 & 190 & 198 & 193 \\
\hline OT & DI1 & 4,1 & 3,3 & 3,0 & 4,9 & 4,7 & 4,7 & 293 & 290 & 275 \\
\hline MM & DI2 & 5,2 & 5,6 & 5,4 & 7,7 & 7,2 & 7,0 & 309 & 326 & 265 \\
\hline$J G A$ & DI1 & 2,3 & 2,5 & 2,7 & 6,9 & 6,5 & 5,7 & - & - & - \\
\hline $\mathrm{FC}$ & DI1 & 3,9 & 5,1 & 6,2 & 7,5 & 7,3 & 7,0 & 144 & 152 & 162 \\
\hline $\mathrm{RB}$ & DI2 & 6,1 & 5,7 & 3,7 & 4,9 & 4,7 & 4,5 & 153 & 157 & 162 \\
\hline EGM & DI2 & 4,4 & 4,4 & 4,7 & 4,4 & 4,4 & 4,2 & 175 & 177 & 179 \\
\hline ENS & DI2 & 5,4 & 4,0 & 3,9 & 6,8 & 6,1 & 5,1 & 295 & 284 & 273 \\
\hline ADF & DI2 & 4,4 & 4,8 & 4,2 & 8,1 & 7,3 & 7,0 & 278 & 210 & 210 \\
\hline JJS & DI1 & 5,1 & 2,6 & 2,6 & 5,4 & 6,5 & 6,1 & 173 & 163 & 164 \\
\hline EAC & Mg21 & 2,8 & 4,2 & 4,8 & 7,7 & 7,4 & 6,8 & 245 & 232 & 232 \\
\hline ICMS & MgE1 & 3,8 & 3,5 & 3,3 & 4,1 & 3,9 & 3,9 & 204 & 201 & 195 \\
\hline SZS & $\mathrm{MgE} 4$ & 4,5 & 3,7 & 3,5 & 4,3 & 4,3 & 4,3 & 201 & 201 & 201 \\
\hline ASB & $\mathrm{MgE} 1$ & 4,7 & 1,9 & 2,6 & 5,0 & 4,4 & 4,2 & 228 & 217 & 245 \\
\hline MM & $\mathrm{MgE} 1$ & 6,7 & 4,7 & 7,9 & 10,1 & 9,7 & 10,3 & 398 & 270 & 320 \\
\hline $\mathrm{FC}$ & MgE2 & 4,7 & 3,4 & 4,9 & 7,0 & 6,0 & 5,6 & - & - & - \\
\hline TJCR & MgE1 & 2,0 & 1,3 & 1,3 & 4,1 & 4,0 & 4,0 & 187 & 193 & 193 \\
\hline VC & $\mathrm{MgE} 1$ & 7,5 & 6,8 & 6,6 & 8,5 & 6,8 & 6,6 & 199 & 182 & 184 \\
\hline RB & MgE1 & 7,3 & 5,1 & 5,1 & 6,3 & 4,9 & 4,9 & 262 & 158 & 158 \\
\hline MERC & MgE2 & 4,6 & 1,6 & 1,8 & 5,3 & 5,6 & 3,5 & 403 & 435 & 263 \\
\hline EGM & MgE1 & 7,7 & 5,4 & 4,9 & 5,9 & 6,4 & 6,3 & 190 & 205 & 205 \\
\hline ENS & $\mathrm{MgE} 1$ & 4,6 & 3,9 & 5,4 & 5,6 & 6,7 & 6,8 & 210 & 182 & 175 \\
\hline SLC & MgE2 & 5,7 & 5,9 & 5,3 & 5,1 & 5,3 & 4,8 & 309 & 315 & 339 \\
\hline SLC & Mg23 & 5,3 & 4,8 & 4,6 & 5,9 & 5,9 & 5,5 & 303 & 303 & 293 \\
\hline MS & CD3 & 5,7 & 5,4 & 4,2 & 5,4 & 5,7 & 4,9 & 184 & 202 & 179 \\
\hline EAC & $\mathrm{VP}(\mathrm{CD}) 4$ & 5,0 & 4,0 & 4,8 & 5,9 & 5,7 & 5,9 & 206 & 236 & 226 \\
\hline SZS & VP1 & 3,9 & 3,9 & 4,1 & 6,1 & 6,1 & 6,1 & 187 & 189 & 203 \\
\hline SZS & VP2 & 2,8 & 3,0 & 3,0 & 5,7 & 5,7 & 5,7 & 225 & 213 & 217 \\
\hline OT & $\operatorname{VP}(C D) 3$ & 5,2 & 3,6 & 4,1 & 3,6 & 3,6 & 3,6 & 185 & 179 & 181 \\
\hline ILMG & CD2 & 6,9 & 2,8 & 2,6 & 5,2 & 4,8 & 4,8 & 266 & 270 & 260 \\
\hline RB & CD3 & 5,9 & 4,7 & 5,1 & 3,9 & 3,9 & 3,7 & 134 & 132 & 144 \\
\hline MERC & CD3 & 1,8 & 3,2 & 2,5 & 3,5 & 4,7 & 2,9 & 263 & 412 & 362 \\
\hline EGM & CD4 & 4,7 & 4,5 & 3,5 & 4,2 & 4,4 & 4,2 & 153 & 148 & 153 \\
\hline SLC & DP1 & 5,9 & 5,7 & 5,7 & 7,7 & 7,9 & 7,7 & 360 & 368 & 364 \\
\hline ADF & CD1 & 5,3 & 4,6 & 5,1 & 7,0 & 7,1 & 7,7 & 309 & 295 & 282 \\
\hline
\end{tabular}




\begin{tabular}{|c|c|c|c|c|c|c|c|c|c|c|}
\hline CASO & RM & FSA 0 & FSA I & FSA F & DCDE 0 & DCDE I & DCDE F & TEVEc 0 & TEVEc I & TEVEc $F$ \\
\hline$\overline{M S}$ & DA2 & 5,7 & 3,7 & 3,4 & 8,2 & 5,3 & 4,9 & 363 & 388 & 394 \\
\hline $\mathrm{CCP}$ & DA2 & 2,4 & 2,4 & 1,7 & 3,4 & 3,4 & 2,4 & 313 & 333 & 305 \\
\hline EAC & DA3 & 1,9 & 1,9 & 2,3 & 2,7 & 2,7 & 3,3 & 348 & 335 & 352 \\
\hline ICMS & DA3 & 2,3 & 2,1 & 1,9 & 3,3 & 3,0 & 2,7 & 339 & 354 & 329 \\
\hline SZS & DA3 & 4,3 & 4,3 & 5,2 & 6,1 & 6,1 & 7,4 & 363 & 363 & 371 \\
\hline OT & DA2 & 2,3 & 4,2 & 2,5 & 3,3 & 6,0 & 3,6 & 447 & 403 & 387 \\
\hline ASB & DA2 & 2,0 & 1,9 & 1,6 & 2,9 & 2,7 & 2,3 & 317 & 322 & 291 \\
\hline MM & DA3 & 4,3 & 4,3 & 5,2 & 6,1 & 6,1 & 7,4 & 363 & 363 & 371 \\
\hline JGA & DA2 & 3,7 & 3,6 & 3,2 & 5,3 & 5,1 & 4,6 & 307 & 328 & 320 \\
\hline $\mathrm{FC}$ & DA3 & 1,5 & 1,8 & 1,3 & 2,1 & 2,6 & 1,9 & 328 & 363 & 402 \\
\hline TJCR & DA2 & 1,6 & 1,4 & 1,4 & 2,3 & 2,0 & 2,0 & 347 & 347 & 358 \\
\hline VC & DA2 & 2,7 & 1,9 & 2,3 & 3,9 & 2,7 & 3,3 & 353 & 322 & 374 \\
\hline ILMG & DA1 & 3,2 & 3,9 & 3,5 & 4,6 & 5,6 & 5,0 & 351 & 384 & 430 \\
\hline $\mathrm{RB}$ & DA4 & 3,4 & 4,8 & 5,0 & 4,9 & 6,9 & 7,2 & 248 & 368 & 535 \\
\hline MERC & DA1 & 4,0 & 2,8 & 2,6 & 5,7 & 4,0 & 3,7 & 438 & 380 & 446 \\
\hline EGM & DA3 & 3,0 & 2,4 & 2,2 & 4,3 & 3,4 & 3,1 & 322 & 295 & 299 \\
\hline ENS & DA3 & 2,4 & 2,9 & 2,8 & 3,4 & 4,1 & 4,0 & 375 & 402 & 406 \\
\hline ADF & DA3 & 3,7 & 3,2 & 3,7 & 5,3 & 4,6 & 5,3 & 318 & 329 & 350 \\
\hline JJS & DA2 & 3,4 & 4,1 & 5,7 & 2,1 & 2,7 & 2,7 & 339 & 427 & 363 \\
\hline MS & DI1 & 3,3 & 2,3 & 2,4 & 4,9 & 5,9 & 8,2 & 392 & 333 & 333 \\
\hline CCP & DI1 & 0,9 & 3,4 & 5,2 & 4,7 & 3,3 & 3,4 & 180 & 386 & 417 \\
\hline EAC & DI2 & 2,2 & 2,1 & 1,9 & 1,3 & 4,9 & 7,4 & 323 & 342 & 348 \\
\hline ICMS & DI2 & 2,7 & 1,8 & 2,3 & 3,1 & 3,0 & 2,7 & 491 & 395 & 447 \\
\hline OT & DI1 & 3,1 & 2,5 & 3,4 & 3,9 & 2,6 & 3,3 & 324 & 253 & 278 \\
\hline MM & DI2 & 1,7 & 2,0 & 1,6 & 4,4 & 3,6 & 4,9 & 284 & 273 & 381 \\
\hline JGA & DI1 & 4,5 & 2,8 & 4,3 & 2,4 & 2,9 & 2,3 & 351 & 325 & 447 \\
\hline $\mathrm{FC}$ & DI1 & 2,5 & 5,0 & 4,9 & 6,4 & 4,0 & 6,1 & 325 & 308 & 318 \\
\hline $\mathrm{RB}$ & DI2 & 2,5 & 3,0 & 3,0 & 3,6 & 7,2 & 7,0 & 284 & 303 & 322 \\
\hline EGM & DI2 & 2,9 & 2,6 & 2,6 & 3,6 & 4,3 & 4,3 & 449 & 405 & 400 \\
\hline ENS & DI2 & 2,2 & 2,9 & 3,4 & 4,1 & 3,7 & 3,7 & 379 & 247 & 368 \\
\hline ADF & DI2 & 2,3 & 1,4 & 1,5 & 3,1 & 4,1 & 4,9 & 278 & 221 & 220 \\
\hline JJS & Dl1 & 1,5 & 1,9 & 1,9 & 3,3 & 2,0 & 2,1 & 220 & 331 & 270 \\
\hline EAC & Mg21 & 1,3 & 1,1 & 0,9 & 1,9 & 1,6 & 1,3 & 246 & 203 & 180 \\
\hline ICMS & MgE1 & 2,9 & 2,2 & 2,1 & 4,1 & 3,1 & 3,0 & 381 & 348 & 400 \\
\hline SZS & $\mathrm{MgE} 4$ & 1,5 & 1,0 & 0,7 & 2,1 & 1,4 & 1,0 & 303 & 299 & 391 \\
\hline ASB & $\mathrm{MgE} 1$ & 3,0 & 1,2 & 1,4 & 4,3 & 1,7 & 2,0 & 369 & 273 & 310 \\
\hline MM & $\mathrm{MgE} 1$ & 2,7 & 3,8 & 3,4 & 3,9 & 5,4 & 4,9 & 291 & 412 & 393 \\
\hline $\mathrm{FC}$ & MgE2 & 3,1 & 1,0 & 1,3 & 4,4 & 1,4 & 1,9 & 454 & 269 & 491 \\
\hline TJCR & $\mathrm{MgE} 1$ & 0,8 & 0,9 & 0,7 & 1,1 & 1,3 & 1,0 & 313 & 269 & 249 \\
\hline VC & $\mathrm{MgE} 1$ & 5,1 & 1,9 & 1,2 & 7,3 & 2,7 & 1,7 & 328 & 380 & 315 \\
\hline RB & MgE1 & 6,1 & 5,2 & 4,8 & 8,7 & 7,4 & 6,9 & 341 & 367 & 375 \\
\hline MERC & MgE2 & 2,6 & 1,7 & 1,6 & 3,7 & 2,4 & 2,3 & 446 & 421 & 399 \\
\hline EGM & $\mathrm{MgE} 1$ & 2,1 & 1,6 & 3,1 & 3,0 & 2,3 & 4,4 & 347 & 249 & 312 \\
\hline ENS & $\mathrm{MgE} 1$ & 2,8 & 1,3 & 2,4 & 4,0 & 1,9 & 3,4 & 342 & 349 & 418 \\
\hline SLC & MgE2 & 2,6 & 3,3 & 3,1 & 3,7 & 4,7 & 4,4 & 355 & 370 & 372 \\
\hline SLC & Mg23 & 3,3 & 1,6 & 1,3 & 4,7 & 2,3 & 1,9 & 372 & 412 & 381 \\
\hline MS & CD3 & 3,9 & 4,7 & 3,3 & 5,6 & 6,7 & 4,7 & 449 & 369 & 340 \\
\hline EAC & $\mathrm{VP}(\mathrm{CD}) 4$ & 1,5 & 1,0 & 3,6 & 2,1 & 1,4 & 5,1 & 368 & 225 & 348 \\
\hline SZS & VP1 & 3,7 & 2,6 & 1,2 & 5,3 & 3,7 & 1,7 & 345 & 405 & 323 \\
\hline SZS & VP2 & 0,6 & 2,0 & 1,6 & 0,9 & 2,9 & 2,3 & 220 & 228 & 333 \\
\hline OT & $\mathrm{VP}(C D) 3$ & 3,7 & 3,3 & 3,4 & 5,3 & 4,7 & 4,9 & 361 & 372 & 375 \\
\hline ILMG & CD2 & 1,8 & 2,0 & 2,5 & 2,6 & 2,9 & 3,6 & 315 & 365 & 408 \\
\hline $\mathrm{RB}$ & CD3 & 3,6 & 4,4 & 4,7 & 5,1 & 6,3 & 6,7 & 263 & 306 & 300 \\
\hline MERC & CD3 & 1,6 & 2,4 & 1,9 & 2,3 & 3,4 & 2,7 & 399 & 437 & 411 \\
\hline EGM & CD4 & 2,2 & 2,0 & 1,7 & 3,1 & 2,9 & 2,4 & 299 & 290 & 280 \\
\hline SLC & DP1 & 1,9 & 1,5 & 1,6 & 2,7 & 2,1 & 2,3 & 269 & 300 & 306 \\
\hline ADF & CD1 & 3,1 & 1,9 & 3,0 & 4,4 & 2,7 & 4,3 & 307 & 275 & 331 \\
\hline
\end{tabular}




\begin{tabular}{|c|c|c|c|c|c|c|c|}
\hline CASO & RM & PV 0 & PV I & PV F & A Máx 0 & A Máx I & A Máx F \\
\hline MS & DA2 & 70 & 55 & 55 & 14,0 & 10,5 & 11,0 \\
\hline CCP & DA2 & 35 & 30 & 25 & 9,1 & 5,2 & 4,5 \\
\hline EAC & DA3 & 28 & 26 & 27 & 3,6 & 2,5 & 3,8 \\
\hline ICMS & DA3 & 36 & 35 & 36 & 16,4 & 13,3 & 15,3 \\
\hline SZS & DA3 & 42 & 42 & 32 & 10,4 & 10,4 & 6,5 \\
\hline OT & DA2 & 40 & 48 & 41 & 5,7 & 10,8 & 6,8 \\
\hline ASB & DA2 & 27 & 33 & 29 & 8,3 & 8,7 & 10,2 \\
\hline MM & DA3 & 42 & 42 & 32 & 10,4 & 10,4 & 6,5 \\
\hline JGA & DA2 & 58 & 44 & 46 & 11,7 & 10,6 & 13,8 \\
\hline FC & DA3 & 30 & 26 & 25 & 7,1 & 8,5 & 2,7 \\
\hline TJCR & DA2 & 25 & 25 & 25 & 5,0 & 4,5 & 5,1 \\
\hline VC & DA2 & 62 & 57 & 67 & 16,6 & 8,5 & 11,5 \\
\hline ILMG & DA1 & 47 & 51 & 51 & 11,9 & 10,8 & 10,1 \\
\hline $\mathrm{RB}$ & DA4 & 40 & 47 & 49 & 8,9 & 7,4 & 8,8 \\
\hline MERC & DA1 & 58 & 64 & 46 & 9,2 & 16,0 & 7,4 \\
\hline EGM & DA3 & 73 & 62 & 61 & 12,3 & 20,2 & 21,5 \\
\hline ENS & DA3 & 37 & 38 & 38 & 6,5 & 7,9 & 7,9 \\
\hline ADF & DA3 & 51 & 45 & 53 & 11,3 & 6,9 & 6,6 \\
\hline JJS & DA2 & 49 & 58 & 70 & 8,1 & 13,2 & 14,0 \\
\hline MS & DI1 & 39 & 43 & 49 & 7,6 & 9,7 & 12,3 \\
\hline CCP & DI1 & 31 & 29 & 29 & 4,7 & 3,7 & 3,2 \\
\hline EAC & DI2 & 36 & 36 & 36 & 20,1 & 17,2 & 16,4 \\
\hline ICMS & DI2 & 43 & 37 & 40 & 6,8 & 6,4 & 5,7 \\
\hline OT & DI1 & 60 & 43 & 43 & 21,9 & 11,0 & 10,9 \\
\hline MM & DI2 & 31 & 46 & 32 & 5,8 & 7,6 & 6,0 \\
\hline JGA & DI1 & 31 & 26 & 37 & 4,7 & 3,4 & 4,2 \\
\hline FC & DI1 & 36 & 48 & 48 & 6,0 & 6,2 & 7,3 \\
\hline RB & $\mathrm{DI} 2$ & 61 & 82 & 73 & 23,1 & 17,6 & 12,3 \\
\hline EGM & $\mathrm{DI} 2$ & 37 & 41 & 40 & 7,3 & 8,6 & 7,0 \\
\hline ENS & $\mathrm{DI} 2$ & 55 & 52 & 51 & 8,8 & 16,9 & 12,4 \\
\hline ADF & DI2 & 37 & 22 & 21 & 7,8 & 7,6 & 8,4 \\
\hline JJS & DI1 & 21 & 28 & 23 & 8,4 & 5,5 & 7,0 \\
\hline EAC & Mg21 & 47 & 28 & 31 & 16,1 & 4,9 & 4,7 \\
\hline ICMS & $\mathrm{MgE} 1$ & 41 & 39 & 40 & 11,5 & 10,9 & 14,9 \\
\hline SZS & $\mathrm{MgE4}$ & 55 & 54 & 53 & 10,2 & 9,7 & 8,5 \\
\hline ASB & $\mathrm{MgE} 1$ & 44 & 28 & 30 & 10,8 & 5,1 & 6,0 \\
\hline MM & $\mathrm{MgE} 1$ & 38 & 56 & 52 & 14,8 & 19,1 & 9,7 \\
\hline $\mathrm{FC}$ & MgE2 & 25 & 21 & 24 & 3,3 & 4,2 & 2,7 \\
\hline TJCR & MgE1 & 17 & 17 & 16 & 4,7 & 3,7 & 5,4 \\
\hline VC & MgE1 & 85 & 32 & 29 & 24,2 & 8,5 & 7,2 \\
\hline RB & MgE1 & 67 & 51 & 44 & 24,1 & 12,2 & 9,6 \\
\hline MERC & MgE2 & 46 & 30 & 28 & 7,4 & 5,6 & 4,7 \\
\hline EGM & $\mathrm{MgE} 1$ & 50 & 69 & 79 & 9,8 & 21,6 & 22,4 \\
\hline ENS & MgE1 & 62 & 52 & 50 & 10,9 & 10,5 & 9,5 \\
\hline SLC & $\mathrm{MgE2}$ & 55 & 63 & 60 & 8,6 & 9,3 & 7,4 \\
\hline SLC & Mg23 & 60 & 42 & 44 & 7,4 & 6,6 & 7,2 \\
\hline MS & CD3 & 61 & 57 & 48 & 12,9 & 14,8 & 11,9 \\
\hline EAC & $\mathrm{VP}(\mathrm{CD}) 4$ & 27 & 29 & 32 & 3,8 & 6,1 & 5,8 \\
\hline SZS & VP1 & 51 & 39 & 47 & 10,4 & 7,4 & 8,4 \\
\hline SZS & VP2 & 26 & 40 & 35 & 3,6 & 6,8 & 8,9 \\
\hline OT & $\operatorname{VP}(C D) 3$ & 43 & 40 & 41 & 8,5 & 7,1 & 6,8 \\
\hline ILMG & CD2 & 30 & 27 & 28 & 6,3 & 5,0 & 5,5 \\
\hline $\mathrm{RB}$ & CD3 & 45 & 52 & 55 & 6,7 & 8,2 & 8,7 \\
\hline MERC & CD3 & 28 & 42 & 41 & 4,7 & 8,6 & 8,0 \\
\hline EGM & CD4 & 61 & 76 & 54 & 21,5 & 20,9 & 9,4 \\
\hline SLC & DP1 & 35 & 57 & 55 & 6,5 & 21,9 & 19,7 \\
\hline ADF & CD1 & 53 & 64 & 64 & 9,7 & 21,5 & 7,8 \\
\hline
\end{tabular}




\section{II- Termo de Consentimento}

HOSPITAL DAS CLÍNICAS

DA

FACULDADE DE MEDICINA DA UNIVERSIDADE DE SÃO PAULO

TERMO DE CONSENTIMENTO LIVRE E ESCLARECIDO

I - DADOS DE IDENTIFICAÇÃO DO SUJEITO DA PESQUISA OU RESPONSÁVEL LEGAL

1. NOME DO PACIENTE

DOCUMENTO DE IDENTIDADE № :

SEXO :M( ) F ( )

DATA NASCIMENTO:

ENDEREÇO

№ $\quad$ APTO:

BAIRRO:

CIDADE

CEP:

TELEFONE: DDD ( )

2. RESPONSÁVEL LEGAL

NATUREZA (grau de parentesco, tutor, curador etc.)

DOCUMENTO DE IDENTIDADE:

SEXO: $M() F()$

DATA NASCIMENTO:

ENDEREÇO:

CIDADE: CEP: $\stackrel{2}{N o}$

II - DADOS SOBRE A PESQUISA CIENTÍFICA

1. TÍTULO DO PROTOCOLO DE PESQUISA

ANÁLISE HEMODINÃMICA E DO TRANSPORTE DE OXIGÊNIO DURANTE A REVASCULARIZAÇÃO DO MIOCÁRDIO SEM UTILIZAÇÃO DE CIRCULAÇÃO EXTRA CORPÓREA PESQUISADOR RESPONSÁVEL: Dra Maria José Carvalho Carmona CARGO/FUNÇÃO: Médica supervisora INSCRIÇÃO CONSELHO REGIONAL № 54.142 UNIDADE DO HCFMUSP: Instituto do Coração HCFMUSP

2. AVALIAÇÃO DO RISCO DA PESQUISA:

$\begin{array}{lll}\text { SEM RISCO } & \text { RISCO MÍNIMO } x & \text { RISCO MÉDIO } \\ \text { RISCO BAIXO } & \text { RISCO MAIOR } & \end{array}$

(probabilidade de que o indivíduo sofra algum dano como consequência imediata ou tardia do estudo)

3. DURAÇÃO DA PESQUISA : 24 meses 


\section{III - REGISTRO DAS EXPLICAÇÕES DO PESQUISADOR AO PACIENTE OU SEU REPRESENTANTE LEGAL SOBRE A PESQUISA, CONSIGNANDO:}

1- justificativa e os objetivos da pesquisa ; 2. procedimentos que serão utilizados e propósitos, incluindo a identificação dos procedimentos que são experimentais; 3. desconfortos e riscos esperados; 4. benefícios que poderão ser obtidos; 5 . procedimentos alternativos que possam ser vantajosos para o indivíduo.

1. Justificativa e os objetivos da pesquisa. Para que o senhor(a) possa ser submetido a cirurgia cardíaca, há necessidade de realização de anestesia geral. Nas cirurgias de revascularização miocardica existem basicamente duas formas para realizá-las. A primeira forma é a mais comum e utiliza a circulação extracorporea, onde um aparelho oxigena e circula o sangue, substituindo temporariamente o coração e os pulmões para que as anastomoses (pontes) podam ser realizados sem grandes dificuldades técnicas. A segunda forma é a relização da revascularização sem circulaçao extracorporea, mas que implica em mudanças na posição do coração para a realização das pontes. Estas mudanças na posição fazem com que o coração e em geral a circulaçao do organismo possam sofrer alterações transitórias. Nosso objetivo nesta pesquisa é estudar essas alteraçoes provocadas pela mudança da posição do coração para a realização das pontes.

2. Procedimentos que serão utilizados e propósitos, incluindo a identificação dos procedimentos que são experimentais: O senhor(a) será anestesiado conforme a rotina para os pacientes submetidos a cirurgia cardíaca sem circulação extracorpórea. Após a indução anestésica será instalado um cateter de Swanz-Ganz, e passado através do esôfago um transdutor que medirá por ultra-som o fluxo que passa pela principal artéria do corpo que é a Aorta. Com estes dispositivos serão feitos cálculos hemodinâmicos e respiratórios que nos permitirão estudar as mudanças que acontecem durante a cirurgia sem CEC. Também serão colhidas amostras de sangue em diferentes etapas da cirurgia.

3. Desconfortos e riscos esperados: O transdutor do Doppler será instalado no esôfago o qual oferece risco mínimo, mas poderia ocasionar discreto desconforto durante o pós-operatório como dor e/ou disfagia (dificuldade para engolir). Serão colhidas também amostras sanguíneas através de cateteres que fazem parte da rotina da cirurgia cardíaca.

4. Benefícios que poderão ser obtidos: Como benefícios tem-se o conhecimento da interferência da movimentação do coração durante o procedimento, podendo otimizar as medidas preventivas ou de tratamento para melhorar as alterações que acontecem durante esta movimentação.

5. Procedimentos alternativos que possam ser vantajosos para o indivíduo: Neste caso, não há procedimentos alternativos. 


\section{IV - ESCLARECIMENTOS DADOS PELO PESQUISADOR SOBRE GARANTIAS DO SUJEITO DA PESQUISA:}

1. acesso, a qualquer tempo, às informações sobre procedimentos, riscos e benefícios relacionados à pesquisa, inclusive para dirimir eventuais dúvidas.

2. liberdade de retirar seu consentimento a qualquer momento e de deixar de participar do estudo, sem que isto traga prejuízo à continuidade da assistência.

3. salvaguarda da confidencialidade, sigilo e privacidade.

4. disponibilidade de assistência no HCFMUSP, por eventuais danos à saúde, decorrentes da pesquisa.

5. viabilidade de indenização por eventuais danos à saúde decorrentes da pesquisa.

\section{INFORMAÇÕES DE NOMES, ENDEREÇOS E TELEFONES DOS RESPONSÁVEIS PELO ACOMPANHAMENTO DA PESQUISA, PARA CONTATO EM CASO DE INTERCORRÊNCIAS CLÍNICAS E REAÇÕES ADVERSAS.}

Em caso de intercorrências clínicas e reações adversas relacionadas ao estudo atual, entrar em contato com:

Dra. Maria José Carvalho Carmona

Av. Dr. Enéas Carvalho de Aguiar, 44

Fone: 3069-5232 (Anestesiologia InCor HCFMUSP)

\section{OBSERVAÇÕES COMPLEMENTARES:}

\section{VII - CONSENTIMENTO PÓS-ESCLARECIDO}

Declaro que, após convenientemente esclarecido pelo pesquisador e ter entendido o que me foi explicado, consinto em participar do presente Protocolo de Pesquisa

São Paulo, de de 2005 . 